\title{
g(1)
}

\section{Fromal Education}

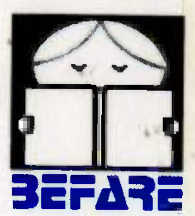

\section{Annual Examination Result}

\section{Analysis 2002-03}
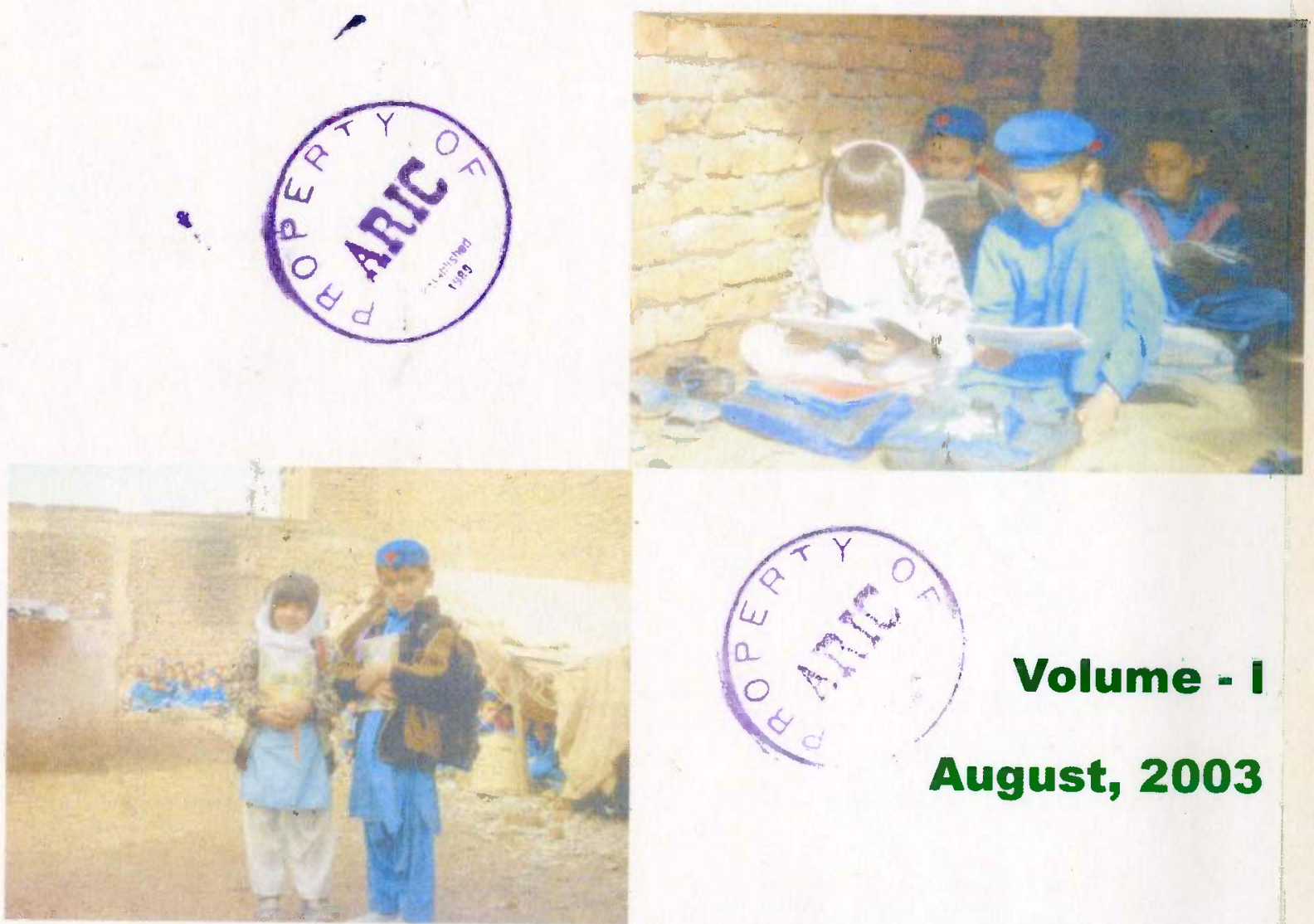

\section{MIS/M\&E Unit}

Basic Education for Afghan Refugees

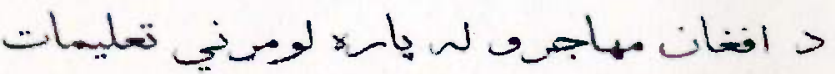
Deutsche Gesellschaft fur Technische Zusammenarbelt (GTZ) Gmbh German Agency for Technical Cooperation 


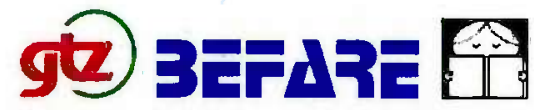

\section{North- West Frontier Province}
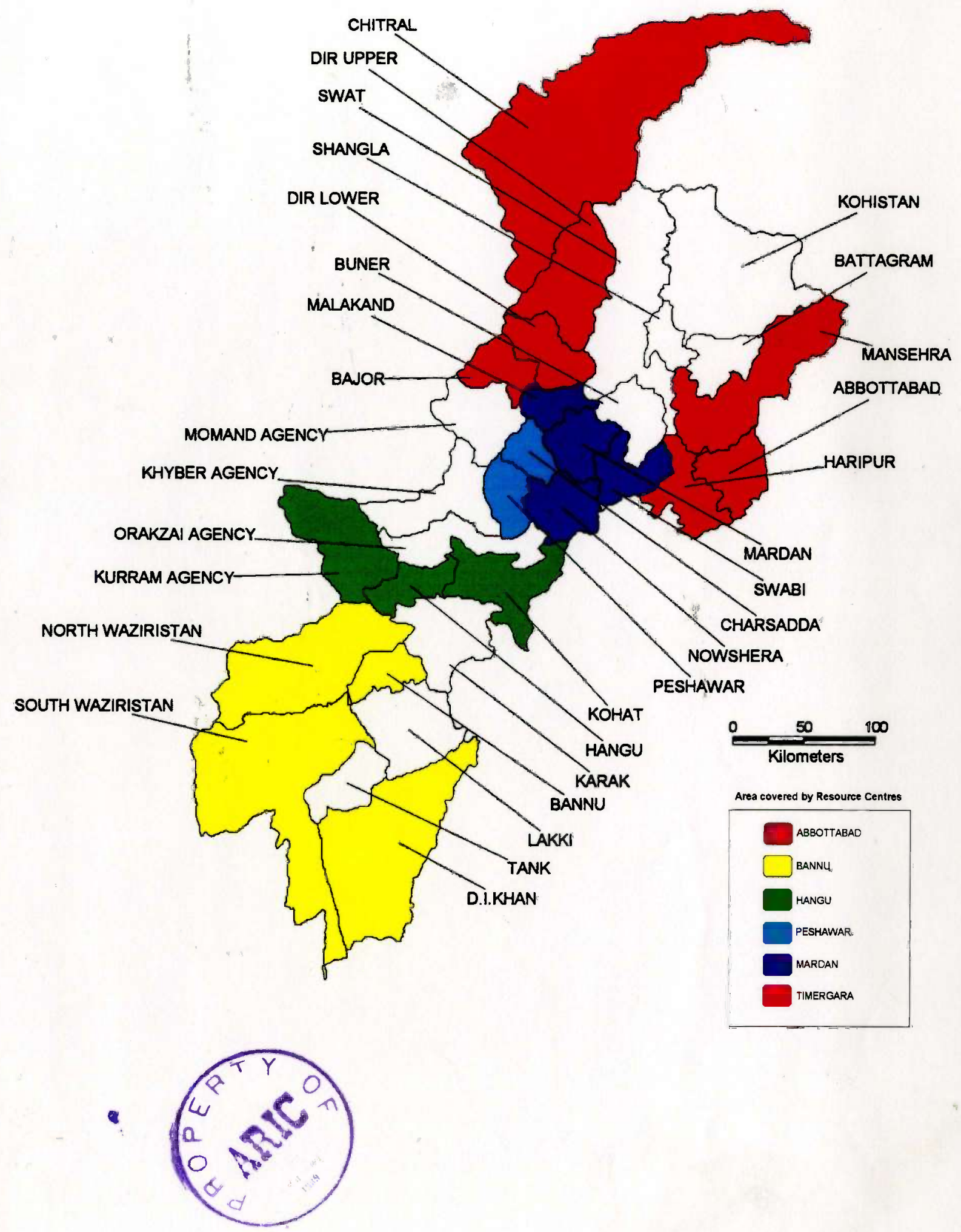


\section{Table of Contents}

PREFACE .....,

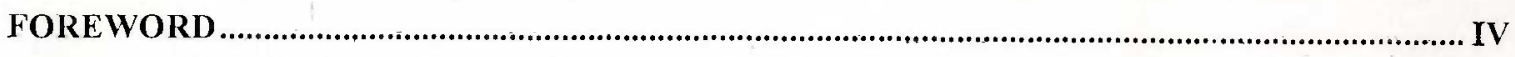

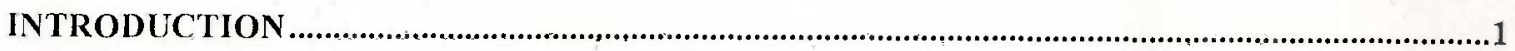

METHODOLOGY ......................,

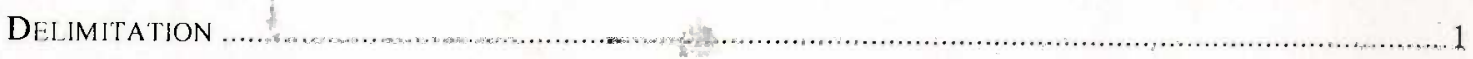

1. ENROLLMENT ....,

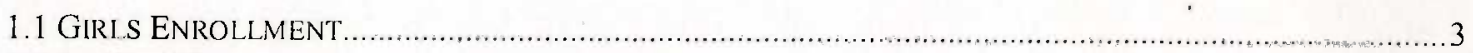

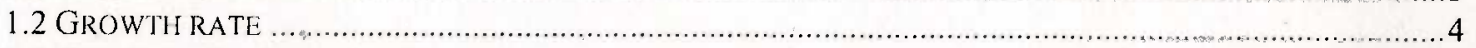

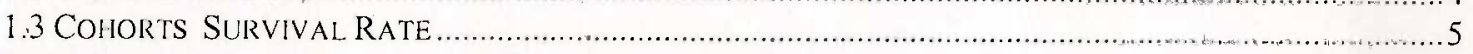

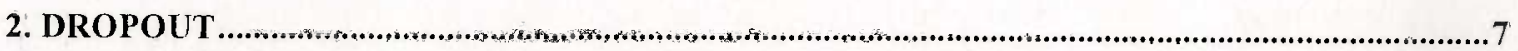

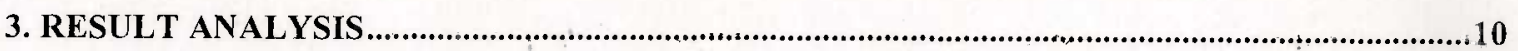

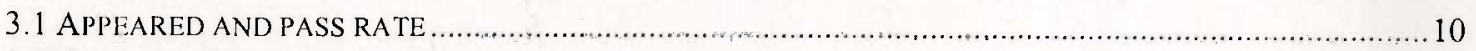

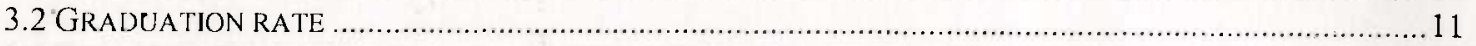

3.3 RESOURCE CENTER WISE STUDENTS PERFORMANCE IN ALL GRADES ........................................... 12

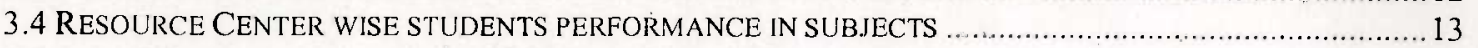

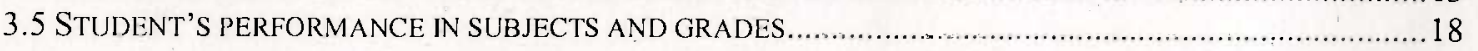

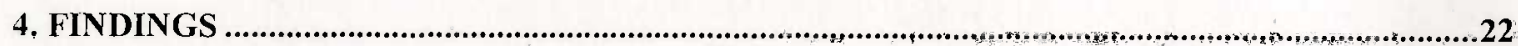

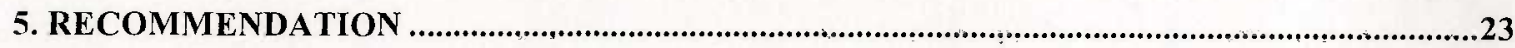

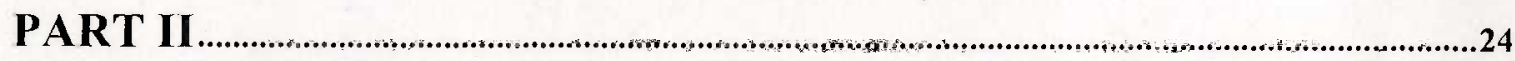

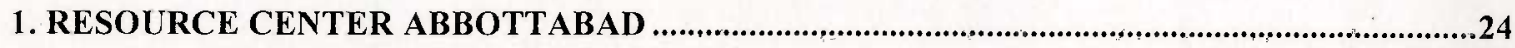

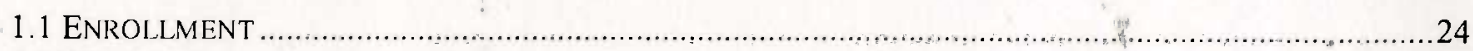

1.2 DROPOUT

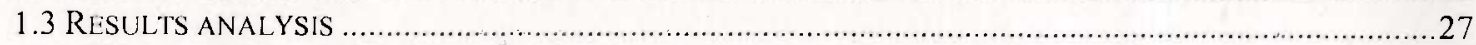

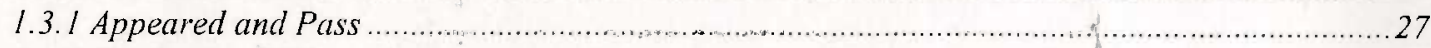

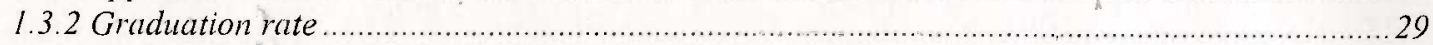

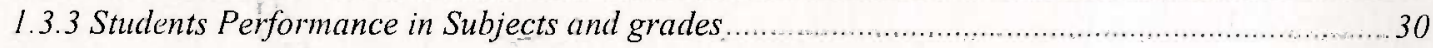

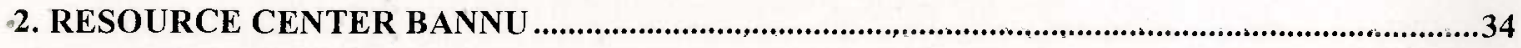

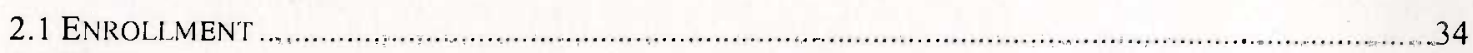

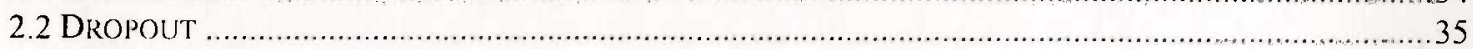

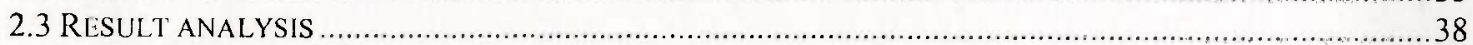

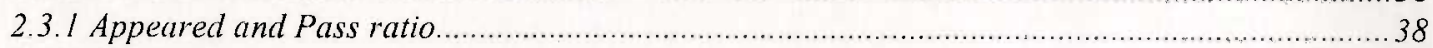

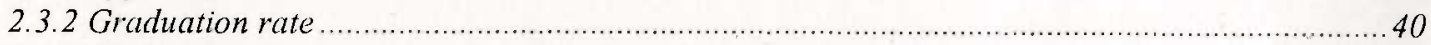

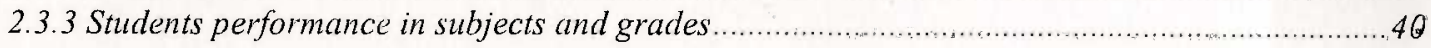

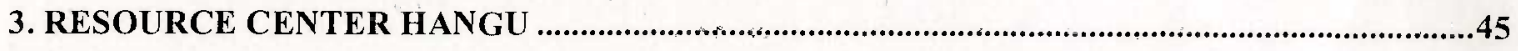

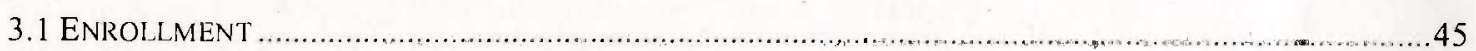

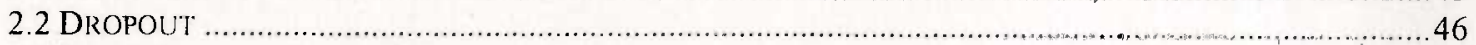

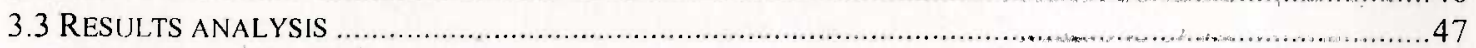

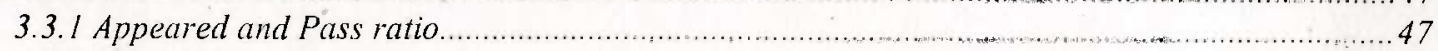

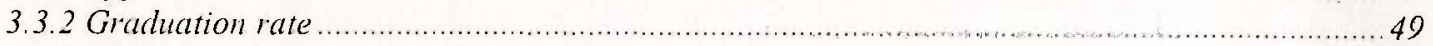

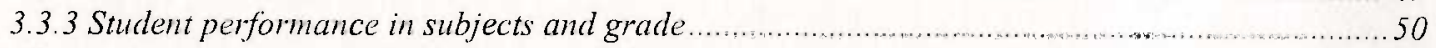

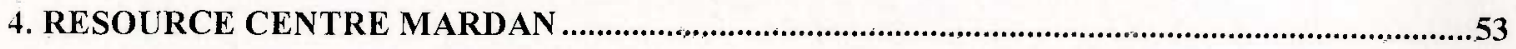

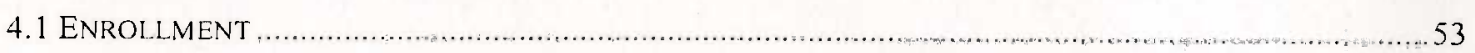




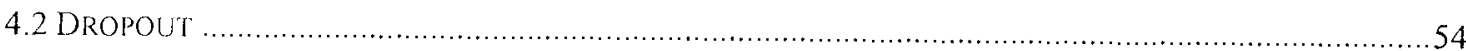

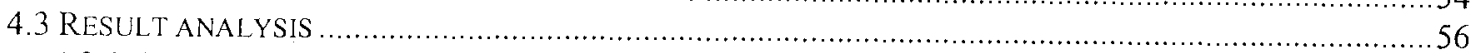

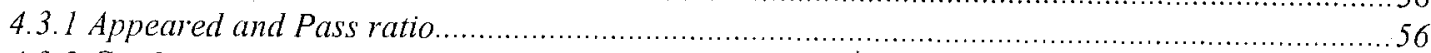

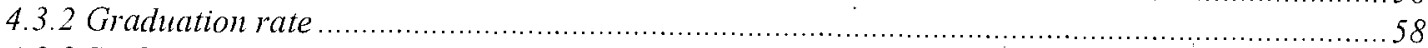

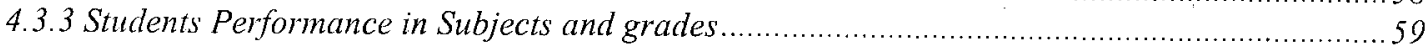

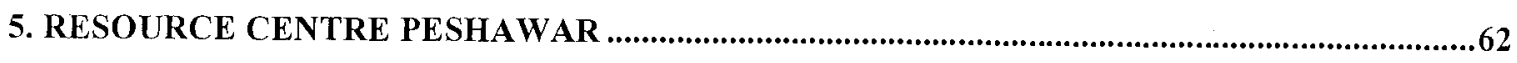

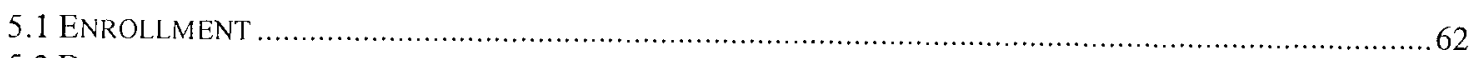

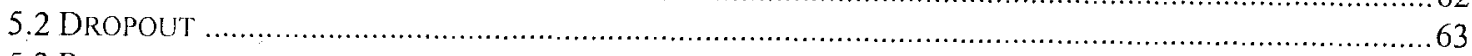

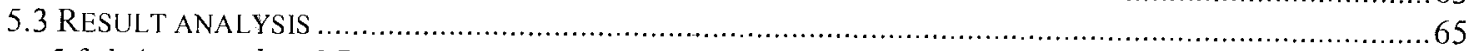

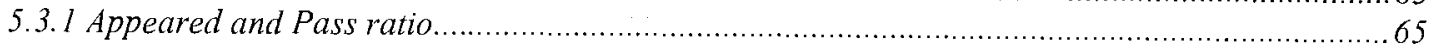

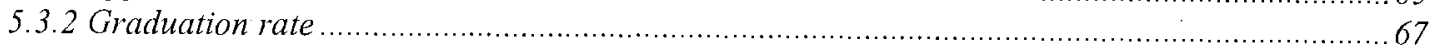

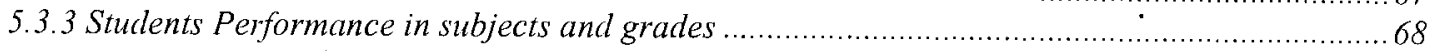

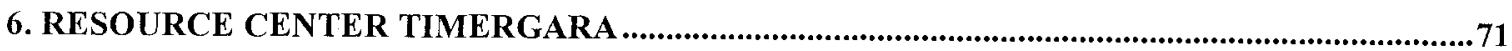

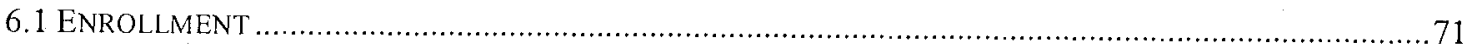

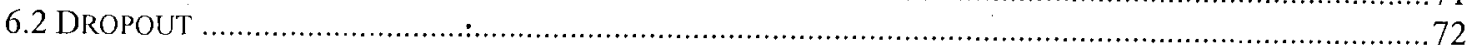

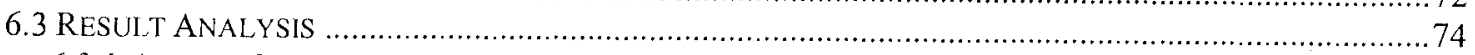

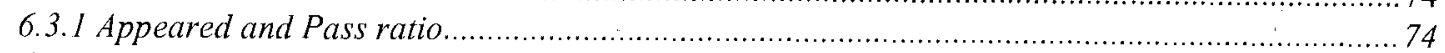

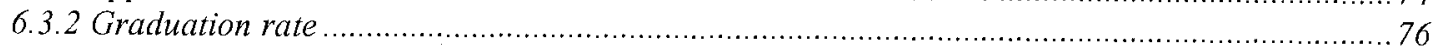

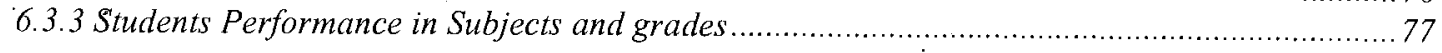

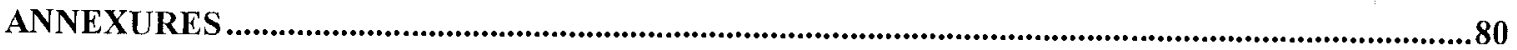

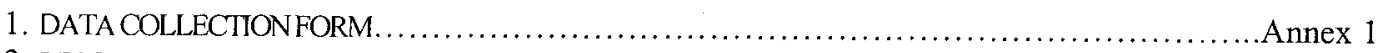

2. RESOURCECENTER BASED ANNUAL RESULTSFOR 2002-03 AND ANALYSIS IN \%.................................Annex 2

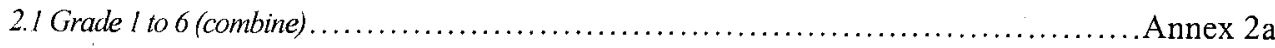

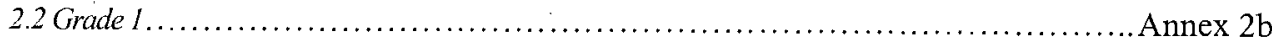

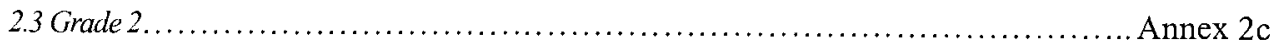

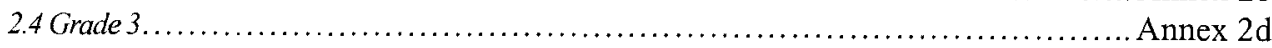

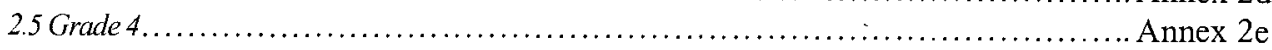

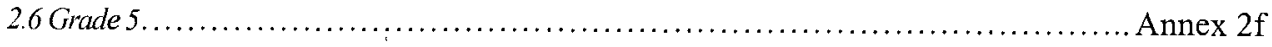

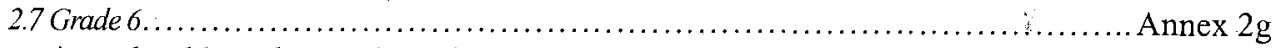

3. District wise school based annual results for 2002-03 and percent analysis.............. Annex 3

(Annex-3 is compiled in separate volume, available upon request) 


\section{Preface}

This study is the first ever to be undertaken on annual examinations of BEFARe schools by the M\&E/MIS Unit with a new approach of analyzing the quality on the basis of average marks of the students in each subject. The importance of knowing at depth the performance of students in various subjects in each resource center cannot be over stated. It is the basis for quality improvement of the system. Such an analysis provides the teachers, supervisors and the head teachers the gaps in the levels of the competencies and the need for relevant changes in teaching strategies and corrective measures. The results would guide the organization in its professional development and quality improvements. These are but a few of the advantages of this analysis for those concerned in both teaching and supervision. It is a mirror that helps to identify flaws in the teaching and learning rather than depend on unscientific approaches.

The next step for the M\&E would be to go further deep to identify the specific weaknesses in the subjects taught in terms of concepts using more statistical methods than mere percentage analysis. That would throw light both on the capacity of the teachers in understanding concepts and learning needs of the students. Changes in the guide books could be also initiated based on such findings. The study also helps the respective Mangers of the Resource Centers to understand the level of performance of their schools per se and vis-à-vis other centers and adopt suitable strategies to improve the standards. It also leads to a healthy competition amongst the Centers. It is strongly suggested that the Resource Centre Mangers study this document and take corrective action.

In general the concept of refugee education now considered as only an emergency measurer by the international community, seemingly may change through studies of this nature, providing new dimensions in emergency education. Emergency education for refugees have to be studied and serious attempts should be taken to improve its qualitative aspects both in terms of introducing new themes such as peace education, environment, gendre etc and providing quantitative and qualitative insights about the performances of students. This study by the M\&E unit of BEFARe provides that important need.

I should congratulate the respective personnel in the M\&E Unit for their untiring efforts and to specially Mr. Rehan Awan for this initiative, Israr Khan for following up of the responsibility as the new head of the unit and Riaz Khan for writing the report and follow up work.

Dr. S.B. Ekanayake

Technical Advisor

September 2003 


\section{Foreword}

It gives me immense pleasure and satisfaction to release this report just before my departure. My formal working relation with GTZ-BEFARe, spread over seven year period, is coming to halt this month. My association with GTZ-BEFARe has remained highly educational and memorable. I strongly believed on team work and at the unit we left no stone unturned to endeavor for the amelioration of quality education. I understand that we might have made some mistakes during the process. Nevertheless, we tried to ensure to gain experience by pondering on mistakes and never let it to cost.

Bringing forth this report "Annual Examination Result Analysis 2002-03" is a step forward in right direction. The report looks into all the aspects of GTZ-BEFARe educational project. It gives an insight to the reader about enrollment, growth rate, dropout and repetition and also presents an analytical picture of students' progress. from each Resource Center. All these analysis, for the first time, are taken down to the district level to provide the management and other concerned official with a vivid picture of the progress made in respective areas. It is expected that district level statistics, comparative views and analysis of trends given in this report would afford both quantitative and qualitative information to the management and planner involved in the development of education at GTZBEFARe to identify shortcomings and re-direct their efforts towards them. However, simple language has been tried to make this report easily understandable and enjoyable to all.

The report is the outcome of team work shown by the M\&E/MIS unit. I would like to acknowledge and thank my team and all those without whom assistance, completion of this report would have not been possible. I owe thanks to Ms. Maryam Khan, Ms. Nasira Nasrine and Mr. Riaz Khan (PM\&E Officers) who took pains in drafting this report; but special acknowledgement and appreciation goes to Riaz Khan who played instrumental role in organizing, editing, designing and finalizing the report. The MIS personnel Mr. Israr Khan, Mr. Liaqat Gul and computer operator Mr. Siraj Ahmad Lodhi also need special mention for their untiring efforts in consolidation, tabulation and projection of statistical data. I gratefully acknowledge the assistance and cooperation of Field Education Supervisors and Master Trainers and schools Head Teachers for collection and verification of field data. Last but not the least, I sincerely pay my gratitude to Mr. Holger Munsch (Chief Technical Advisor), Dr. S. B. Ekanayake (Technical Advisor) and all Project Managers for their continued support, co-operation and guidance.

August, 2003

Mohammad Rehan Awan

Project Manager,

MIS/PM\&E unit 


\section{Introduction}

GTZ-BEFARe has been imparting basic education in formal and non-formal sectors to Afghan refugee since 1985. Presently, there are 320 formal schools functioning under its responsibility. The academic year 2002-03 concluded in March with the announcement of the annual result. After the announcement of the results MIS/PM\&E unit, in collaboration with Formal Education unit commenced to collect data of the results for analysis. The exercise aimed to analyze the increase in enrollment, dropout rate and explore gender wise student performance in the exam, in order to establish the levels of achievement.

This report is the outcome of that exercise. It is composed of two parts. Part 1 present the overview of the enrollment and growth rates, dropout and repetition rates and identify trends from the available statistics. It also gives an analytical picture of the students' performance. Part 2 underlines the detail information of all aspects such as enrollment and dropout rates and gender based analysis of the progress of students for each Resource Center separately.

\section{Methodology}

The data collected from the field is the major source of information for this report. However, for analysis of trends and comparison of statistics, previously available data was also made use of.

For primary data collection MIS/PM\&E unit developed a proforma, which was administered to each school separately. Field Education Supervisors (FES) were responsible for data collection. Head Teachers (HT) were made responsible to calculate the average marks by using simple arithmetic mean for their respective schools. The data, thus calculated was transferred to proforma and returned to FES, who after checking forwarded on to Master-Trainers (MTs). MTs, after verifying validity of the data, funneled the sheets to the MIS/PM\&E unit where the data was fed into the computer for analysis. To maintain accuracy, calculations were carried out by database and spreadsheet programme. Graphical presentation of data was done through Microsoft Excel.

\section{Delimitation}

Collection of student marks on individual basis would have required more resources and time therefore average data of student's marks was collected from schools by applying arithmetic mean. Every effort was made to present the factual situation, but the collection of data in an average basis per school may have influenced the factual situation. 


\section{Enrollment}

Total enrollment in the BEFARe formal schools in the year 2002-03 was 123,660, twice as compared to the figure for 1996-97 which was 60,804. The highest and lowest enrollment figures were recorded in the Resource Centers of Peshawar and Bannu as 36,719 and 9,617 respectively, indicated in Table 1.

Similarly, the highest enrollment of girls was also high in Peshawar $(10,036)$ followed by Timergara $(8,392)$ and with the lowest in Bannu $(1,836)$. A high number of fresh enrollment of girls' was witnessed in Peshawar and Timergara, which was 9,503 and 7,686 respectively.

Table 1: Resource Center enrollments, repeaters and fresh enrollments

\begin{tabular}{|c|c|c|c|c|c|c|c|c|c|}
\hline \multirow{2}{*}{$\begin{array}{l}\text { Resource } \\
\text { Center }\end{array}$} & \multicolumn{3}{|c|}{ Enrolled } & \multicolumn{3}{|c|}{ Repeater } & \multicolumn{2}{|r|}{ Fresh } & \multirow{2}{*}{$\frac{\text { Total }}{\text { Tol }}$} \\
\hline & Boys & Gils & Total & Boys & Girls & Total & Boys & Girls & \\
\hline Abbotabad & 15,361 & 4,496 & 19,857 & 1,445 & 286 & 1,731 & 13,916 & 4,210 & 18,126 \\
\hline Bannu & 7,781 & 1,836 & 9,617 & 529 & 51 & 580 & 7,252 & 1,785 & 9,037 \\
\hline Hungu & 16,043 & 2,859 & 18,902 & 1,374 & 229 & 1,603 & 14,669 & 2,630 & 17,299 \\
\hline Mardan & 12,874 & 5,257 & 18,131 & 1,159 & 277 & 1,436 & 11,715 & 4,980 & 16,695 \\
\hline Peshawar & 26,683 & 10,036 & 36,719 & 1,682 & 533 & 2,215 & 25,001 & 9,503 & 34,504 \\
\hline Shalman & 2,055 & 1,396 & 3,451 & - & - & - & 2,055 & 1,396 & 3,451 \\
\hline Timergara & 8,591 & 8,392 & 16,983 & 826 & 706 & 1,532 & 7,765 & 7,686 & 15,451 \\
\hline Total & 89,388 & 34,272 & 123,660 & 7,015 & 2,082 & 9.097 & $82: 373$ & 32.190 & 114563 \\
\hline $1996-97^{\star}$ & 51,839 & 8,965 & 60,804 & 0 & 0 & 0 & 51,839 & 8,965 & 60,804 \\
\hline
\end{tabular}

In order to accommodate the influx of students many more new schools were opened. Thus the total number of schools has increased to 320 during 2002-03 from 285 in 2001-02. Where the opening of separate schools for boys and girls was not possible, co-education was introduced to ensure that no child was denied of the right to education. Moreover, double shift schools were also introduced in areas where opening of a new school was not feasible on technical grounds. Thus the cost-effectiveness of the educational process has also been maintained by the project. The above is indicative of the project's endeavor towards its prime aim of increasing access to education.

Grade 1 and 2 constituted the bulk of enrollment for both genders but in higher grades the enrollment has dwindled. Dropout, failure from early grades could be the major factor cited for the decline in the number of enrolled students in higher grades.

Unfortunately, there is no single curriculum being taught to Afghan refugee children. The schools associated with various agencies or run on a private basis 
implement various curricula. BEFARe has developed and implemented its own curriculum. The project emphasis on enrolling students in the initial grade to allow the students to fully develop the competencies taught, ensuring the quality of education at BEFARe schools.

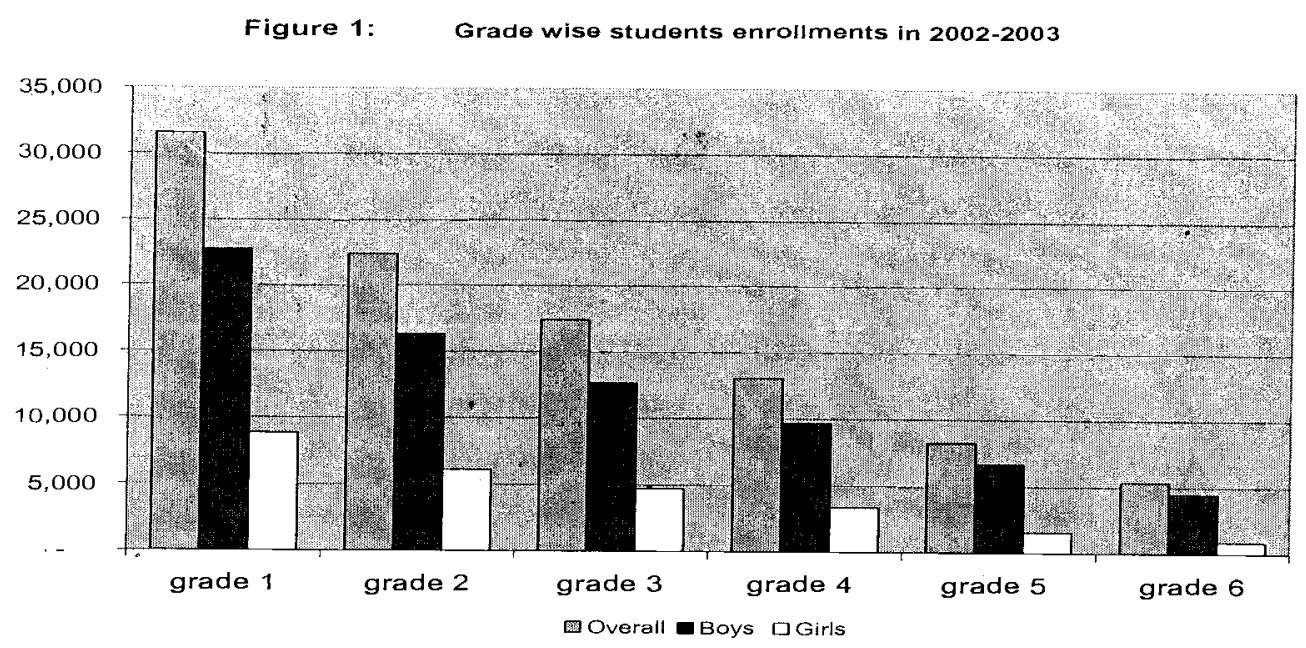

\subsection{Girls Enrollment}

The girls constituted 15\% of the total enrollment in 1996-97 (Annual Examination Result Analysis 1996-97). This ratio has risen significantly and was recorded as $28 \%$ for the academic year 2002-03. The registered number of girl students during the academic year $2002-03$ was 34,272 , which is an increase of $232 \%$ to the base of 1996-97 figure of 8,965 .

It is important to note that the increase in girls' enrollment is not grade specific. Table 2 represents a steady increase in girls' enrollment as compared to the boys in all grades. The ratio of girls as compared to boys in grade 1, 2, 3, 4, 5, and 6 was measured as $55.7 \%, 35.2 \%, 30.7 \%, 29.4 \%, 28.4 \%$ and $20.2 \%$ respectively, which is more than double compared to the data of 1996-97. It can also be noted that the ratio of girls enrollment to boys also increases with the grades from 1 to 6 (graph 1).

Gender and development is the cross cutting theme of GTZ-BEFARe's educational development process. Women are highly marginalized in the Afghan community, hence this is considered as a central target group in the endeavor for educational promotion by GTZ-BEFARe. Taking the community on board with special emphasis on females, in all stages of the educational process, was the cornerstone of the strategy. Significant efforts were made through the Community Participation unit to enable the community to appreciate and create an awareness of the significance of female education. For this purpose Female School Management Committees were formed in all female schools who worked along side the project personnel for the improvement of female education. Similarly, all female schools were staffed with female teachers and female Master Trainers were engaged to enhance teaching capacities of those teachers 
in pedagogy and to reduce the cultural barriers in female education. This gradual increase in female enrollment reflects the efforts and seriousness of the project towards the development of female education.

Table 2: Grade wise gender comparisons of students

\begin{tabular}{|c|c|c|c|c|c|c|}
\hline $\begin{array}{l}\text { year } \\
\text { yeat? }\end{array}$ & $\begin{array}{l}\text { Grade } 1 \text { Girls } \\
\text { as a } \% \text { of Grade } \\
1 \text { Boys }\end{array}$ & $\begin{array}{l}\text { Grade } 2 \text { Girls } \\
\text { as a } \% \text { of } \\
\text { Grade } 2 \text { Boys }\end{array}$ & $\begin{array}{l}\text { Grade } 3 \text { Girls } \\
\text { as a \% of } \\
\text { Grade } 3 \text { Boys }\end{array}$ & $\begin{array}{l}\text { Grade } 4 \text { Girs } \\
\text { as a } \% \text { of } \\
\text { Grade } 4 \text { Boys }\end{array}$ & $\begin{array}{l}\text { Grade } 5 \text { Girls } \\
\text { as a \% of } \\
\text { Grade } 5 \text { Boys }\end{array}$ & $\begin{array}{l}\text { Grade } 6 \text { Girls as } \\
\text { a } \% \text { of Grade } 6 \\
\text { Boys }\end{array}$ \\
\hline $1996-97$ & $23.2 \%$ & $19.7 \%$ & $13.0 \%$ & $10.5 \%$ & $8.4 \%$ & $5.2 \%$ \\
\hline 1997-98 & $25.7 \%$ & $25.4 \%$ & $15.9 \%$ & $12.8 \%$ & $9.3 \%$ & $8.0 \%$ \\
\hline 1998-99 & $28.8 \%$ & $30.5 \%$ & $18.7 \%$ & $13.9 \%$ & $11.5 \%$ & $9.4 \%$ \\
\hline 1999-2000 & $38.0 \%$ & $31.7 \%$ & $29.2 \%$ & $21.3 \%$ & $14.3 \%$ & $13.2 \%$ \\
\hline $2000-2001$ & $34.2 \%$ & $39.1 \%$ & $40.5 \%$ & $31.7 \%$ & $24.7 \%$ & $20.2 \%$ \\
\hline 2001-2002 & $37.3 \%$ & $35.0 \%$ & $36.1 \%$ & $33.4 \%$ & $22.2 \%$ & $18.9 \%$ \\
\hline 2002.2003 & $55.7 \%$ & $\quad 35.2 \%$ & $30.7 \%$ & $29.4 \%$ & $28.4 \%$ & $20.2 \%$ \\
\hline
\end{tabular}

\subsection{Growth rate}

There has been appreciable increase witnessed in enrollment for boys and girls during the last six years. It is also encouraging to note that the growth rate of girls' enrollment has been more than boys (Table 2).

The increase in enrollment is calculated in two ways and presents the increase through two different perspectives i.e. yearly increase and increase as compared to the enrollment figure of 1996, (the year when BEFARe took over schools from commissionerate for Afghan Refugee) which is shown in the extreme right column in Table 3.

During the year 2002-03 the officially documented figure of enrollment was 123,600 . The recorded figure of enrollment during $2001-02$ was 105,375 and in 1996-97 was 60,804 . The increase in the $2002-03$ enrollment figure was $17 \%$ as compared to the enrollment of 2001-02. And the percent increase in enrollment of 2002-03 in comparison to the enrollment of 1996-97 was 103 percent.

Table 3 provides the detail statistics and comparative analysis of gender based growth rate for the last six years. The growth rate shown in Table 3 is calculated by computing the increase in value (variance value of 2002-03 to last year enrollment and 1996-97 enrollment). The increased value was then divided by last year enrollment and multiplied by 100 for conversion to percentage. Similarly, the variance value was divided by 1996-97 enrollments and multiplied by 100 for increase rate in percent to the base of 1996-97 value. 
Table 3: Increase in enrollment by gender and years

\begin{tabular}{|c|c|c|c|c|c|c|c|}
\hline \multirow[b]{2}{*}{ years } & \multirow[b]{2}{*}{ Overall } & \multirow[b]{2}{*}{ Boys } & \multirow[b]{2}{*}{ Girls } & \multirow{2}{*}{$\begin{array}{l}\% \text { of girls } \\
\text { students }\end{array}$} & \multirow{2}{*}{$\begin{array}{l}\% \text { of boys } \\
\text { studnets }\end{array}$} & \multicolumn{2}{|c|}{ Increase in enrollment } \\
\hline & & & & & & yearly & as compared to 96 \\
\hline 1996-97 & 60,804 & 51,839 & 8,965 & $15 \%$ & $85 \%$ & & \\
\hline $1997-98$ & 64,011 & 53,162 & 10,849 & $17 \%$ & $83 \%$ & $5 \%$ & $5 \%$ \\
\hline 1998-99 & 68,926 & 55,822 & 13,104 & $19 \%$ & $81 \%$ & $8 \%$ & $13 \%$ \\
\hline $1999-00$ & 85,755 & 65,996 & 19,759 & $23 \%$ & $77 \%$ & $24 \%$ & $41 \%$ \\
\hline $2000-01$ & 97,373 & 72,316 & 25,057 & $26 \%$ & $74 \%$ & $14 \%$ & $60 \%$ \\
\hline 2001-02 & 105,375 & 78,944 & 26,431 & $25 \%$ & $75 \%$ & $8 \%$ & $73 \%$ \\
\hline $2002-03$ & 123,660 & 89,388 & 34,272 & $28 \%$ & $\begin{array}{r}72 \% \\
\end{array}$ & $17 \%$ & $103 \%$ \\
\hline
\end{tabular}

Table 3 illustrates the increase in girls' proportion to the total enrollment. In 199697 girls' constituted $15 \%$ of the total enrollment which has increased almost by two fold to $28 \%$ in $2002-03$.

\section{Graph 2: $\quad$ Increase in enrollment in 1996-97}

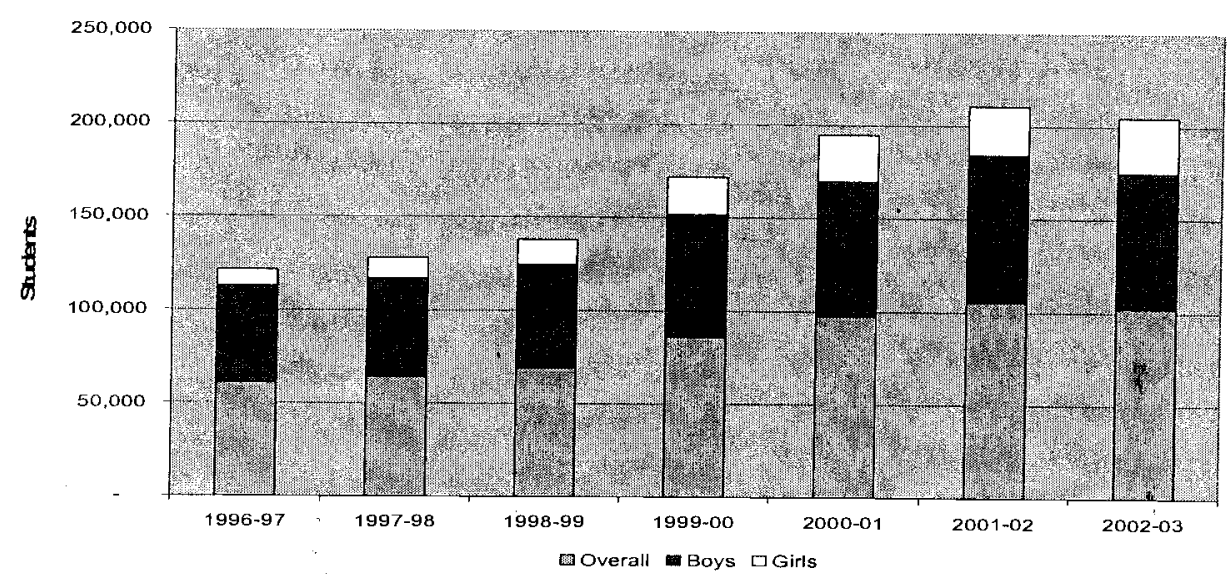

\subsection{Cohorts Survival Rate}

Cohort survival rate refers to a group of students enrolled in grade 1 in specific year, successfully complete the 6 year cycle of primary education.

So far up to 2002-03 only two batches have graduated from BEFARe schools. As GTZ-BEFARe took over the basic education responsibility in 1996-97 from Commissionerate for Afghan (CAR), the batch enrolled in 1996-97 was treated as the first batch.

\footnotetext{
* A generational group as defined in demographics, statistics, or market research: for example: "The cohort of people aged 30 to $39 . .$. were more conservative" (American Demographics).
} 
Table 4: Cohort of students

\begin{tabular}{|l|r|r|r|r|r|r|}
\hline & \multicolumn{7}{|c|}{ Cohort of Students } \\
\hline & Grade 1 & Grade 2 & Grade 3 & Grade 4 & Grade 5 & Grade 6 \\
\hline $1996-97$ & & 14,298 & 9,557 & 6,720 & 4,725 & 3,071 \\
\hline $1997-98$ & 24,846 & & 9,511 & 6,682 & 4,839 & 2,953 \\
\hline $1998-99$ & 25,526 & 17,175 & & 7,131 & 4,995 & 3,270 \\
\hline $1999-00$ & 31,579 & 20,797 & 14,353 & & 5,965 & 3,929 \\
\hline $2000-01$ & 29,204 & 24,189 & 19,121 & 12,268 & & 4,794 \\
\hline 20040 & 33,378 & 24,099 & 18,783 & 14,271 & 8,887 & \\
\hline $2002-03$ & 42,985 & 27,264 & 20,012 & 15,277 & 11,190 & 6,932 \\
\hline
\end{tabular}

Table 4 indicates that 23,943 students were enrolled in grade 1 during the session of 1996-97. Out of this figure only 5,957 students remained enrolled till grade 6 and successfully passed the grade 6 in 2001-02. The cohort survival rate of this group of students for the session 1996-97 which concluded in 2001-02, was $25 \%$ (Boys $26 \%$ and Girls $21 \%$ ).

Similarly, the cohort survival rate of group of students who were enrolled during the 1997-98 and completed the 6 year cycle period of primary education, graduated in 2002-03 was estimated as $28 \%$, where the survival rates for boys and girls were recorded as $29 \%$ and $23 \%$ respectively.

Figure 3: $\quad$ Comparision cohort survival rate of two batches

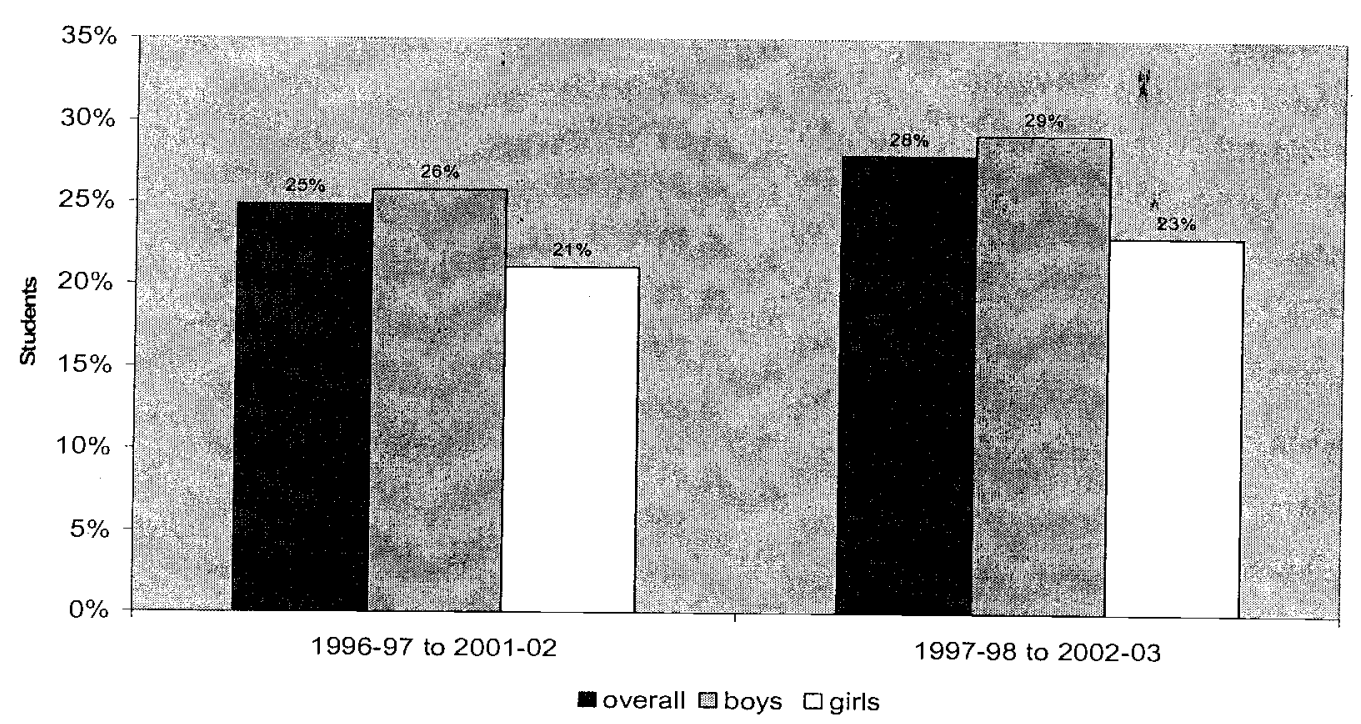

It is encouraging to note the increasing trend in cohort survival rate between those two batches. The overall cohort survival rate has improved from $25 \%$ in the period $1996-2002$ to $28 \%$ during the period $1997-2003$. 
Figure 4: Grade wise comparasion of student survival (cohort) for two batches

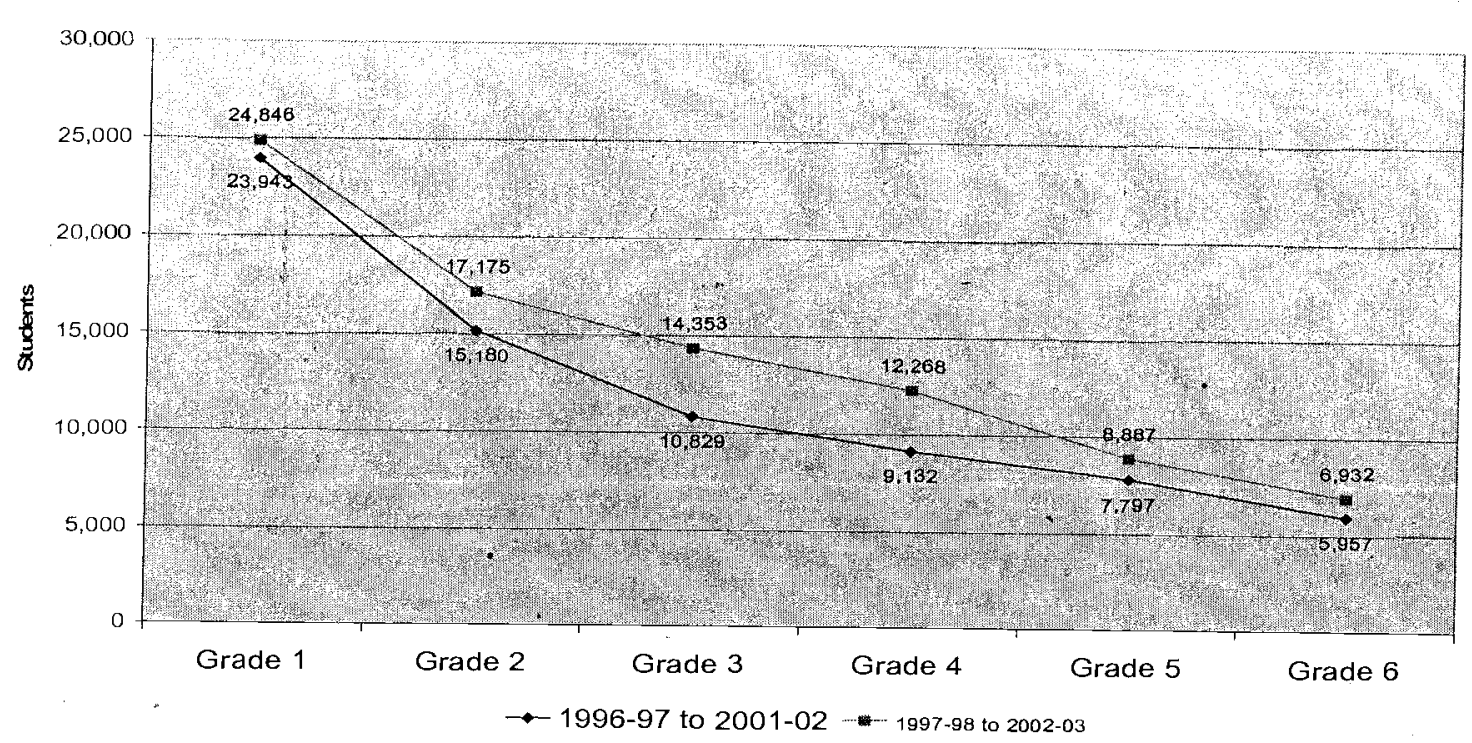

\section{Dropout}

Dropout is a vital issue the project is faced with from the very onset and various attempts were initiated to curtail it. Yet, it could not be contained completely due to some obvious reasons.

Despite all attempts made to reduce the dropout, the rate has been on the rise during the 2002-03. This year the dropout ratio reached $16 \%$ which is double that of 1996-97, which was 8\%. Except Timergara, in all the other Resource Center the dropout rate was above $10 \%$, for both boys and girls. The Resource Center in Peshawar was leading with the dropout rate of 25\% (boys 23\% and girls $30 \%$ ). The second highest figure was observed in Abbottabad and Mardan which was $13 \%$ (Table 5 ).

The main reason for such a high dropout rate was the repatriation drive and demolition of camps in the suburban areas of Peshawar.

Exceedingly high dropout percentage was witnessed in Shalman camp where the figure was $37 \%$ (boys $37 \%$ and girls $37 \%$ ). Shalman camp was established on an emergency basis immediately after the US led coalition attacked Afghanistan. Since it was maintained as a separate emergency camp, it is treated separately in the analysis. Nonetheless, this camp has been included in the administration of Peshawar Resource Center since April 2003. 
Table 5: Resource Center dropout rate by gender

\begin{tabular}{|c|c|c|c|c|c|c|c|c|c|}
\hline \multirow{2}{*}{$\begin{array}{l}\text { Resource } \\
\text { Center }\end{array}$} & \multicolumn{3}{|c|}{ Enrolled } & \multicolumn{3}{|c|}{ Dropped } & \multicolumn{3}{|c|}{ Dropout in \% } \\
\hline & Boys & Girls & Total & Boys & Girls & Total & Boys & Girls & Overall \\
\hline Abbotabad & 15,361 & 4,496 & 19,857 & 1,785 & 747 & 2,532 & $12 \%$ & $17 \%$ & $13 \%$ \\
\hline Bannu & 7,781 & 1,836 & 9,617 & 806 & 203 & 1,009 & $10 \%$ & $11 \%$ & $10 \%$ \\
\hline Hungu & 16,043 & 2,859 & 18,902 & 1,929 & 353 & 2,282 & $12 \%$ & $12 \%$ & $12 \%$ \\
\hline Mardan & $\begin{array}{r}12,874 \\
\end{array}$ & 5,257 & 18,131 & 1,480 & 967 & 2,447 & $11 \%$ & $18 \%$ & $13 \%$ \\
\hline Peshawar & 26,683 & 10,036 & 36,719 & 6,126 & 3,039 & 9,165 & $23 \%$ & $30 \%$ & $25 \%$ \\
\hline Shalman & 2,055 & 1,396 & 3,451 & 758 & 517 & 1,275 & $37 \%$ & $37 \%$ & $37 \%$ \\
\hline Timergara & 8,591 & 8,392 & 16,983 & 434 & 535 & 969 & $5 \%$ & $6 \%$ & $6 \%$ \\
\hline Total $(2002-03)$ & 89,388 & 34,272 & 123,660 & 13,318 & 6.361 & 19,679 & $15 \%$ & $19 \%$ & $16 \%$ \\
\hline 1996-97 & 51,839 & 8,965 & 60,804 & 4,164 & 575 & 4,739 & $8 \%$ & $6 \%$ & $8 \%$ \\
\hline
\end{tabular}

It can be observed from Table 5 that the dropout rate of girls $(19 \%)$ is high compared to the boys (15\%). The rate of dropout amongst girls in all Resource Centers was also greater than that of boys.

According to a survey report (October 2002) of the Community Participation \& Development Unit of GTZ-BEFARe, the reasons for dropouts are numerous. The report states "the survey findings reflect a host of reasons for dropouts. Besides repatriation, child labour, adolescent/engagement of girl child, relocation of families due to demolition of camps in urban Peshawar, admission in better standard (English medium) schools were also cited." (Report CP\&D unit in GTZBEFARe).

Table 6: Grade wise dropout ratio by gender

\begin{tabular}{|c|c|c|c|c|c|c|c|c|c|}
\hline \multirow{2}{*}{ W } & \multirow{2}{*}{ Boys } & Enrolled & \multirow{2}{*}{ overall } & \multirow{2}{*}{$\frac{3}{\text { Boys }}$} & \multicolumn{2}{|l|}{ Dropped } & \multicolumn{3}{|c|}{ Dropout in \% } \\
\hline & & Girls & & & Girls & Overall & Boys & Girls: & Overall \\
\hline Grade I & 27,614 & 15,371 & 42,985 & 3700 & 3129 & 6,829 & $13 \%$ & $20 \%$ & $16 \%$ \\
\hline Grade II & 20,172 & 7,092 & 27,264 & 3234 & 1248 & 4,482 & $16 \%$ & $18 \%$ & $16 \%$ \\
\hline Grade III & 15,311 & 4,701 & 20,012 & 2279 & 711 & 2,990 & $15 \%$ & $15 \%$ & $15 \%$ \\
\hline Grade IV & 11,810 & 3,467 & 15,277 & 1953 & 596 & 2,549 & $17 \%$ & $17 \%$ & $17 \%$ \\
\hline Grade V & 8,714 & 2,476 & 11,190 & 1382 & 450 & 1,832 & $16 \%$ & $18 \%$ & $16 \%$ \\
\hline Grade VI & 5,767 & 1,165 & 6,932 & 770 & 227 & 997 & $13 \%$ & $19 \%$ & $14 \%$ \\
\hline Total & 89,388 & 34,272 & 123,660 & 13,318 & 6,361 & 19.679 & $15 \%$ & $19 \%$ & $16 \%$ \\
\hline
\end{tabular}

The dropout rate between grades was also very high. It is important to note that the dropout rate in all grades was observed as more or less equal during 200203 . Generally a declining dropout trend was observed in the higher grade in years hitherto. 


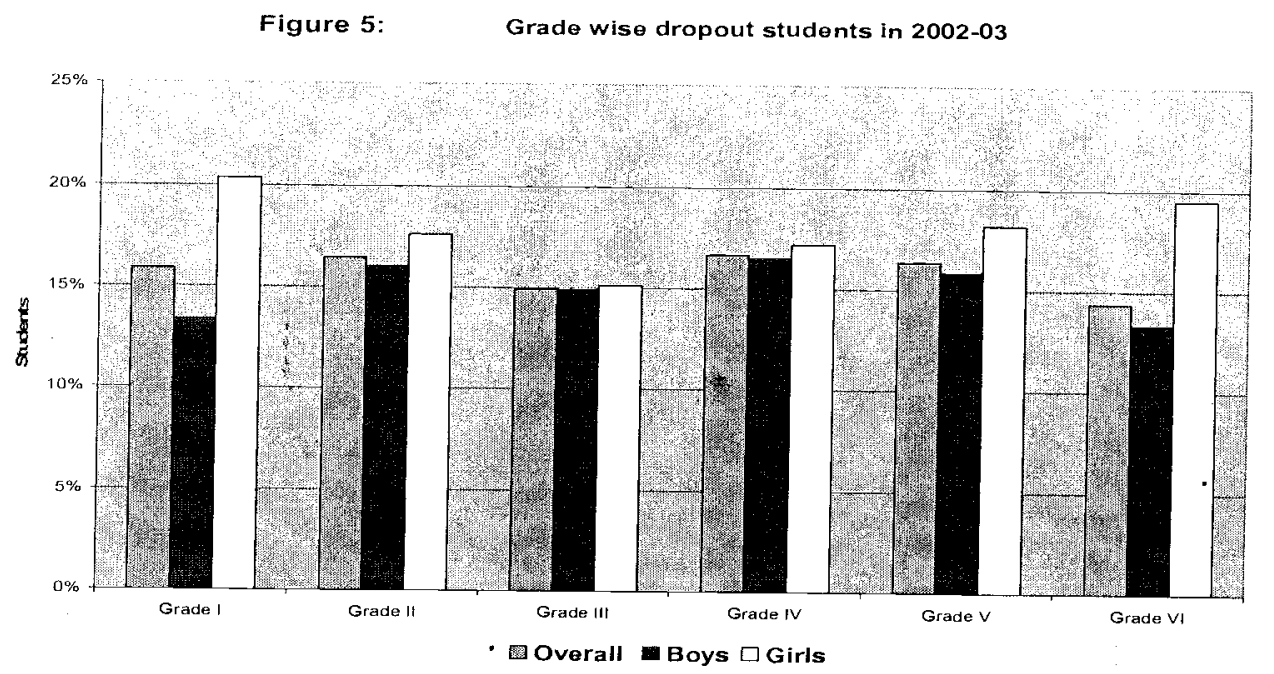

The dropout rate had remained around $8 \%$ since 1996-97. But in the year covered in the report it has increased to $16 \%$, due to reasons discussed earlier. The dropout rate of girls has been more which has affected in the increase of the overall rate of dropouts in the BEFARe schools. The girls' dropout was recorded as high as $19 \%$ during $2002-03$, as compared to $6 \%$ in $1996-97$.

Although the dropout trend has been rising high during the last few years, yet the ratio of enrollment was significantly higher than the rate of dropout, which has resulted in an overall higher rate of retention. Similarly, efforts of the project to keep the dropout under check for a few years were noteworthy.

Figure 6: $\quad$ Dropout trends for the last few years

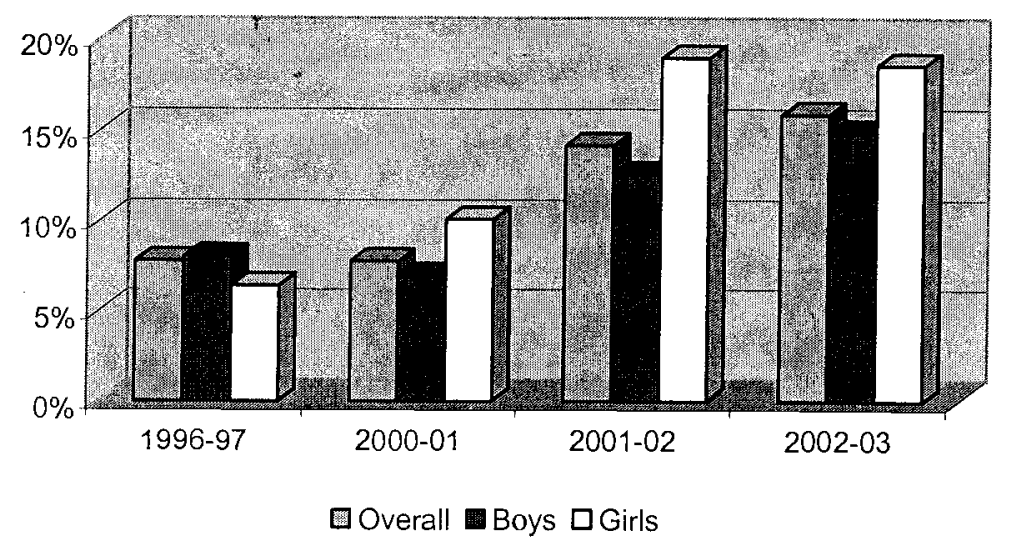




\section{Result Analysis}

\subsection{Appeared and pass rate}

A total of 123,660 students were enrolled in all the BEFARe schools. Of the total of $99,019(80 \%)$ enrolled $72,739(81 \%)$ students boys and $26,280(77 \%)$ girls appeared in the annual examination during 2002-03. The remaining students numbering 24,641 were dropouts. Some proportion of students was not allowed to take the exam due to the stipulated criteria in relation to class attendance.

Table 7 presents an encouraging and impressive pass percentage. Out of the 99,019 students who appeared for the exam 90,865 students were successful, which was an overall pass percentage of 92 ( $92 \%$ for boys and $91 \%$ for girls').

It can be seen from Table 7 that the pass percentage has improved considerably in $2002-03(92 \%$ ) as compared to the rate of $72 \%$ in 1996-97 (Result analysis report 1996-97).

Table 7: Resource Center wise details of appeared, passed and failed students by gender

\begin{tabular}{|c|c|c|c|c|c|c|c|c|c|c|c|c|}
\hline \multirow{2}{*}{$\begin{array}{c}\text { Resource } \\
\text { Center }\end{array}$} & \multicolumn{3}{|c|}{ Appeared } & \multicolumn{3}{|c|}{ Passed } & \multicolumn{3}{|c|}{ Failed } & \multicolumn{3}{|c|}{ Pass\%ages } \\
\hline & Boys & Girls & Total & Boys: & Girls: & Total & Boys & Girs & Total & Boys & Girls & Overall \\
\hline Abbotabad & 13372 & 3630 & 17,002 & 12,378 & 3,303 & 15,681 & 988 & 287 & 1,275 & $93 \%$ & $91 \%$ & $92 \%$ \\
\hline Bannu & 6839 & 1592 & 8,431 & 6,373 & 1,512 & 7,885 & 503 & 102 & 605 & $93 \%$ & $95 \%$ & $94 \%$ \\
\hline Hungu & 12994 & 2375 & 15,369 & 11,830 & 2,204 & 14,034 & 965 & 173 & 1,138 & $91 \%$ & $93 \%$ & $91 \%$ \\
\hline Mardan & 10908 & 3848 & 14,756 & 9,903 & 3,506 & 13,409 & 945 & 344 & 1,289 & $91 \%$ & $91 \%$ & $91 \%$ \\
\hline Peshawar & 19708 & 6720 & 26,428 & 18,234 & 6,043 & 24,277 & 1,724 & 733 & 2,457 & $93 \%$ & $90 \%$ & $92 \%$ \\
\hline Shalman & 1176 & 778 & 1,954 & 1,116 & 759 & 1,875 & 58 & 46 & 104 & $95 \%$ & $98 \%$ & $96 \%$ \\
\hline Timergara & 7742 & 7337 & 15,079 & 7,022 & 6,682 & 13,704 & 718 & 631 & 1,349 & $91 \%$ & $91 \%$ & $91 \%$ \\
\hline Total & 72,739 & 26280 & 98,019 & 66.856 & 24,009 & 90,865 & 5,901 & 2,316 & 8.217 & $92 \%$ & $91 \%$ & $92 \%$ \\
\hline 1996-97 & 47,675 & 8,390 & 56,065 & 34,432 & 5,999 & 40,431 & 13,242 & 2,392 & 15,634 & $72 \%$ & $72 \%$ & $72 \%$ \\
\hline
\end{tabular}

Among the Resource Centers, Bannu was leading the list with an overall pass percentage of $94 \%$, followed by Peshawar and Abbottabad with a rate of $92 \%$. Nonetheless, pass percentage of the emergency based Shalman camp was even more impressive and was recorded to be the highest amongst all with $96 \%$.

Girls trail $1 \%$ behind the overall passing rate of $91 \%$ to the boy's percent rate of $92 \%$. However, at Resource Center level girls appear to be ahead of boys in terms of pass percentage in Bannu, Hungu, while they are in par with boys in Abbottabad, Mardan, Timergara. But in Peshawar they are lagging behind boys with a rate of $90 \%$ as compared to $93 \%$ of the pass rate for boys. 
Peshawar has a higher rate of failure with 2,457 while and Bannu has the lower failure numbers with 605 . Peshawar is trailed by Timergara, Mardan and Abbottabad with failure figuring $1,349 \& 1,289$ and 1,275 respectively.

Girls' failure rate is observed to be high in Timergara and least in Bannu. In general girls' failure rate is found to be less than that of boys.

Table 8: Grade wise details of pass ratio by gender

\begin{tabular}{|c|c|c|c|c|c|c|c|c|c|c|c|c|}
\hline \multirow{2}{*}{$\begin{array}{l}\text { Resource } \\
\text { Center }\end{array}$} & \multicolumn{3}{|c|}{ Appeared } & \multirow{2}{*}{\multicolumn{3}{|c|}{ Passed }} & \multicolumn{3}{|c|}{ Eailed } & \multicolumn{3}{|c|}{ Pass\%ages } \\
\hline & Boys. & Girls & Total & & & Total & Boys & Girls & Total & Boys & Girls & Overail \\
\hline Grade 1 & 22,232 & 11,362 & 33,594 & 20,146 & 10,228 & 30,374 & 2,231 & 1,118 & 3,349 & $91 \%$ & $90 \%$ & $90 \%$ \\
\hline Grade 2 & 16,496 & 5,629 & 22,125 & 15,014 & 5,203 & 20,217 & 1,314 & 493 & 1,807 & $91 \%$ & $92 \%$ & $91 \%$ \\
\hline Grade 3 & 12,568 & 3,784 & 16,352 & 11,628 & 3,441 & 15,069 & 964 & 343 & 1,307 & $93 \%$ & $91 \%$ & $92 \%$ \\
\hline Grade 4 & 9,527 & 2,735 & 12,262 & 8,753 & 2,493 & 11,246 & 745 & 221 & 966 & $92 \%$ & $91 \%$ & $92 \%$ \\
\hline Grade 5 & 7,081 & 1,886 & 8,967 & 6,645 & 1,776 & 8,421 & 431 & 124 & 555 & $94 \%$ & $94 \%$ & $94 \%$ \\
\hline Grade 6 & 4,835 & 884 & 5,719 & 4,670 & 868 & 5,538 & 216 & 17. & 233 & $97 \%$ & $98 \%$ & $97 \%$ \\
\hline Total & 72,739 & 26,280 & 99019 & 66,856 & 24,009 & 90,865 & 5901 & 2,316 & 8,217 & $92 \%$ & $91 \%$ & $92 \%$ \\
\hline
\end{tabular}

Grade wise analysis of boys and girls presents interesting but marginal difference of $1 \%$ in the pass ratio. Failure rate in grade 1 is observed to be exceedingly high for both boys and girls and gradually decreases with higher grades (Table 8 ).

\subsection{Graduation rate}

Graduation rate defined is the number of students who successfully complete grade 6 in comparison to the total number of students actually enrolled in grade 6 at the beginning of the academic year. Table 9 reflects the graduation rate for boys and girls which were calculated at $81 \%$ and $75 \%$ respectively, while the overall graduation rate remained at $80 \%$ during $2002-03$.

Table 9: Graduation rate by gender during 2002-03

\begin{tabular}{|l|r|r|c|}
\hline Gender & $\begin{array}{l}\text { Enrollment } \\
\text { in grade 6 }\end{array}$ & Pass & Graduaiton rate \\
\hline Boys & 5,767 & 4,670 & $\mathbf{8 1 \%}$ \\
\hline Girls & 1,165 & 868 & $\mathbf{7 5 \%}$ \\
\hline Overall & 6,932 & 5,538 & $\mathbf{8 0} \%$ \\
\hline \multicolumn{2}{|r|}{ Source: } & \multicolumn{3}{c}{ BEFARe Study 2003} \\
\hline
\end{tabular}

It is worthy to note that the overall graduation rate has increased to $80 \%$ this year as compared to the rate of $75 \%$ for the period $1996-97$. 


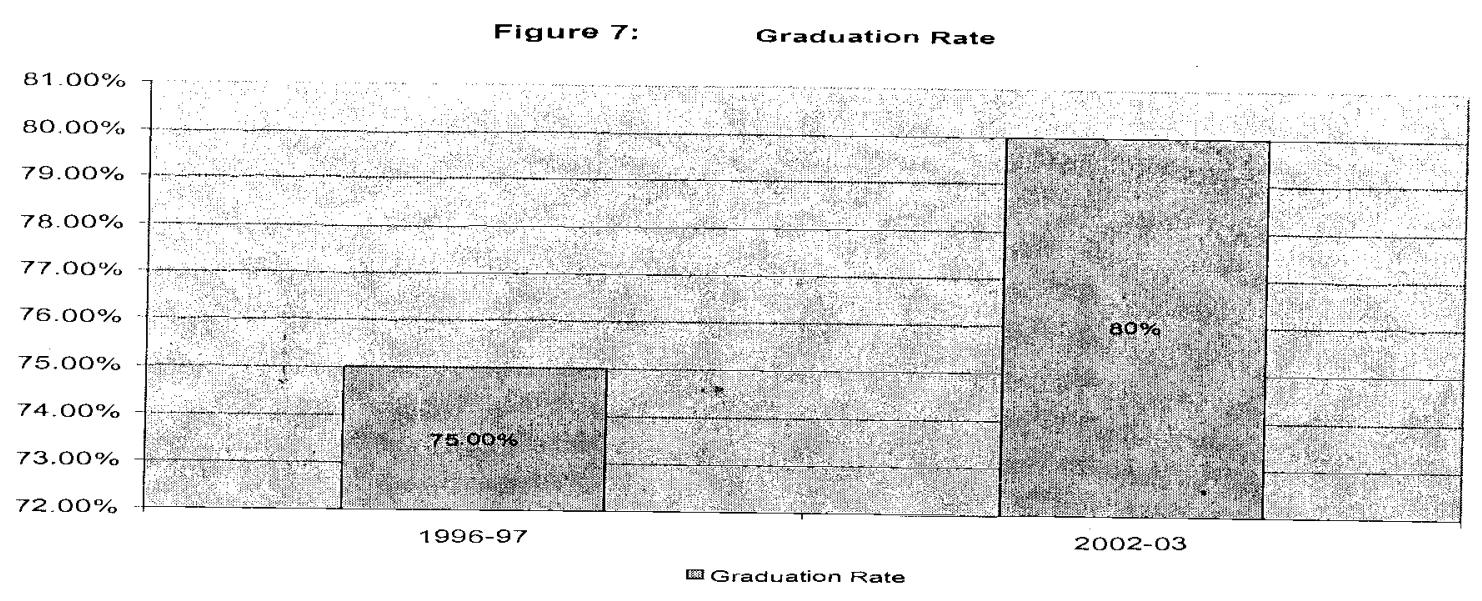

\subsection{Resource Center wise students performance in all grades}

Table 10: Resource Center wise distribution of marks by grade and gender

\begin{tabular}{|c|c|c|c|c|c|c|c|c|c|c|c|c|c|c|}
\hline \multirow{2}{*}{$\begin{array}{l}\text { Resource } \\
\text { Centre }\end{array}$} & \multirow{2}{*}{\multicolumn{2}{|c|}{\begin{tabular}{|l|l|}
\multicolumn{2}{|c|}{ Grade 1} \\
Boys & Girls \\
\end{tabular}}} & \multicolumn{2}{|c|}{ Grade 2} & \multicolumn{2}{|c|}{ Grade 3} & \multicolumn{2}{|c|}{ Grade 4} & \multicolumn{2}{|c|}{ Grade 5 : } & \multicolumn{2}{|c|}{ Grade 6} & \multicolumn{2}{|c|}{ Total } \\
\hline & & & Boys & Girls & Boys: & Girls & Boys: & Girls & Boys & Girls & Boys & Girls & Boys & Girls: \\
\hline Abbottabad & $73 \%$ & $72 \%$ & $73 \%$ & $74 \%$ & $75 \%$ & $73 \%$ & $74 \%$ & $74 \%$ & $75 \%$ & $71 \%$ & $77 \%$ & $82 \%$ & $75 \%$ & $74 \%$ \\
\hline Bannu & $65 \%$ & $67 \%$ & $66 \%$ & $65 \%$ & $66 \%$ & $61 \%$ & $67 \%$ & $77 \%$ & $70 \%$ & $0 \%$ & $73 \%$ & $59 \%$ & $68 \%$ & $66 \%$ \\
\hline Hungu & $67 \%$ & $65 \%$ & $66 \%$ & $67 \%$ & $67 \%$ & $69 \%$ & $65 \%$ & $69 \%$ & $69 \%$ & $74 \%$ & $71 \%$ & $81 \%$ & $68 \%$ & $71 \%$ \\
\hline Mardan & $71 \%$ & $64 \%$ & $66 \%$ & $64 \%$ & $66 \%$ & $67 \%$ & $66 \%$ & $71 \%$ & $67 \%$ & $75 \%$ & $71 \%$ & $81 \%$ & $68 \%$ & $70 \%$ \\
\hline Peshawar & $67 \%$ & $68 \%$ & $67 \%$ & $71 \%$ & $68 \%$ & $71 \%$ & $68 \%$ & $71 \%$ & $69 \%$ & $73 \%$ & $73 \%$ & $79 \%$ & $69 \%$ & $72 \%$ \\
\hline Shalman & $63 \%$ & $61 \%$ & $67 \%$ & $64 \%$ & $70 \%$ & $76 \%$ & $73 \%$ & $0 \%$ & $69 \%$ & $0 \%$ & $68 \%$ & $0 \%$ & $68 \%$ & $67 \%$ \\
\hline Timergara & $62 \%$ & $62 \%$ & $62 \%$ & $61 \%$ & $65 \%$ & $60 \%$ & $64 \%$ & $62 \%$ & $66 \%$ & $66 \%$ & $68 \%$ & $67 \%$ & $65 \%$ & $63 \%$ \\
\hline
\end{tabular}

Table 10 indicates Resource Center wise distribution of student's average percentage of marks obtained in all grades for boys and girls. Maximum score of student's marks has been between 60 and 70 . It is interesting to note that none of the boys in any grade could score above $80 \%$ marks; however, this feat was achieved by girls in grade 6 in Abbottabad, Hangu and Mardan.

Abbottabad was found to be leading in all Resource Centers in terms of high average scores for both boys and girls which was between $75 \%$ and $74 \%$. Timergara was at the bottom of the list of all Resource Centers where boys and girls scored the least total average number of marks (65\% and $63 \%)$.

It can be seen from Table 10 that girls' average score was more than boys in three Resource Centers namely Hangu, Mardan and Peshawar but was less in the other three Resource Centers namely Abbottabad, Bannu and Timergara.

Table 10 also shows that a small proportion of girls in grade 6 in Abbottabad, Hungu and Mardan could obtain marks above $80 \%$ while the remaining students in all grades score was between 60 and 70 . It is noticeable that both the highest 
and lowest marks were scored by girls' in grade 6 . The highest and lowest marks recorded in Abbottabad and Bannu were $82 \%$ and $59 \%$ respectively.

In general it could be concluded that students in upper grades have performed well as compared to the students in lower grades and there is need for better teaching/learning at lower grades.

\subsection{Resource Center wise students performance in subjects}

Table 11: Resource Center wise distribution of marks by subject and gender in Grade 1

\begin{tabular}{|c|c|c|c|c|c|c|c|c|c|c|c|c|c|c|c|c|}
\hline \multirow{2}{*}{$\begin{array}{l}\text { Resource } \\
\text { Centre }\end{array}$} & \multicolumn{2}{|c|}{ Math } & \multicolumn{2}{|c|}{ Islamiat } & \multicolumn{2}{|c|}{ Drawing } & \multicolumn{2}{|c|}{ Calligraphy } & \multicolumn{2}{|c|}{ Sport } & \multicolumn{2}{|c|}{ Pashito } & \multicolumn{2}{|c|}{ Quran } & \multicolumn{2}{|c|}{ DT Total } \\
\hline & Boys & Girls & Boys & Ginls & Boys & Girls & Boys & Girls & Boys & Girls & Boys & Gins & Boys & Girls & Boys & Girls \\
\hline Abbottabad & $71 \%$ & $70 \%$ & $71 \%$ & $69 \%$ & $75 \%$ & $74 \%$ & $72 \%$ & $74 \%$ & $81 \%$ & $80 \%$ & $73 \%$ & $69 \%$ & $71 \%$ & $69 \%$ & $73 \%$ & $72 \%$ \\
\hline Bannu & $61 \%$ & $64 \%$ & $62 \%$ & $64 \%$ & $.67 \%$ & $70 \%$ & $68 \%$ & $69 \%$ & $75 \%$ & $\%$ & $63 \%$ & $66 \%$ & $61 \%$ & $62 \%$ & $65 \%$ & $67 \%$ \\
\hline Hungu & $63 \%$ & $59 \%$ & $63 \%$ & $59 \%$ & 71 & $70 \%$ & 65 & $65 \%$ & $82 \%$ & $81 \%$ & $61 \%$ & $61 \%$ & $61 \%$ & $60 \%$ & $67 \%$ & $65 \%$ \\
\hline Mardan & $85 \%$ & $62 \%$ & $64 \%$ & $62 \%$ & $71 \%$ & $66 \%$ & $71 \%$ & $62 \%$ & $81 \%$ & $74 \%$ & $63 \%$ & $61 \%$ & $65 \%$ & $63 \%$ & $1 \%$ & $64 \%$ \\
\hline Peshawar & \begin{tabular}{|l|}
$61 \%$ \\
\end{tabular} & $61 \%$ & $63 \%$ & $62 \%$ & $71 \%$ & $72 \%$ & $68 \%$ & $71 \%$ & $84 \%$ & $87 \%$ & $62 \%$ & $61 \%$ & $60 \%$ & $62 \%$ & $67 \%$ & $68 \%$ \\
\hline Shalman & \begin{tabular}{|l|}
$58 \%$ \\
\end{tabular} & $56 \%$ & $56 \%$ & $57 \%$ & $63 \%$ & $62 \%$ & 65 & $65 \%$ & $79 \%$ & $77 \%$ & $63 \%$ & $56 \%$ & $55 \%$ & $55 \%$ & $63 \%$ & $61 \%$ \\
\hline imergara & $58 \%$ & $59 \%$ & $58 \%$ & $60 \%$ & $64 \%$ & $61 \%$ & $59^{\circ}$ & $60 \%$ & $78 \%$ & $77 \%$ & $59 \%$ & $60 \%$ & $58 \%$ & $59 \%$ & $62 \%$ & $62 \%$ \\
\hline
\end{tabular}

Among the Resource Centers Abbottabad has the highest rate of percent in grade 1 with $73 \%, 72 \%$ for boys and girls respectively. Timergara had the lowest with total scores $63 \%, 61 \%$ for boys and girls '.

Subject wise analysis (Table 11) shows that the highest marks (87\%) were scored in Sports interestingly by girls. In Maths the maximum mark recorded was $85 \%$ scored by boys in Mardan, while the minimum $59 \%$ mark was in Hangu by girls.

In Islamiat and Pashto, boys had obtained the highest marks $71 \%, 58 \%$ in Abbottabad and lowest $73 \%, 59 \%$ in Timergara accordingly.

Figure 8: $\quad$ Grade 2 students performance

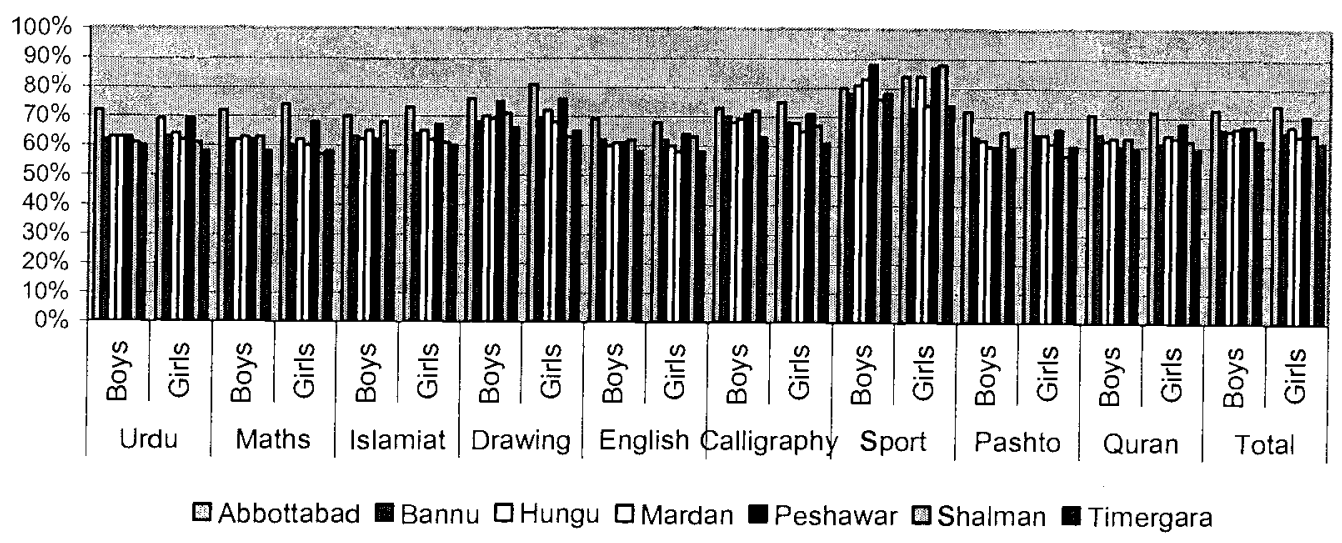


In grade 2, the marks of the girls $74 \%$ were found to be the maximum of the total average marks from Abbottabad. The minimum mark was recorded as $61 \%$ scored by girls' from the schools in Timergara Resource Center.

In Urdu and English, maximum mark for boys was $72 \%$ and $69 \%$ and for girls it was $69 \%$ and $68 \%$ respectively in Abbottabad. The minimum mark in Urdu and English was recorded $60 \%, 58 \%$ for boys and $58 \%, 58 \%$ for girls accordingly in Timergara Resource Center.

In Mathematics, girls led the table with 74\%. However, the lower figure of $58 \%$ was shared by both girls and boys. Both boys and girls from Abbottabad had scored the highest in mathematics while students in Timergara scored the lowest (table 12).

Table 12: Resource Center wise distribution of marks by subject and gender in Grade 3

\begin{tabular}{|c|c|c|c|c|c|c|c|c|c|c|c|c|c|c|c|c|c|c|}
\hline \multirow{2}{*}{$\begin{array}{l}\text { Resource } \\
\text { Centre }\end{array}$} & \multicolumn{2}{|c|}{ Urdu } & \multicolumn{2}{|c|}{ Maths } & \multicolumn{2}{|c|}{ Islamiat } & \multicolumn{2}{|c|}{ Drawing } & \multicolumn{2}{|c|}{ English } & \multicolumn{2}{|c|}{ Sport } & \multicolumn{2}{|c|}{ Pashto } & \multicolumn{2}{|c|}{ Qurran } & \multicolumn{2}{|c|}{ Total } \\
\hline & Boys & Girls & Boys & Gins & Boys & Girs & Boys & Cins & Boys & Girls & Boys & Gins & Boys & Girs & Boys & Girls & Boys & Gils: \\
\hline Abbottabad & $72 \%$ & $69 \%$ & $71 \%$ & $71 \%$ & $74 \%$ & $71 \%$ & $78 \%$ & $80 \%$ & $71 \%$ & $66 \%$ & $84 \%$ & $84 \%$ & $74 \%$ & $72 \%$ & $74 \%$ & $71 \%$ & $75 \%$ & $73 \%$ \\
\hline Bannu & $64 \%$ & $61 \%$ & $62 \%$ & $59 \%$ & $64 \%$ & $60 \%$ & $69 \%$ & $60 \%$ & $62 \%$ & $60 \%$ & $78 \%$ & $69 \%$ & $63 \%$ & $60 \%$ & $63 \%$ & $62 \%$ & $66 \%$ & 01 \\
\hline Hungu & $65 \%$ & $66 \%$ & $60 \%$ & $65 \%$ & $63 \%$ & $66 \%$ & $71 \%$ & $74 \%$ & $64 \%$ & $63 \%$ & $85 \%$ & $84 \%$ & $62 \%$ & $68 \%$ & $65 \%$ & $66 \%$ & $67 \%$ & $69 \%$ \\
\hline \begin{tabular}{|l|} 
Mardan \\
\end{tabular} & $65 \%$ & $69 \%$ & $61 \%$ & $59 \%$ & $64 \%$ & $65 \%$ & $69 \%$ & $69 \%$ & $63 \%$ & $68 \%$ & $82 \%$ & $79 \%$ & $61 \%$ & $63 \%$ & $65 \%$ & $66 \%$ & $66 \%$ & $67 \%$ \\
\hline Peshawar & $67 \%$ & $73 \%$ & $59 \%$ & $63 \%$ & $64 \%$ & $66 \%$ & $74 \%$ & $79 \%$ & $65 \%$ & $66 \%$ & $88 \%$ & $89 \%$ & $63 \%$ & $63 \%$ & $64 \%$ & $68 \%$ & $68 \%$ & $71 \%$ \\
\hline Shalman & $64 \%$ & $74 \%$ & $66 \%$ & $63 \%$ & $66 \%$ & $74 \%$ & $74 \%$ & $79 \%$ & $67 \%$ & $76 \%$ & $84 \%$ & $93 \%$ & $71 \%$ & $74 \%$ & $66 \%$ & $73 \%$ & $70 \%$ & $76 \%$ \\
\hline Timergara & $62 \%$ & $57 \%$ & $60 \%$ & $56 \%$ & $60 \%$ & $57 \%$ & $69 \%$ & $62 \%$ & $61 \%$ & $56 \%$ & $81 \%$ & $73 \%$ & $62 \%$ & $58 \%$ & $63 \%$ & $60 \%$ & $65 \%$ & $60 \%$ \\
\hline
\end{tabular}

Abbottabad was ahead of all Resource Centers in grade 3 where the recorded total average marks for boys and girls were $75 \%$ and $73 \%$ respectively. Timergara is at the bottom of the list with score at $65 \%$ for boys and $60 \%$ for girls.

In three Resource Centers (Hangu, Mardan and Peshawar) average marks of girls were higher than boys while in the remaining Resource Centers boys had scored more than girls.

In Urdu and English, boys from Abbottabad had scored high marks $72 \%$ and $71 \%$ while girls in Peshawar had secured the maximum average marks $73 \%$ in Urdu but the total average marks for girls in English were dropped to $56 \%$.

In Mathematics, high average marks of boys and girls $(71 \%, 71 \%)$ were recorded again in Abbottabad and least $(60 \%, 56 \%)$ in Timergara.

In Islamiat and Pashto, boys have obtained high average marks $(74 \%, 74 \%)$ in Abbottabad and girls' has scored least average marks (57\%, 58\%) in Timergara accordingly. 
Figure 9: $\quad$ Grade 4 students performance

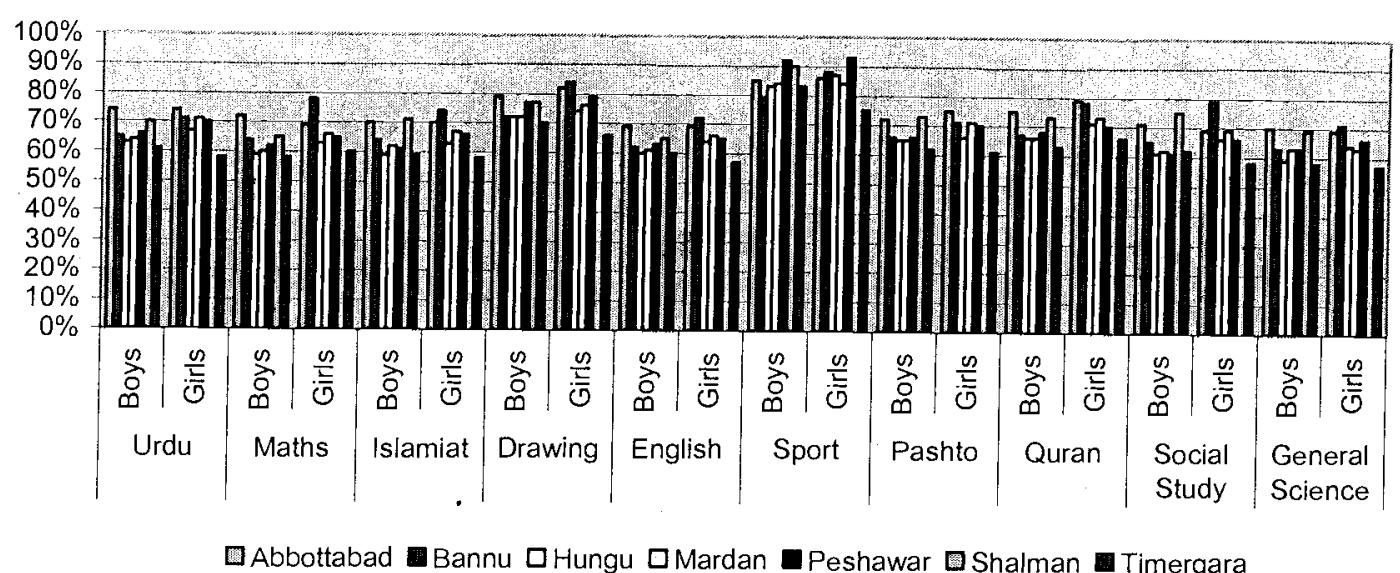

Interestingly in grade 4 Resource Center Bannu has preceded the other Resource Centers with maximum total average marks $77 \%$ obtained by girls followed by boys score of $74 \%$ at Abbottabad Resource Center.

High total average marks scoring over 90 s could be seen for both boys and girls for sports in Peshawar Resource Center, followed by girl's $84 \%$ and $82 \%$ score for drawing from Bannu and Abbottabad respectively.

In Urdu, Abbottabad is ahead with high average calculated marks $74 \%$ each for boys and girls. Timergara again was found lagging behind with $61 \%$ and $58 \%$ marks for boys and girls. $72 \%$ average marks for girls were recorded in English from Bannu Resource Center and the lowest score of $57 \%$ of girls was again from Timergara.

In Social Studies and General Science, girls in Bannu had scored maximum average marks of $79 \%, 71 \%$ followed by boys from Abbottabd with an average marks of $70 \%$ and $74 \%$. Timergara was again found with lower calculated values.

Abbottabad is leading in Pashto having secured high average marks followed by Bannu and Mardan and Timeraga at the bottom with the lowest scores. 
Figure 10: $\quad$ Grade 5 student performance

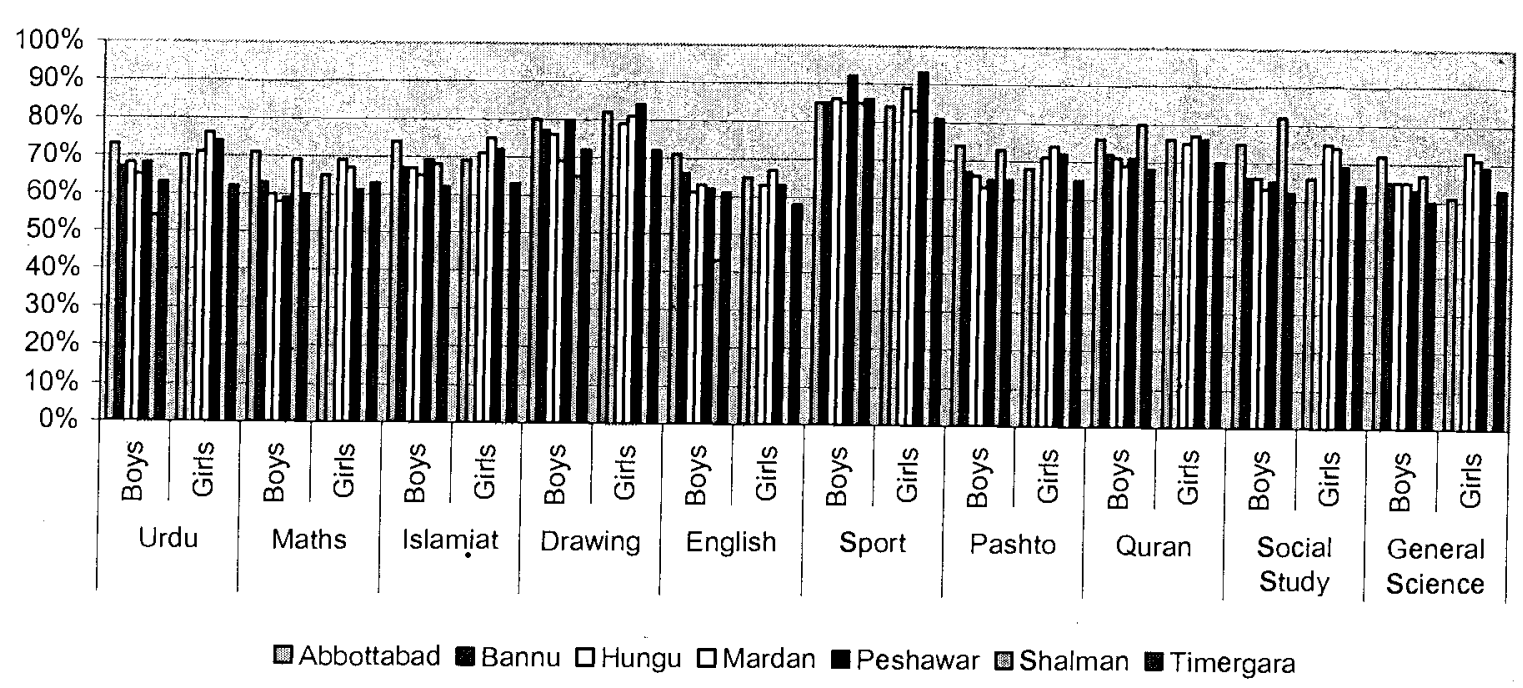

In grade 5 girls total average marks in all subjects were found to be greater than average marks of boys in three Resource Centers (Hangu, Mardan and Peshawar) calculated as $74 \%, 75 \%$ and $73 \%$ accordingly.

In sports again high marks in 90 s were to be observed for boys and girls in Peshawar and Abbottabad Resource Center trailed behind in average marks in the subject of drawing.

In Urdu and English, girls have performed better than boys in Hangu, Mardan and Peshawar Resource Centers (71\%, 76\% 74\%). However students in the Resource Center Abbottabad had recorded high average marks for boys and girls $(73 \%, 70 \%)$ as compared to the other Resource Centers.

In Mathematic, Abbottabad has higher average marks with $71 \%$ scored by boys followed by Hangu where high calculated average mark $69 \%$ was scored by girls'. The lowest average percent of marks was from in Peshawar Resource Center which was $59 \%$ and $61 \%$ for boys and girls respectively.

In Social Studies and General Science, performance of boys at Abbottabad and girls in Hangu was calculated to be better as compared to other Resource Centers. The upper calculated figure in these subjects was estimated $75 \%$ each for boys and girls and lower value for boys was calculated $62 \%$ and girls $61 \%$. 
Figure 11: Grade 6 students performance

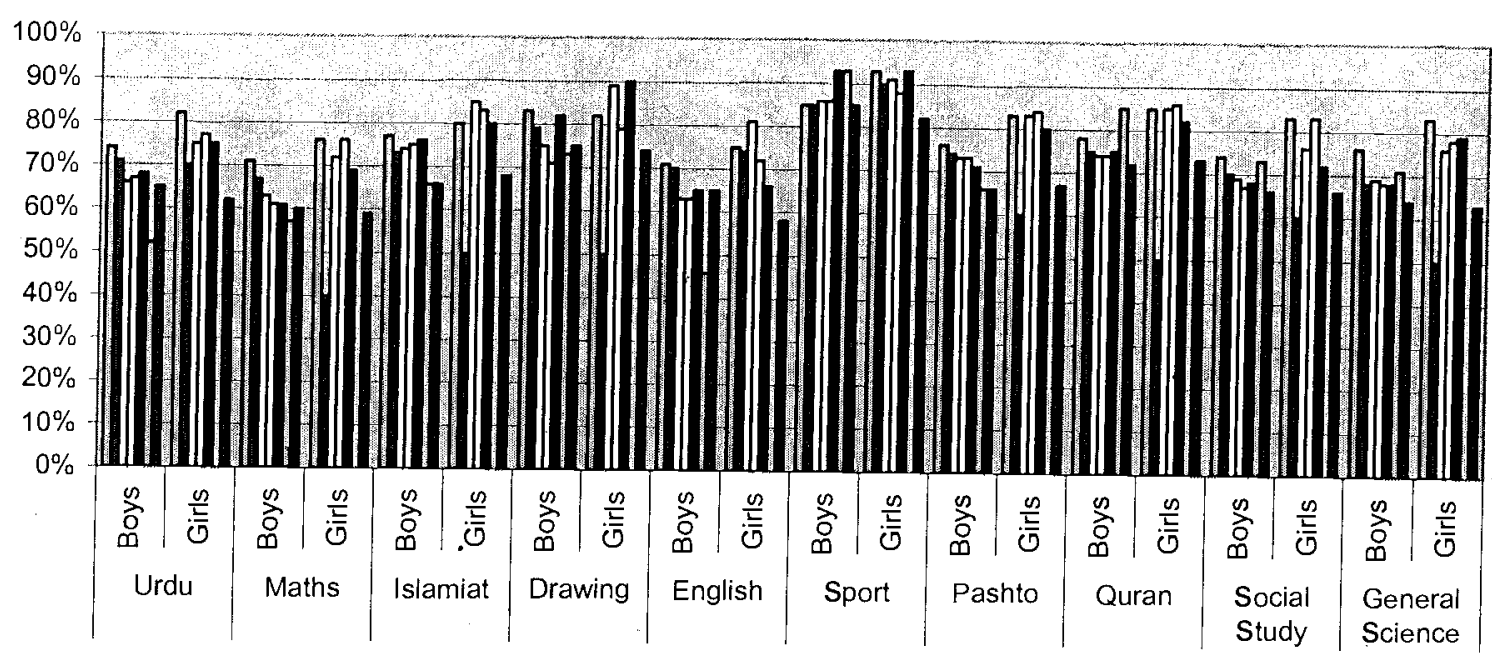

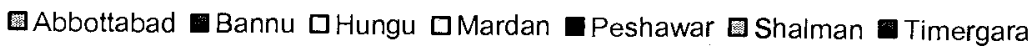

In grade 6 , Abbottabad is in forefront with high average marks for boys and girls $(77 \%, 82 \%)$ followed by Resource Centers Hangu and Mardan $71 \%, 81 \%$ for boys and girls in each of the Resource Centers. Timergara and Banuu was placed at the bottom with least recorded values $68 \%$ for boys at Timergara and $59 \%$ for girls in Bannu.

In Urdu, girls have excelled over boys in Abbottabad, Hangu, Mardan and Peshawar and trailed behind in the other Resource Center. Similarly, average marks for girls in English were more than boys in all Resource Centers except Timergara.

In Pashto, Abbottabad was found to be ahead of all Resource Centers with average marks $76 \%, 83 \%$ for boys and girls respectively while Timergara was observed to be at the bottom in comparison with other Resource Centers.

In Mathematics, children in the Resource Center Abbottabad had scored the highest marks and Timergara was again behind with lowest average marks for boys and girls. However the lowest recorded marks was in Bannu with surprisingly a very low average marks of $40 \%$ for girls.

In Social Studies and General Science, the performance of students from Resource Center Abbottabad was observed to be the best among all Resource Centers. The highest and least values in these subjects were scored by girls to be $83 \%$ and $50 \%$ which was from Abbottabad and Bannu Resource Centers respectively. 


\subsection{Student's performance in subjects and grades}

The table 13 below present student average marks in various subjects and grades.

Table 13: Subject wise distribution of student's marks by grade and gender

\begin{tabular}{|c|c|c|c|c|c|c|c|c|c|c|c|c|c|c|}
\hline \multirow[b]{2}{*}{ Subjects } & \multirow{2}{*}{\multicolumn{2}{|c|}{\begin{tabular}{|l|} 
Grade 1 \\
Boys Tirls
\end{tabular}}} & \multicolumn{2}{|c|}{ Grade 2} & \multicolumn{2}{|c|}{ Grade 3} & \multicolumn{2}{|c|}{ Grade 4} & \multicolumn{2}{|c|}{ Grade 5} & \multicolumn{2}{|c|}{ Grade 6} & \multicolumn{2}{|c|}{ Total } \\
\hline & & Girls & Boys & Girls & Boys & Girls & Boys & Girls: & Boys & Girls & Boys & Gir/s & Boys & Girls \\
\hline Urdu & & $=$ & $63 \%$ & $64 \%$ & $66 \%$ & $67 \%$ & $66 \%$ & $69 \%$ & $65 \%$ & $71 \%$ & $66 \%$ & $74 \%$ & $65 \%$ & $69 \%$ \\
\hline Maths & $65 \%$ & $62 \%$ & $63 \%$ & $63 \%$ & $63 \%$ & $62 \%$ & $63 \%$ & $67 \%$ & $63 \%$ & $65 \%$ & $63 \%$ & $65 \%$ & $63 \%$ & $64 \%$ \\
\hline Islamiat & $62 \%$ & $62 \%$ & $64 \%$ & $65 \%$ & $65 \%$ & $66 \%$ & $64 \%$ & $66 \%$ & $67 \%$ & $70 \%$ & $72 \%$ & $74 \%$ & $66 \%$ & $67 \%$ \\
\hline Drawing & $69 \%$ & $68 \%$ & $71 \%$ & $71 \%$ & $72 \%$ & $72 \%$ & $74 \%$ & $77 \%$ & $74 \%$ & $80 \%$ & $77 \%$ & $77 \%$ & $73 \%$ & $74 \%$ \\
\hline English & & 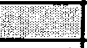 & $62 \%$ & $62 \%$ & $65 \%$ & $65 \%$ & $63 \%$ & $66 \%$ & $61 \%$ & $63 \%$ & $63 \%$ & $71 \%$ & $63 \%$ & $65 \%$ \\
\hline Calligraphy & $67 \%$ & $67 \%$ & $69 \%$ & $68 \%$ & 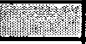 & 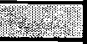 & 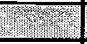 & nin & 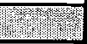 & & 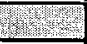 & 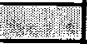 & $68 \%$ & $67 \%$ \\
\hline Sports & $80 \%$ & $78 \%$ & $81 \%$ & $.81 \%$ & $83 \%$ & $82 \%$ & $85 \%$ & $86 \%$ & $86 \%$ & $86 \%$ & $88 \%$ & $90 \%$ & $84 \%$ & $84 \%$ \\
\hline Pashtu & $63 \%$ & $62 \%$ & $63 \%$ & $63 \%$ & $65 \%$ & $65 \%$ & $67 \%$ & $69 \%$ & $68 \%$ & $70 \%$ & $71 \%$ & $76 \%$ & $66 \%$ & $68 \%$ \\
\hline Quran & $62 \%$ & $61 \%$ & $63 \%$ & $64 \%$ & $66 \%$ & $67 \%$ & $68 \%$ & $73 \%$ & $72 \%$ & $75 \%$ & $76 \%$ & $77 \%$ & $68 \%$ & $69 \%$ \\
\hline Social Studies & 2 & 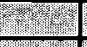 & - & - & 5 & 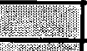 & $65 \%$ & $68 \%$ & $68 \%$ & $70 \%$ & $70 \%$ & $73 \%$ & $68 \%$ & $70 \%$ \\
\hline Gen. Sc & & 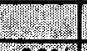 & 5 & 2 & 0 & 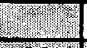 & $64 \%$ & $65 \%$ & $65 \%$ & $67 \%$ & $69 \%$ & $72 \%$ & $66 \%$ & $68 \%$ \\
\hline Total & $67 \%$ & $66 \%$ & $67 \%$ & $67 \%$ & $68 \%$ & 68\% & $68 \%$ & $70 \%$ & $69 \%$ & $72 \%$ & $72 \%$ & 75\% & $68 \%$ & $70 \%$ \\
\hline
\end{tabular}

It is important to mention here that girls' had excelled boys in overall performance. The percentage average marks for girls were calculated as $70 \%$ as compared to boys $68 \%$.

Table 13 depicts an almost uniform performance for boys and girls in lower grades; however girls' performance has improved significantly in higher grades. Similarly, total average marks were observed to be increasing along with the grades for both boys and girls'.

The highest total percent of average marks was scored by girls in grade 6 as $75 \%$ and the lowest $66 \%$ was also scored by girls in grade 1 .

According to the Formal Education (FE) grading system of distribution of marks all the boys and girls in all grades fall into "B" (61-80). However, neither boys nor girls had obtained " $A$ " $(\mathbf{8 1 - 1 0 0})$ in the subjects. It is important to highlight that the total average marks of the majority of student's were between 60 and 70 .

A total of 11 subjects are taught at primary level spread over the 6 years period. In Urdu the percentage of the total average marks were recorded at $65 \%$ and $69 \%$ for boys and girls respectively while the scores obtained in English was lower to $63 \%$ and $65 \%$ for both boys and girls.

The results of mathematic could be stated as poor for both boys and girls with only total scores $63 \%$ and $64 \%$ respectively. 
Social studies and general science were taught to students in higher grades 4,5 and 6 . Interestingly the calculated average marks for girls' were recorded to be better than boys. The total average marks were documented as $70 \%, 68 \%$, for girls' and $68 \%, 66 \%$ for boys in social studies and general science accordingly.

Figure 12: Comparison of Boys and Girls average marks in all subjects

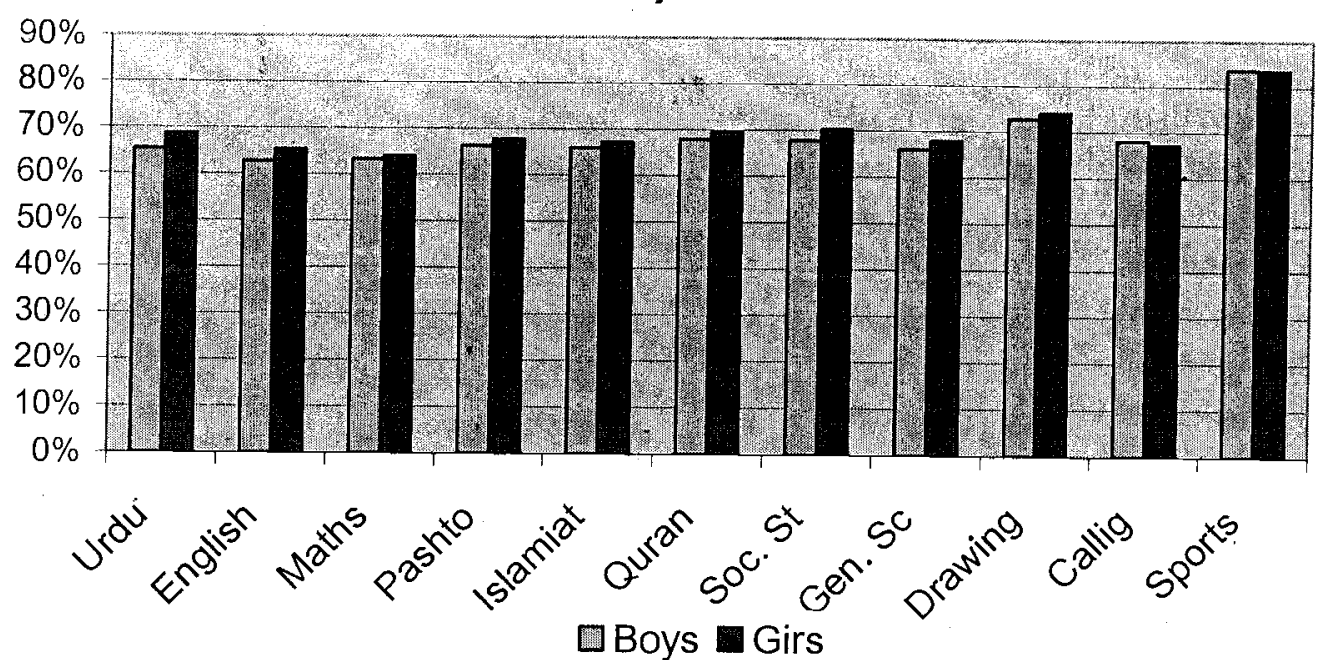

The results of Islamiat and the Quran indicate that the performance in all grades in these subjects was almost similar, where girls lead than the boys.

The best performance was noted in Sport for both boys and girls with an average mark of $84 \%$ for each.

It can be concluded from the above analysis that average marks of both boys and girls fall in the category "B". However girls' average marks was calculated in 70 s while boys in 60 s.

Firgure 13: Comparison of avarage marks in various subjects

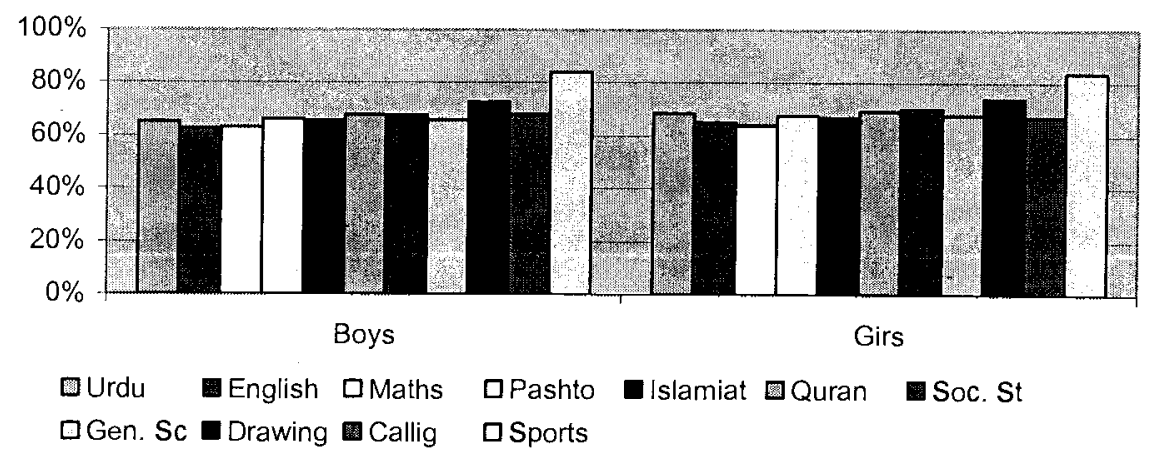


Figure 14: Maximum and Minimum Enrollment in Resource Centres

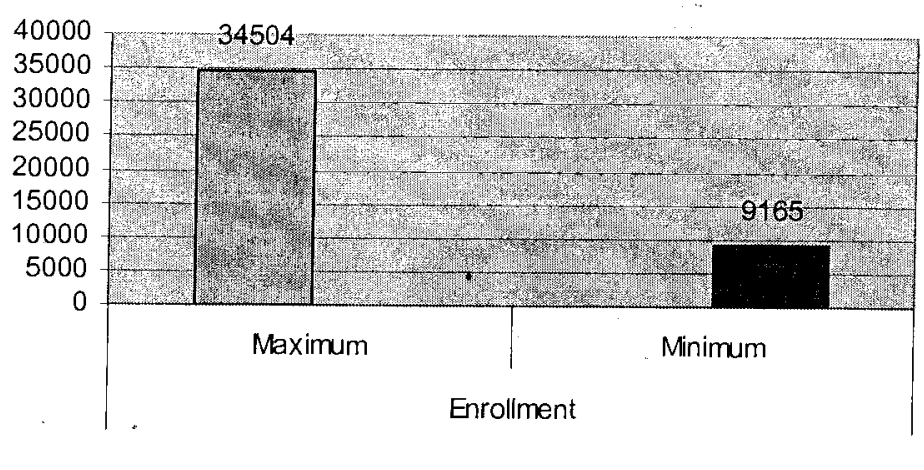

O. Peshaw ar Bannu

Figure 15: Maximum and Minimum Dropouts in Resource Centers

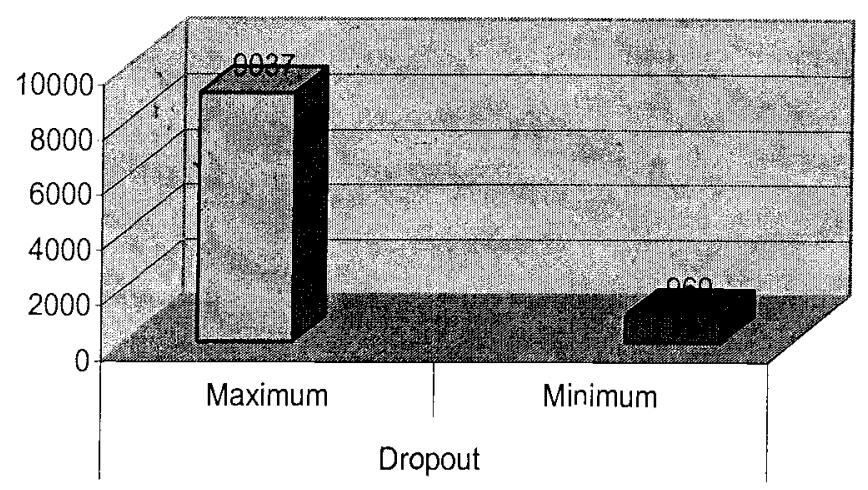

圆Peshawar Timergara 
Fig: 16 Maximum \& Minimum percentage of Marks in Resource Centers

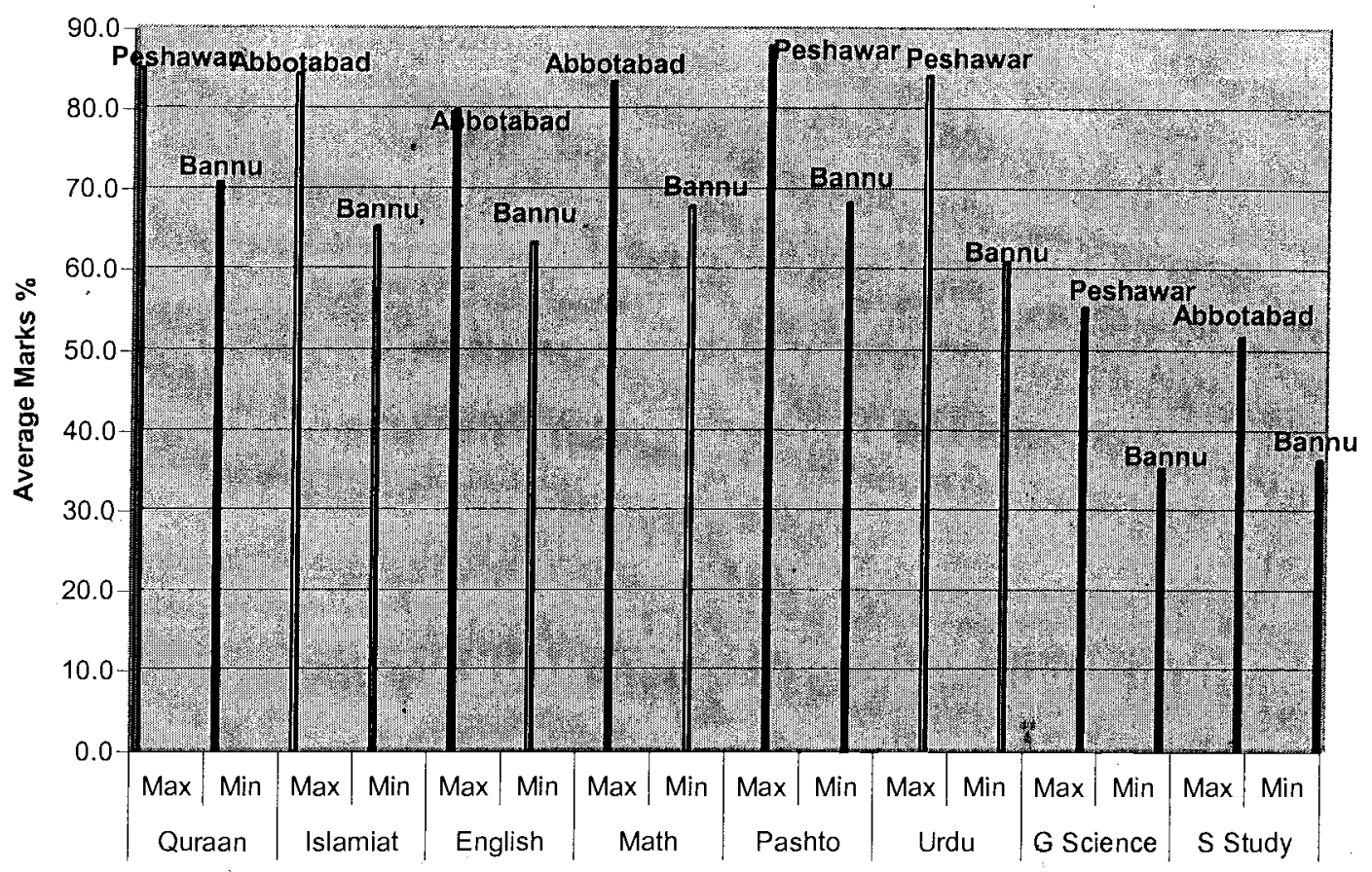




\section{Findings}

\section{Enrollment}

- Total enrollment has increased by $17 \%$ as compared to the figure of the previous year enrolled and 103\% to the total enrollment in 1996-97

- The proportion of girls enrollment has increased by $28 \%$ as compared to the girls enrollment in 1996-97

\section{Repeaters}

- Repeaters were noted to be $7 \%$ and fresh enrollment was estimated as $93 \%$

\section{Dropout}

- High dropout rate $(15 \%)$ was observed for this year which was more than twice to the previous years dropout rate of $7 \%$

- Dropout among girls was higher than boys

- Girls' dropout rate of $100 \%$ was recorded in grade 5 in Nowshera district

- An equal dropout ratio was calculated in all grades

\section{Examination and Results}

- $99,019(80 \%)$ students appeared in the examination out of the total enrolled 123,660

- Rate of appearance of boys $981 \%)$ was high than girls $(77 \%)$

- Total pass percentage was recorded $92 \%$ (boys $92 \%$ and girls $91 \%$ ) which is an increase from $72 \%$ in $1996-97$

- It was observed that pass percentage increases from lower to higher grades

- Boys hold highest pass percentage of $99 \%$ in Bannu Resource Center

- Girls performance in terms of marks percentage was better than boys

- Girls performance has improved towards category " $A$ " $(81-100)$ from lower to higher grades in all Resource Centers

- Abbottabad Resource Center hold high pass marks percentages for both boys and girls and Timergara hold the lowest

- Students' performance in Resource Center Peshawar compared to other Resource Centers could be termed un-satisfactory, notwithstanding the fact of the availability of a large number of qualified staff in the Resource Center.

\section{Cohort Survival and Graduation Rate}

- Cohort survival rate has improved for boys and girls

- $80 \%$ students ( $81 \%$ boys and $75 \%$ girls) has graduated during $2002-03$

- The highest graduation rate of $90 \%$ was found for boys in Resource Center Bannu whereas for girls it was $84 \%$ in Timergara Resource Center 


\section{Recommendation}

Based on the detail analysis of all statistics the following suggestions are forwarded to improve the qualitative aspect of education.

- To enhance the effectiveness of education, FE unit requires to develop and follow a well defined marking mechanism based on standard benchmarks that would facilitate and increase the reliability of the performance measurement.

- To minimize the biasness and favoritism it is suggested that the examinations should be conducted under the supervision of a neutral invigilator. It is further recommended that the papers should be checked at a neutral place (Resource Center) and by neutral persons.

- To strengthen the quality of education the class strength in early grades should not exceed 40 students. Moreover, qualified and professional teachers should be assigned with the task to teach the initial grades. In case of constraint of inadequate number of teachers the introduction of multi-grade teaching at higher grades is recommended.

- Admission of under age students in grade 1 is adversely affecting students' performance and result in high dropouts. Thus admission to student below 5 years of age should be avoided in regular grades. Strict adherence to admission policy in this regard would serve the purpose.

- The Head Teachers are placed with dual responsibility of teaching and administration. To effectively manage the administrative affairs the Head Teachers, if possible, should be freed from teaching responsibility.

- At some places in hilly areas annual examination commences immediately after the winter vacation, which adversely affects the students performance in the exam. The annual exam in such areas, if possible, should be re-scheduled to some other suitable time.

- Dari speaking students encompasses significant proportion of enrollment. To over come the difficulty faced by those student studying in Pashto. Dari curriculum should be introduced (if feasible) at the earliest to improve their performance.

- While calculating the percentage of attendance, late admission students should be treated separately to ensure the students are not debarred unnecessarily from the exam.

- To allow more students to appear in the annual exam, a change in the rule of $75 \%$ attendance should be introduced in schools in hilly area

- There is an urgent need to improve $T / L$ at lower grades

- Importance of concept based evaluation 


\section{Part II}

\section{Resource Center Abbottabad}

\subsection{Enrollment}

Total enrollment in Abbottabad Resource Center was 19,857 included 15,361 boys and 4,496 girls. Abbottabad Resource Center contribution to the total enrollment of 123,660 was $16 \%$. The proportion of district Haripure enrollment to the total enrollment in Abbottabad was more than other districts which was documented as 8,960 boys and 3048 girls. The lowest enrollment for both genders was recorded in district Ghazi which was 1,121 and 261 boys and girls respectively.

Abbottabad Resource Center has three districts namely Ghazi, Haripure and Mansehra districts. Among them Haripur district has the high strength of student as 12,006 in comparison to other districts in Abbottabad Resource Center.

Table A1: Distribution of students by districts

\begin{tabular}{|l|r|r|r|r|r|r|r|r|r|}
\hline \multirow{2}{*}{ District } & \multicolumn{3}{|c|}{ Enrolled } & \multicolumn{3}{|c|}{ Repeater } & \multicolumn{3}{c|}{ Fresh enrollment } \\
\cline { 2 - 10 } & Boys & Girls & Total & Boys & Girls & Total & Boys & Girls & Total \\
\hline Ghazi & 1121 & 261 & 1,382 & 175 & 23 & 198 & 946 & 238 & 1,184 \\
\hline Haripure & 8960 & 3046 & 12,006 & 706 & 172 & 878 & 8,254 & 2,874 & 11,128 \\
\hline Mansehra & 5280 & 1189 & 6,469 & 564 & 91 & 655 & 4,716 & 1,098 & 5,814 \\
\hline Total & $\mathbf{1 5 , 3 6 1}$ & $\mathbf{4 , 4 9 6}$ & $\mathbf{1 9 , 8 5 7}$ & $\mathbf{1 , 4 4 5}$ & $\mathbf{2 8 6}$ & $\mathbf{1 , 7 3 1}$ & $\mathbf{1 3}, \mathbf{9 1 6}$ & $\mathbf{4 , 2 1 0}$ & $\mathbf{1 8 , 1 2 6}$ \\
\hline
\end{tabular}

High percentage of repeaters was recorded in district Ghazi in both genders which were $16 \%$ (175) boys and $9 \%$ (23) girls followed by District Mansehra in which the rate of repeaters was calculated to be $11 \%$ (564) boys and $8 \%(91)$ girls. The least percent of repeat cases for boys and girls were noted in district Haripure as $8 \%(706)$ and $6 \%(172)$ respectively.

District Wise Share in Total Enrollment

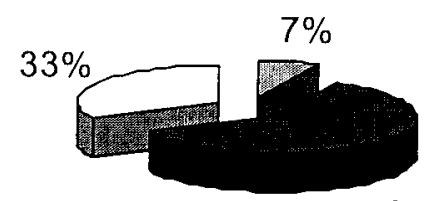

$60 \%$

Ghazi Haripure $\square$ Mansehra 
The significant percentage of repeaters reflects the change in attitude of Afghan refugees towards education. Their active involvement in the education process enabled the communities to realize the importance of education and not to withdraw the student after failure. The CP\&D should be credited for ensuring the active involvement of community in the education process.

\subsection{Dropout}

In Abbottabad Resource Center highest dropout was observed in Ghazi district especially in grade 1 and 5among girls. Haripure district remained second for dropout particularly in grade 2, 4 and 6 among girls. The lowest rate of dropout was recorded in Mansehra district in all grades except grade 3 girls.

The main reason for the dropout in Afghan community is Poverty. To earn livelihood they do different types of work which required them to go outside their place of residence thus making their habitation temporary in a particular area. Ghazi and Haripur districts, due to seasonal migration of the families to Punjab province during harvesting season where they work as daily wager, suffered the retention rate of students in schools.

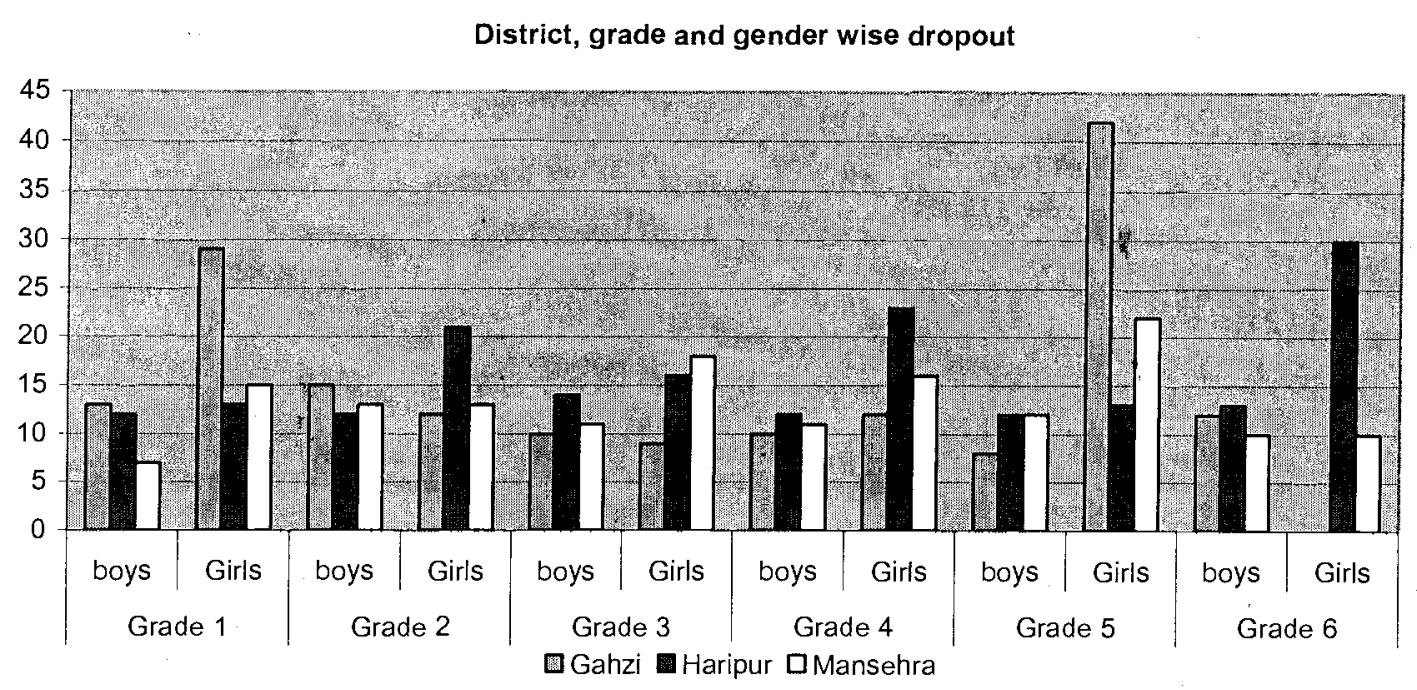




\section{Grade wise dropout statistic of all districts in Abbottabad Resource Center}

Table A2: Grade wise details of dropout of district Ghazi

\begin{tabular}{|c|c|c|c|c|c|c|c|}
\hline & \multicolumn{2}{|c|}{ Enrolled } & \multicolumn{3}{|c|}{ Dropped } & \multicolumn{2}{|c|}{ Dropout in \% } \\
\hline & Boys & Girls & Boys & Girls & Overall & Boys & Girls \\
\hline Grade I & 398 & 139 & 53 & 40 & 93 & $13 \%$ & $29 \%$ \\
\hline Grade II & 260 & 57 & 39 & 7 & 46 & $15 \%$ & $12 \%$ \\
\hline Grade III & 172 & 33 & 17 & 3 & 20 & $10 \%$ & $9 \%$ \\
\hline Grade IV & 125 & 18 & 12 & 4 & 16 & $10 \%$ & $22 \%$ \\
\hline Grade V & 91 & 14 & 7 & 6 & 13 & $8 \%$ & $43 \%$ \\
\hline Grade VI & 75 & - & 9 & 0 & 9 & $12 \%$ & $0 \%$ \\
\hline Total & 1,121 & 261 & $\begin{array}{r}137 \\
\end{array}$ & 60 & $\begin{array}{r}197 \\
\end{array}$ & $12 \%$ & $23 \%$ \\
\hline
\end{tabular}

In Ghazi district High dropout was observed in girls especially in grade 1, 3 and 4 which was $29 \%, 25 \%$ and $43 \%$ respectively. While in boys high dropout was recorded in grade 1, 2 and 6 which was $13 \%, 15 \%$ and $12 \%$ respectively. The highest percentage of dropout among boys was in grade 2 while in girls was in grade 5 .

While analyzing the dropout among districts it was noted that the dropout rate in Ghazi district was high in grade 1 and 2 for boys and for girls high dropout was found to be in grade 1 and 5 as compare to other districts in the entire Resource Center.

Table A3: Grade wise details of dropout of district Haripur

\begin{tabular}{|l|r|r|r|r|r|r|r|}
\hline & \multicolumn{3}{|c|}{ Enrolled } & \multicolumn{3}{c|}{ Dropped } & \multicolumn{2}{c|}{ Dropout in \% } \\
\cline { 2 - 8 } & Boys & Girls & Boys & Girls & Overall & Boys & Girls \\
\hline Grade I & 2813 & 1482 & 332 & 189 & 521 & $12 \%$ & $13 \%$ \\
\hline Grade II & 1,957 & 745 & 243 & 158 & 401 & $12 \%$ & $21 \%$ \\
\hline Grade III & 1,564 & 402 & 215 & 63 & 278 & $14 \%$ & $16 \%$ \\
\hline Grade IV & 1,158 & 219 & 134 & 51 & 185 & $12 \%$ & $23 \%$ \\
\hline Grade V & 877 & 141 & 106 & 19 & 125 & $12 \%$ & $13 \%$ \\
\hline Grade VI & 591 & 57 & 74 & 17 & 91 & $13 \%$ & $30 \%$ \\
\hline TotaI & $\mathbf{8 , 9 6 0}$ & $\mathbf{3 , 0 4 6}$ & $\mathbf{1 , 1 0 4}$ & $\mathbf{4 9 7}$ & $\mathbf{1 , 6 0 1}$ & $\mathbf{1 2 \%}$ & $\mathbf{1 6} \%$ \\
\hline
\end{tabular}

Overall gender wise dropout in Haripur district was $12 \%$ and $16 \%$ in boys and girls accordingly. Grade wise highest dropout among boys was recorded in grade 3 which was $14 \%$ while in girls it was in grade 6 as $30 \%$. Grade wise high dropout in girls was noted in grade 2, 4 and 6 which was $21 \%, 23 \%$ and $30 \%$ respectively. Besides child labor (boys) and helping parents in their work, the main reason for the high dropout among girls is the cultural constraint of not allowing girls' education in the upper grades due to attainment of age of puberty and engagements. 
Table A4: Grade wise details of dropout of district Mansehra

\begin{tabular}{|l|r|r|r|r|r|r|r|}
\hline & \multicolumn{2}{|c|}{ Enrolled } & \multicolumn{2}{|c|}{ Dropped } & \multicolumn{2}{c|}{ Dropout in \% } \\
\cline { 2 - 7 } & Boys & Girls & Boys & \multicolumn{1}{c|}{ Girls } & Overall & \multicolumn{1}{c|}{ Boys } & \multicolumn{1}{c|}{ Girls } \\
\hline Grade I & 1525 & 39 & 109 & 59 & 168 & $7 \%$ & $15 \%$ \\
\hline Grade II & 1,241 & 253 & 157 & 34 & 191 & $13 \%$ & $13 \%$ \\
\hline Grade III & 935 & 216 & 101 & 38 & 139 & $11 \%$ & $18 \%$ \\
\hline Grade IV & 686 & 152 & 75 & 25 & 100 & $11 \%$ & $16 \%$ \\
\hline Grade V & 518 & 130 & 63 & 29 & 92 & $12 \%$ & $22 \%$ \\
\hline Grade VI & 375 & 48 & 39 & 5 & 44 & $10 \%$ & $10 \%$ \\
\hline Total & $\mathbf{5 , 2 8 0}$ & $\mathbf{1 , 1 8 9}$ & $\mathbf{5 4 4}$ & $\mathbf{1 9 0}$ & $\mathbf{7 3 4}$ & $\mathbf{1 0 \%}$ & $\mathbf{1 6 \%}$ \\
\hline
\end{tabular}

In Mansehra district the overall gender wise dropout rate was recorded as $10 \%$ in boys and $16 \%$ in girls which was low as compare to Ghazi and Haripur districts dropout $(12 \%$ and $23 \%)$ and $(12 \%$ and $16 \%)$.

Highest dropout was noted. $(13 \%)$ for boys in grade 2 and $(22 \%)$ in girls in grade 5 accordingly. Grade wise high rate of dropout in boys was observed in grade 2 and 5 which was $13 \%$ and $12 \%$ respectively.

\subsection{Results analysis}

\subsubsection{Appeared and Pass ratio}

The total pass percentage of Resource Center Abbottabad was computed $92 \%$ (boys 93\% and girls 91\%). Total 17,002 students were enrolled in Resource Center Abbottabad during the academic year 2002-03, out of which 15,681 students appeared in the examination. 15,681 students $(12,378$ boys and 3,303 girls) were declared successful and 1,275 students were failed in the exanimation (988 boys and 287 girls).

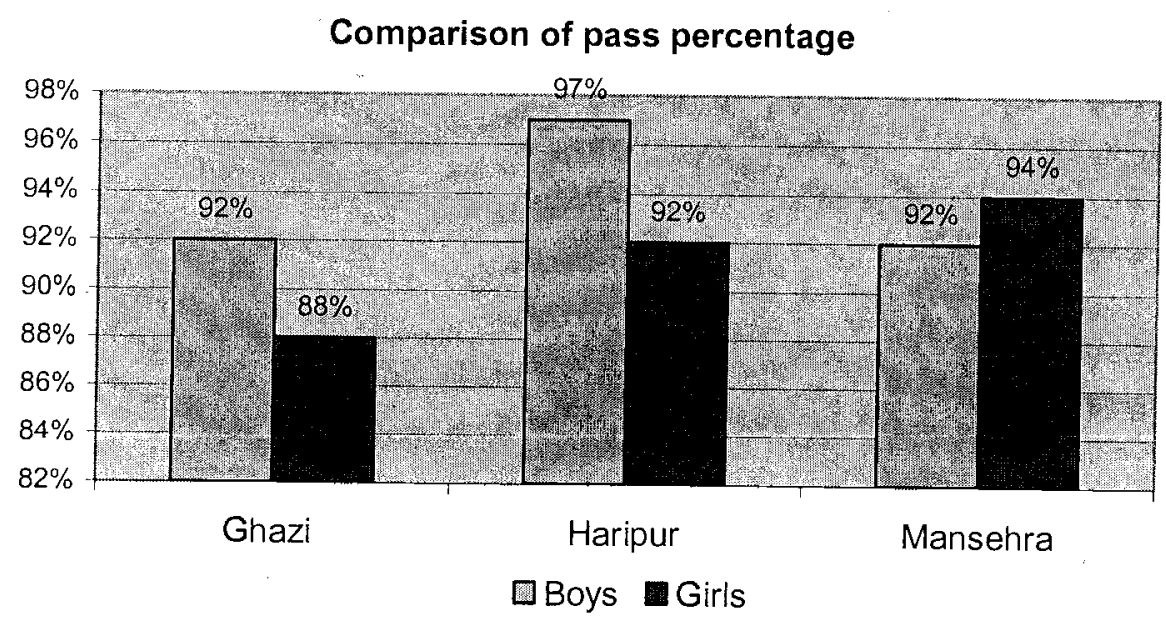

Haripur district was leading the other districts with $97 \%$ and $92 \%$ pass ratio for boys and girls respectively. Girls with $92 \%$ pass percent were ahead of boys 
$(88 \%)$ in Ghazi district while trailing again with $92 \%$ to boys $94 \%$ pass ratio in district Mansehra.

District wise details of appeared, not appeared and pass percentage are given as under.

In the academic year 2002-2003, from Ghazi district a total of 1,149 students comprising of 977 boys and 172 girls appeared in the exam in which $92 \%$ (896) boys and $88 \%$ (151) girls were successful.

In grade wise and gender wise comparison it was observed that the highest pass percentage was observed in boys $94 \%$ in grade 6 . Furthermore in all grades the boys pass percentage was also above $90 \%$ while in girls it varied between $85 \%$ and $93 \%$. The lowest pass percentage was noted for girls in grade 1 which was $85 \%$.

The total rate of students who were not appeared in exam due to short attendance was $3 \%$. In grade wise analysis the higher rate of students who were not appeared in exam was in grade 1 which was $7 \%$.

Table A5: Grade wise details of appeared and pass students in district Ghazi

\begin{tabular}{|c|c|c|c|c|c|c|c|c|c|c|c|}
\hline \multirow[b]{2}{*}{ Grade } & 5 & \multicolumn{2}{|c|}{ Appeared } & \multicolumn{3}{|c|}{ Not Apeared } & 25: & \multicolumn{2}{|c|}{ Passed } & \multicolumn{2}{|c|}{ Passed $\%$} \\
\hline & Boys & Gils & Total & Boys & Girls & Total & $\%$ & Boys & Girls & Boys & Girls: \\
\hline Grade I & 343 & 72 & 415 & 2 & 27 & 29 & 7 & 315 & 61 & $92 \%$ & $85 \%$ \\
\hline Grade If & 219 & 50 & 269 & 2 & 0 & 2 & 1 & 199 & 46 & $91 \%$ & $92 \%$ \\
\hline Grade III & 153 & 28 & 181 & 2 & 2 & 4 & 2 & 142 & 24 & $93 \%$ & $86 \%$ \\
\hline Grade IV & 113 & 14 & 127 & 0 & 0 & of & 0 & 102 & 13 & $90 \%$ & $93 \%$ \\
\hline Grade V & 83 & 8 & 91 & 1 & 0 & 1 & 1 & 76 & 7 & $92 \%$ & $88 \%$ \\
\hline Grade VI & 66 & 0 & 66 & 0 & 0 & 0 & 0 & 62 & 0 & $94 \%$ & $0 \%$ \\
\hline Total & 977 & 172 & 1149 & 7 & 29 & 36 & 3 & 896 & 151 & $92 \%$ & $88 \%$ \\
\hline
\end{tabular}

In Haripur district a total of 10,050 students appeared in the annual examination for the year 2002-2003. This figure included 7,564 boys and 2,486 girls. The pass ratio in boys in Ghazi district was observed as $97 \%$ and in girls $92 \%$.

In gender and grade wise analysis it was also observed that the pass percentage has improved as students moved to higher grades i.e. boys in grade 1 it was $99 \%$ while in girls it was $100 \%$. Overall result was very impressive as all the percentages were above 90 except in grade 4 in girls which is $89 \%$.

Total number of students who were not appeared in exam due to short attendance was 355 comprising $7 \%$ of the total enrollment in district Haripur. The higher rate of not appeared students was observed in grade 1 and 5 which was $5 \%$ while in other grades it was less. 
Table A6: Grade wise details of appeared and pass students in district Haripur

\begin{tabular}{|l|r|r|r|r|r|r|r|r|r|r|r|}
\hline & \multicolumn{3}{|c|}{ Appeared } & \multicolumn{3}{c|}{ Not Apeared } & \multicolumn{2}{|c|}{ Pas sed } & \multicolumn{2}{|c|}{ Passed \% } \\
\cline { 2 - 14 } & Boys & Gils & Total & Boys & Girls & Total & $\%$ & Boys & Girls & Boys & Girls \\
\hline Grade I & 2396 & 1244 & 3640 & 85 & 49 & 134 & 4 & 2327 & 1149 & $97 \%$ & $92 \%$ \\
\hline Grade II & 1646 & 577 & 2223 & 68 & 10 & 78 & 3 & 1601 & 526 & $97 \%$ & $91 \%$ \\
\hline Grade III & 1300 & 337 & 1637 & 49 & 2 & 51 & 3 & 1264 & 308 & $97 \%$ & $91 \%$ \\
\hline Grade N & 979 & 168 & 1147 & 45 & 0 & 45 & 4 & 925 & 149 & $94 \%$ & $89 \%$ \\
\hline Grade V & 749 & 120 & 869 & 22 & 2 & 24 & 3 & 726 & 110 & $97 \%$ & $92 \%$ \\
\hline Grade VI & 494 & 40 & 534 & 23 & 0 & 23 & 4 & 490 & 40 & $99 \%$ & $100 \%$ \\
\hline Total & $\mathbf{7 5 6 4}$ & $\mathbf{2 4 8 6}$ & $\mathbf{1 0 0 5 0}$ & $\mathbf{2 9 2}$ & $\mathbf{6 3}$ & $\mathbf{3 5 5}$ & $\mathbf{7}$ & $\mathbf{7 , 3 3 3}$ & $\mathbf{2 , 2 8 2}$ & $\mathbf{9 7 \%}$ & $\mathbf{9 2 \%}$ \\
\hline
\end{tabular}

During academic year 2002-2003 total numbers of 5,437 students comprising 4,507 boys and 930 girls appeared in the annual examination in Mansehra district. Overall pass percentage among boys was $92 \%$ and girls $94 \%$.

Overall percentage of the students who did not appear in exam was $5 \%$. In grade wise analysis the higher rate was observed in grade 1 which was $7 \%$ while the lower percentage $(3 \%)$ was noted in grade 2.

Table A7: Grade wise details of appeared and pass students in district Mansehra

\begin{tabular}{|c|c|c|c|c|c|c|c|c|c|c|c|}
\hline \multirow{2}{*}{ 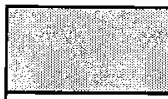 } & \multicolumn{3}{|c|}{ Appeared } & \multicolumn{3}{|c|}{ Not Apeared } & \multicolumn{3}{|c|}{ Passed } & \multicolumn{2}{|c|}{ Passed \% } \\
\hline & Boys & Gils & Total & Boys & cirs & Total & $9 \%$ & Boys & Girls & Boys & Gills \\
\hline Grade I & 1301 & 17 & 1618 & 115 & 14 & 129 & 7 & 1189 & 281 & $91 \%$ & $89 \%$ \\
\hline Grade II & 1062 & 205 & 1267 & 22 & 14 & 36 & 3 & 966 & 194 & $1 \%$ & $95 \%$ \\
\hline Grade III & 801 & 162 & 963 & 33 & 16 & 49 & 5 & 733 & 150 & $2 \%$ & $93 \%$ \\
\hline Grade IV & 578 & 118 & 696 & 33 & 9 & 42 & 6 & 541 & 110 & $94^{\circ}$ & $93 \%$ \\
\hline Grade V & 440 & 88 & 528 & 15 & 13 & 28 & 5 & 415 & 95 & $94 \%$ & $108 \%$ \\
\hline rade $\mathrm{VI}$ & 325 & 40 & 365 & 11 & 9 & 20 & 5 & 305 & 40 & $94 \%$ & $100 \%$ \\
\hline otal & 4507 & 930 & 5437 & 229 & 775 & 304 & 5 & 4,149 & 870 & $92 \%$ & $94 \%$ \\
\hline
\end{tabular}

\subsubsection{Graduation rate}

In the academic session 2002-2003 total enrollment of grade 6 in Abbottabad Resource Center was 1,146 comprising of 1,041 boys and 105 girls. Among them $82 \%$ (857) boys and $76 \%(80)$ girls were graduated successfully.

The highest percentage of graduation was recorded in Ghazi district among boys as $83 \%$ while the lowest graduation rate was observed among girls in Haripur district as $70 \%$.

Table A8: District wise graduation rate

\begin{tabular}{|c|c|c|c|c|c|c|}
\hline \multirow[b]{2}{*}{ District } & \multicolumn{2}{|c|}{ Enrollment } & \multicolumn{2}{|c|}{ Pass } & \multicolumn{2}{|c|}{ Percentage } \\
\hline & Boys & Ginls & Boys & Gils & Boys & Girls \\
\hline Ghazi & 75 & 0 & 62 & 0 & $83 \%$ & $0 \%$ \\
\hline Haripur & 591 & 57 & 490 & 40 & $83 \%$ & $70 \%$ \\
\hline Mansehra & 375 & 48 & 305 & 40 & $81 \%$ & $83 \%$ \\
\hline Total & 1041 & 105 & 857 & 80 & $82 \%$ & $76 \%$ \\
\hline
\end{tabular}


Graduation Rate Resource Center Abbottabad

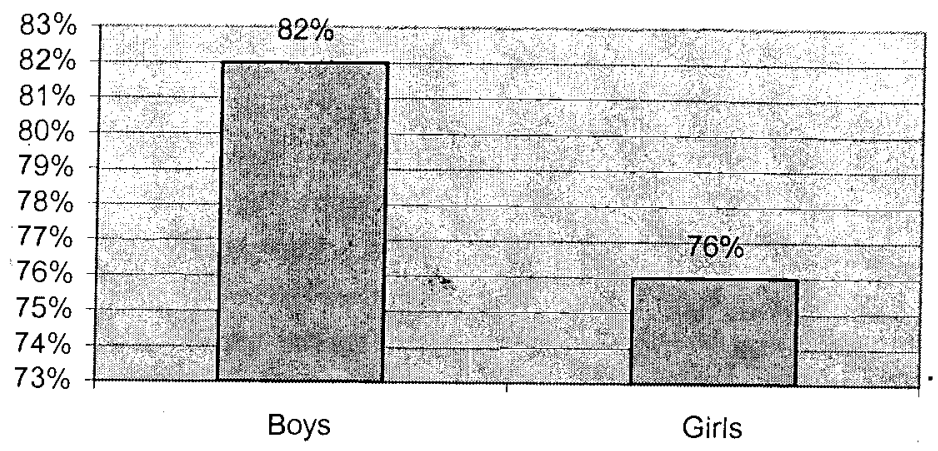

\subsubsection{Students Performance in Subjects and grades}

\section{District Ghazi}

In subject and grade wise analysis it was noted in Ghazi district that in Urdu subject the average marks of boys moved in an increasing trend and mainly falls in grade "B" ( min.72-max.83). The highest average marks were scored by boys in grade 5 as $83 \%$ while in the same grade the girls scored the lowest average marks as $61 \%$.In all grades the overall scored grade by the girls was " $C$ " (min.61$\max .70)$.

In Mathematics, the boys' overall calculated average marks falls in grade "B" (min.69-max.79). The highest marks were obtained by the boys as $79 \%$ in grade 2. Slight fluctuation was observed in grade wise marks of boys. Overall marks of girls were remained in grade "C" (min.65-max.70) while the highest marks among girls were $75 \%$ in grade 4 .

Overall grade wise marks of boys in Islamiat subject were observed in grade "B" (min.68-max.82). The highest average marks among boys were noted in grade 3 and then decreased in grade 4 but in grade 6 it again came to grade "B". Whilst in girls a constant fluctuation in average marks was noted in each grade ranging form grade "C" to "B".

In English subject, the overall grade among boys and girls was recorded as "C" (min.63-max.80). The highest average marks were obtained by the boys in grade 5 where the girls' average marks were $70 \%$. 
Table A9: Subject wise distribution of average marks in district Ghazi

\begin{tabular}{|c|c|c|c|c|c|c|c|c|c|c|c|c|}
\hline \multirow{2}{*}{ Subject } & \multicolumn{2}{|c|}{ Grade 1} & \multicolumn{2}{|c|}{ Grade 2} & \multicolumn{2}{|c|}{ Grade 3} & \multicolumn{2}{|c|}{ Grade 4} & \multicolumn{2}{|c|}{ Grade 5} & \multicolumn{2}{|c|}{ Grade 6} \\
\hline & Boys & Girls & Boys & Girls & Boys & Girls & Boys & Girls & Boys & Girls & Boys & Girls \\
\hline Urdu & & 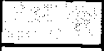 & 74 & 63 & 67 & 67 & 72 & 70 & 83 & 61 & 76 & \\
\hline Mathematics & 69 & 65 & 79 & 70 & 72 & 69 & 70 & 75 & 67 & 67 & 75 & \\
\hline islamiat & 73 & 68 & 67 & 75 & 82 & 77 & 68 & 60 & 78 & 72 & 80 & - \\
\hline Drawing & 89 & 80 & 80 & 75 & 83 & 85 & 82 & 83 & 80 & 86 & 76 & \\
\hline Englișh & 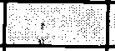 & 3 & 68 & 70 & 68 & 63 & 72 & 65 & 80 & 70 & 71 & - \\
\hline Calligraphy & 72 & 76 & 66 & 71 & 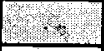 & & s. & 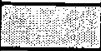 & 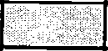 & 5 & 달 & - \\
\hline Sport & 89 & 67 & 69 & 70 & 88 & 93 & 93 & 90 & 80 & 73 & 88 & - \\
\hline Pashto & 77 & 70 & 79 & 69 & 81 & 75 & 68 & 73 & 73 & 64 & 80 & - \\
\hline Quran & 79 & 70 & 73 & 65 & 81 & 61 & 78 & 71 & 79 & 83 & 80 & - \\
\hline Social Study & 8 & 1 & & $=3$ & 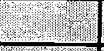 & 20 & 79 & 65 & 68 & 67 & 73 & - \\
\hline General Science & - & 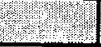 & & retsing & $\pi / 2$ & 2 & 71 & 71 & 74 & 63 & 75 & - \\
\hline
\end{tabular}

In Pashto, subject all grades including boys and girls fall under grade "B" except the girls' in grade 5 where they scored grade " $C$ ". Similarly in the Quran the obtained grade by both genders was grade " $B$ " and " $A$ " in grade 5 by the girls.

In Social Studies, the girls' average marks were lower than that of boys. While in General Science the marks remained under grade "B" except girls in grade 5.

\section{District Haripur}

In district Haripur it was observed that in all grades both genders scored same grade in Urdu subject which was "B" (min.71-max.79) while the highest marks 82 "A" were scored by girls in grade 6.

Similarly in Mathematics the same grade "B" (66-max.78) was noted in all grades. The highest average marks were obtained by the girls in grade 2 .

Likewise in Islamiat and English subjects all grades including boy and girls scored grade "B" (min.68-max.78) (min.67-min 78) in each subject respectively. In both cases the highest average marks were obtained by the girls in grade 6 .

In Pashto subject the score remained in grade "B" (min.70-max.75) of both genders except girls in grade 4 and 6 where the average marks were $83 \%$ and $85 \%$ respectively. 
Table A 10: Subject wise distribution of average marks in district Haripur

\begin{tabular}{|c|c|c|c|c|c|c|c|c|c|c|c|c|}
\hline \multirow{2}{*}{ Subject } & \multicolumn{2}{|c|}{ Grade 1} & \multicolumn{2}{|c|}{ Grade 2} & \multicolumn{2}{|c|}{ Grade 3} & \multicolumn{2}{|c|}{ Grade 4} & \multicolumn{2}{|c|}{ Grade 5} & \multicolumn{2}{|c|}{ Grade 6} \\
\hline & Boys & Girls & Boys & Girls & Boys & Girls & Boys & Girls & Boys & Girls & Boys & Girls \\
\hline Urdu & ? & & 72 & 71 & 73 & 70 & 74 & 79 & 73 & 71 & 74 & 82 \\
\hline Mathematics & 70 & 71 & 72 & 78 & 70 & 70 & 70 & 66 & 68 & 68 & 67 & 77 \\
\hline Islamiat & 71 & 70 & 71 & 75 & 73 & 71 & 68 & 75 & 73 & 73 & 76 & 78 \\
\hline Drawing & 76 & 75 & 77 & 85 & 79 & 85 & 83 & 72 & 80 & 88 & 87 & 85 \\
\hline English & 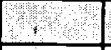 & 1 & 70 & 69 & 72 & 70 & 69 & 74 & 69 & 67 & 70 & 78 \\
\hline Calligraphy & 73 & 73 & 75 & 79 & 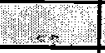 & 2. & 2 & 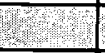 & ? & & 2 & 5 \\
\hline Sport & 83 & 83 & 83 & 89 & 87 & 88 & 87 & 94 & 87 & 89 & 90 & 94 \\
\hline Pashto & 71 & 70 & 70 & 75 & 71 & 75 & 71 & 83 & 72 & 73 & 75 & 85 \\
\hline Quran & 71 & 70 & 71 & 75 & 73 & 72 & 73 & 85 & 75 & 81 & 76 & 85 \\
\hline Social Study & 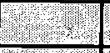 & $\begin{aligned} 129 \\
\end{aligned}$ & 2. & 47 & 2 & 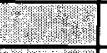 & 70 & 77 & 74 & 72 & 74 & 80 \\
\hline General Science & 25: & Writ & 2 & $y^{2}$ & inges & 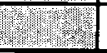 & 68 & 73 & 70 & 72 & 75 & 89 \\
\hline
\end{tabular}

Similarly, the average marks in all grades (including girls and boys) in the Quran was also in grade "B" (min.70-max.76) except girls of grade 4,5 and 6 who obtained $85 \%, 81 \%$ and $85 \%$ respectively and were place in "A".

In Social Studies and General Science, all grade scored "B" (min.70-max.77) (min.68-max.75) except girls in grade 6 who got "A" (89\%) in social Studies.

It is very interesting to note that the girls' performance especially in grade 6 was excellent where they got grade " $\mathbf{A}$ " in all subjects except Mathematics and English which was in grade " $\mathbf{B}$ ".

\section{District Mansehra}

In Mansehra district, the performance of students (boys and girls) in Urdu subject remained in grade " $\mathrm{C}$ " (min.66, max.75) except girls' in grade 6 who got $81 \%$ average marks and just entered in " $\mathbf{A}$ " and at the same time grade wise increasing trend in marks was noted for both genders.

The same grade "B" (min. 69, max. 76) was observed both in grade wise and gender wise analysis of Mathematics subject. It was also noted that the boys' performance remained the same $(72 \%)$ from grade 1 and 3 while in grade 4 and 6 it rose to $75 \%$ and $76 \%$ successively. Similarly in girls the marks remain in $69 \%$ and $67 \%$ but rose to $72 \%$ and $71 \%$ in grade 3 and 4 , but again dropped to $62 \%$ in grade 5 and again shoot up to $73 \%$ in grade 6 . 
Table A11: Subject wise distribution of average marks in district Mansehra

\begin{tabular}{|c|c|c|c|c|c|c|c|c|c|c|c|c|}
\hline \multirow{2}{*}{ Subject } & \multicolumn{2}{|c|}{ Grade 1} & \multicolumn{2}{|c|}{ Grade 2} & \multicolumn{2}{|c|}{ Grade 3} & \multicolumn{2}{|c|}{ Grade 4} & \multicolumn{2}{|c|}{ Grade 5} & \multicolumn{2}{|c|}{ Grade 6} \\
\hline & Boys & Girls & Boys & Girls & Boys & Girls & Boys & Girls & Boys & Girls & Boys & Girls \\
\hline Urdu & & P & 71 & 66 & 72 & 67 & 73 & 70 & 73 & 70 & 75 & 81 \\
\hline Mathematics & 72 & 69 & 72 & 67 & 72 & 72 & 75 & 71 & 75 & 62 & 76 & 73 \\
\hline Islamiat & 71 & 66 & 70 & 68 & 74 & 70 & 72 & 67 & 75 & 63 & 77 & 83 \\
\hline Drawing & 72 & 70 & 76 & 73 & 76 & 71 & 75 & 72 & 80 & 73 & 79 & 78 \\
\hline English & .4 & 4 & 69 & 68 & 70 & 61 & 69 & 64 & 71 & 62 & 72 & 72 \\
\hline Calligraphy & $\therefore 70$ & 76 & 71 & 68 & 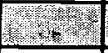 & 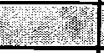 & 3) & (2) & (E) & & Wy & 12 \\
\hline Sport & 76 & 75 & 79 & 76 & 79 & 77 & 81 & 78 & 83 & 79 & 80 & 92 \\
\hline Pashto & 74 & 67 & 75 & 65 & 76 & 68 & 73 & 68 & 76 & 63 & 77 & 81 \\
\hline Quran & 69 & 68 & 71 & 69 & 73 & 71 & 78 & 75 & 77 & 68 & 79 & 86 \\
\hline Social Study & 27 & $27+y^{2}$ & (1) & 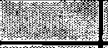 & 210.-1 & $2-2$ & 72 & 63 & 77 & 59 & 75 & 87 \\
\hline General Science & PI & 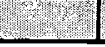 & D. & 2.1. & (2) & 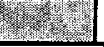 & 72 & 65 & 73 & 48 & 77 & 74 \\
\hline
\end{tabular}

During the analysis of Islamiat and Quran it was noted that all grades including boys and girls obtained grade "B" (min. 66, max.77) (min.68, max. 79) respectively except girls of grade 6 whose got "A" with $83 \%$ and $86 \%$ in each case.

Similarly in English the average marks in all grades falls under grade "B" (min.61, max.72). The lowest average marks $(63 \%)$ were obtained by the girls in grade 3 while the highest marks (62\%) were obtained by both genders in grade 6 .

In the analysis of Social Study and General Science a substantial fluctuation was noted as boys in grades remained in "B" while in girls it moved from "B" to " $C$ " and finally shoot up to grade " $A$ " and that's how again the girls remained on the top.

Similarly in General Science in all grades, grade "B" (min.65, max.77) was retained except girls in grade 5 who got grade "C" (48 avg. marks). 


\section{Resource Center Bannu}

\subsection{Enrollment}

Total enrollment in Bannu Resource Centre was recorded 9,617 which included 7,781 boys and 1,836 girls. Bannu Resource Center contributed $8 \%$ to the total enrollment 123,660 . Out of total 9,617 students 9,033 were the newly admitted and 584 were repeaters (failed students). It is important to mention that the girls' enrollment has increased in Bannu as compared to year hitherto. Bannu Resource Center administering very conservative tribal agencies where female education has been attached low priority. The increase in girls' enrollment indicates a change in the attitude of people towards female education.

Bannu Resource Center has four districts namely, Bannu, D.I.Khan, Miran shah and Wanna under its administration. Miranshah and Wanna were the most populous districts with total enrollment 4,057 and 2,512 number of students respectively.

Table B1: Distribution of students by districts

\begin{tabular}{|c|c|c|c|c|c|c|c|c|c|}
\hline \multirow{2}{*}{ District } & \multicolumn{3}{|c|}{ Enrolled } & \multicolumn{3}{|c|}{ Repeater } & \multicolumn{3}{|c|}{ Fresh } \\
\hline & Boys & Girls & Total & Boys: & Sils & Total & Boys & Girls & Total \\
\hline Bannu & 916 & 346 & 1,262 & 117 & 16 & 133 & 799 & 330 & 1,129 \\
\hline D.I.Khan & 1,414 & 372 & 1,786 & 53 & 14 & 67 & 1,361 & 358 & 1,719 \\
\hline Miranshah & 3,416 & 641 & 4,057 & 325 & 25 & 350 & 3,091 & 616 & 3,707 \\
\hline Wana & 2,035 & 477 & 2,512 & 34 & 0 & 34 & 2,001 & 477 & 2,478 \\
\hline Total & 7.781 & 1,836 & 9,617 & 529 & 55 & 584 & 7,252 & 1.781 & 9,033 \\
\hline
\end{tabular}

Girls' constituted $20 \%(1,781)$ to the total fresh enrollment 9,033. Miran shah district has the highest numbers of girls' student (616) and the lower number of girls' enrollment (330) was noted in Bannu districts. The major reason of girls' low enrollment in bannu was the lack of separate schools for girls' from the very onset and was established in 2001.

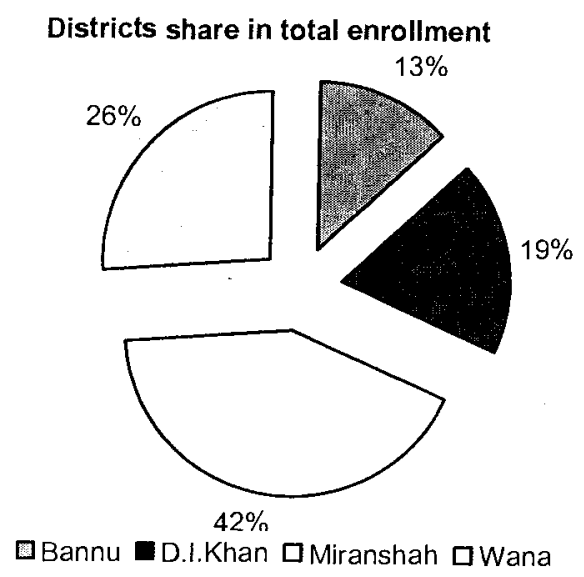




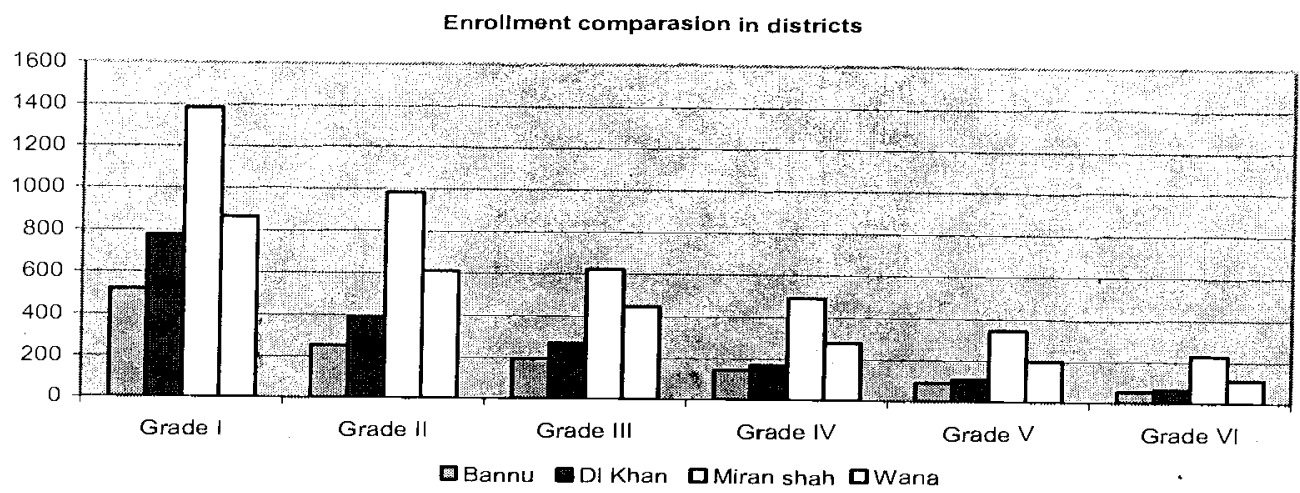

Major proportion of enrollment was observed to be in early grades and the enrollment tended to decrease in higher grades. As fresh enrollment is preferably carried out in early grades than later, failure and dropout could be the major reason cited for the down ward trend in enrollment.

\subsection{Dropout}

The total dropout ratio calculated in Bannu was $10 \%$ (boys $10 \%$ and girls $11 \%$ ). It is observed that the girls' dropout rate $(11 \%)$ was high than boys $(10 \%)$. The highest dropout was recorded in district Wanna (14) followed by Miran shah $(11 \%)$. Bannu district dropout (4\%) was the least among all districts.

Table B2 indicates very high Girls' dropout in wanna districts which was computed $19 \%$. It is surprising that no girls' dropout was documented in district Bannu at all.

Table B2: Districts wise dropout of students

\begin{tabular}{|l|r|r|r|r|r|r|r|r|r|}
\hline \multirow{2}{*}{ District } & \multicolumn{3}{|c|}{ Enrolled } & \multicolumn{3}{|c|}{ Dropout } & \multicolumn{3}{c|}{ Dropout in \% } \\
\cline { 2 - 11 } & Boys & Girls & Total & Boys & Girls & Total & Boys & Girls & Total \\
\hline Bannu & 916 & 346 & 1,262 & 56 & 0 & 56 & $6 \%$ & $0 \%$ & $4 \%$ \\
\hline D.I.Khan & 1,414 & 372 & 1,786 & 119 & 39 & 158 & $8 \%$ & $10 \%$ & $9 \%$ \\
\hline Miranshah & 3,416 & 641 & 4,057 & 316 & 123 & 439 & $9 \%$ & $19 \%$ & $11 \%$ \\
\hline Wana & 2,035 & 477 & 2,512 & 315 & 41 & 356 & $15 \%$ & $9 \%$ & $14 \%$ \\
\hline Total & $\mathbf{7 , 7 8 1}$ & $\mathbf{1 , 8 3 6}$ & $\mathbf{9 , 6 1 7}$ & $\mathbf{8 0 6}$ & $\mathbf{2 0 3}$ & $\mathbf{1 0 0 9}$ & $\mathbf{1 0} \%$ & $\mathbf{1 1} \%$ & $\mathbf{1 0 \%}$ \\
\hline
\end{tabular}

\section{Grade wise dropout statistic of all districts in Bannu Resource Center}

Like enrollment high dropout could be seen in initial grades, and in higher grades the dropout has dwindled. It can also be observed from the graph given below that dropout in boys was high as compared to girls'. But it is important to mention here that there was no girls' enrollment in higher grades as girls' schools have only been opened in 2001 . 


\section{Grade wise dropout in Bannu}

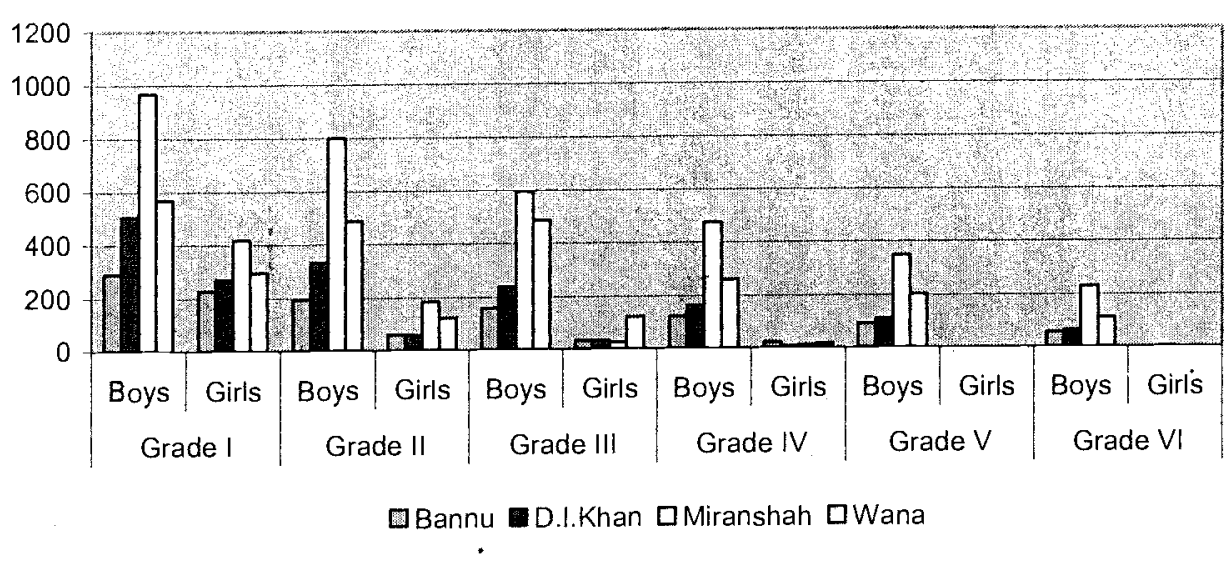

Table B3: Grade wise dropout details of district Bannu

\begin{tabular}{|c|c|c|c|c|c|c|}
\hline \multirow{2}{*}{ Pitis } & \multicolumn{2}{|c|}{ Enrolled } & \multicolumn{2}{|c|}{ Dropped } & \multicolumn{2}{|c|}{ Dropout in \% } \\
\hline & Boys: & Girks & Boys & Girls & Boys & Cirls \\
\hline Grade I & 290 & 228 & 0 & 0 & $0 \%$ & $0 \%$ \\
\hline Grade 11 & 195 & 59 & 17 & 0 & $9 \%$ & $0 \%$ \\
\hline Grade III & 159 & 35 & 14 & 0 & $9 \%$ & $0 \%$ \\
\hline Grade IV & 122 & 24 & 16 & 0 & $13 \%$ & $0 \%$ \\
\hline Grade V & 93 & 0 & 5 & 0 & $5 \%$ & $0 \%$ \\
\hline Grade VI & 57 & & 4 & 0 & $7 \%$ & $0 \%$ \\
\hline Total & 916 & 3.46 & 56 & 0 & $60 \%$ & $0 \%$ \\
\hline
\end{tabular}

Bannu district has the lowest dropout rate $6 \%$ in boys and no dropout in girls' was recorded in district Bannu. The status of schools in Bannu was regarded to be seasonal, which were supposed to have high dropout rate. Maximum of $13 \%$ dropout in boys was calculated in grade 4 and no dropout was documented in grade 1.

Table B4: Grade wise dropout details of district D.I.Khan

\begin{tabular}{|l|r|r|r|r|r|r|}
\hline & \multicolumn{2}{|c|}{ Enrolled } & \multicolumn{3}{c|}{ Dropped } & \multicolumn{2}{|c|}{ Bropout In $\%$} \\
\cline { 2 - 7 } & Boys & Girls & Boys & Girls & Boys & Girls \\
\hline Grade I & 505 & 271 & 26 & 21 & $5 \%$ & $8 \%$ \\
\hline Grade II & 333 & 58 & 50 & 5 & $15 \%$ & $9 \%$ \\
\hline Grade III & 237 & 34 & 15 & 8 & $6 \%$ & $24 \%$ \\
\hline Grade IV & 163 & 8 & 23 & 5 & $14 \%$ & $63 \%$ \\
\hline Grade V & 111 & 0 & 2 & 0 & $2 \%$ & $0 \%$ \\
\hline Grade VI & 65 & 1 & 3 & 0 & $5 \%$ & $0 \%$ \\
\hline Total & $\mathbf{1 , 4 1 4}$ & $\mathbf{3 7 2}$ & $\mathbf{1 1 9}$ & $\mathbf{3 9}$ & $\mathbf{8} \%$ & $\mathbf{1 0 \%}$ \\
\hline
\end{tabular}

In D.I.Khan district, girls' dropout $(10 \%)$ was more than boys $(8 \%)$. Maximum dropout was estimated $63 \%$ in girls from grade 4 and $15 \%$ in boys from grade 3 . Table B3 depict exceedingly high dropout $63 \%$ in girls from grade 4 . There was a mix sort of dropout trend observed in various grades. High dropout rate was to be 
found in grade 2, 3 and 4 for both boys and girls while relatively low dropout could be seen in grades 1,5 and 6 .

There is strong social taboo that girls should not mix with boys. They did not admitted girls in school with boys and separate schools for girls was established in 2001, thus there was no grade IV and above in their schools.

Table B5: Grade wise dropout details of district Miran Shah

\begin{tabular}{|l|r|r|r|r|r|r|}
\hline & \multicolumn{2}{|c|}{ Enrolled } & \multicolumn{3}{|c|}{ Dropped } & \multicolumn{2}{|c|}{ Dropoul in \% } \\
\cline { 2 - 7 } & Boys & Girls & Boys & Cirls & Boys & Girls \\
\hline Grade I & 967 & 418 & 58 & 104 & $6 \%$ & $25 \%$ \\
\hline Grade II & 799 & 184 & 101 & 17 & $13 \%$ & $9 \%$ \\
\hline Grade III & 596 & 26 & 58 & 2 & $10 \%$ & $8 \%$ \\
\hline Grade IV & 476 & 13 & 52 & 0 & $11 \%$ & $0 \%$ \\
\hline Grade V & 349 & 0 & 32 & 0 & $9 \%$ & $0 \%$ \\
\hline Grade VI & 229 & 0 & 15 & 0 & $7 \%$ & $0 \%$ \\
\hline Total & $\mathbf{3 , 4 1 6}$ & 641 & 316 & 123 & $9 \%$ & $19 \%$ \\
\hline
\end{tabular}

In Miran Shah district, in grade 1 girls' dropout $25 \%$ was the maximum while in boys the maximum calculated dropout $(13 \%, 10 \%$ and $11 \%)$ was found in grade 2,3 , and 4 respectively. In grade 5 and 6 the dropout has decreased for boys and for girls there was no enrollment at all. The girls' dropout has also decreased to $9 \%, 8 \%$ in grades 2 and 3 accordingly.

Table B6: Grade wise dropout details of district Wanna

\begin{tabular}{|l|r|r|r|r|r|r|}
\hline & \multicolumn{2}{|c|}{ Enrolled } & \multicolumn{2}{c|}{ Dropped } & \multicolumn{2}{c|}{ Bropout in $\%$} \\
\cline { 2 - 7 } & Boys & Girls & Boys & Girls & Boys & Girls \\
\hline Grade I & 569 & 295 & 64 & 24 & $11 \%$ & $8 \%$ \\
\hline Grade II & 488 & 122 & 71 & 11 & $15 \%$ & $9 \%$ \\
\hline Grade III & 404 & 42 & 54 & 6 & $13 \%$ & $14 \%$ \\
\hline Grade IV & 260 & 18 & 61 & 0 & $23 \%$ & $0 \%$ \\
\hline Grade V & 202 & 0 & 49 & 0 & $24 \%$ & $0 \%$ \\
\hline Grade VI & 112 & 0 & 16 & 0 & $14 \%$ & $0 \%$ \\
\hline Total & $\mathbf{2 , 0 3 5}$ & $\mathbf{4 7}$ & $\mathbf{3 1 5}$ & $\mathbf{4 1}$ & $15 \%$ & $\mathbf{9 \%}$ \\
\hline
\end{tabular}

Boy's total dropout (15\%) was greater than girls (9\%) (Table B6). A high dropout rate was computed in all grades for boys. There were only three grades having girls enrollment and the dropout was increasing from grade $1(8 \%)$ to grade 3 $(14 \%)$.

Although Wanna is an agency hosting to a conservative society where less appreciation to female education is accorded. Yet under such a situation the low girls' dropout as compared to boys is noteworthy achievement to the credit of Community Participation and good administration of school management.

The government in recent time has started raids in camps to get hold of Al-qaida suspects. Due to fear of being caught for investigation the families has shifted to other camps. This could be the major factor contributed to dropout. 


\subsection{Result analysis}

\subsubsection{Appeared and Pass ratio}

The total pass percentage of Resource Center Bannu was greatly impressive which was computed $94 \%$ ( $93 \%$ boys and $95 \%$ girls). It is important to cite that the Bannu Resource Center result in terms of pass percentage was observed to be the best among all Resource Center. 9,617 students were enrolled in Resource Center Bannu during the academic year 2002-03, out of which 8,431 students appeared in the examination. 7,885 students $(6,372$ boys and 1,215 girls) were declared successful and 605 students were declared not successful in the exanimation.

\section{Comparison of pass percentage}

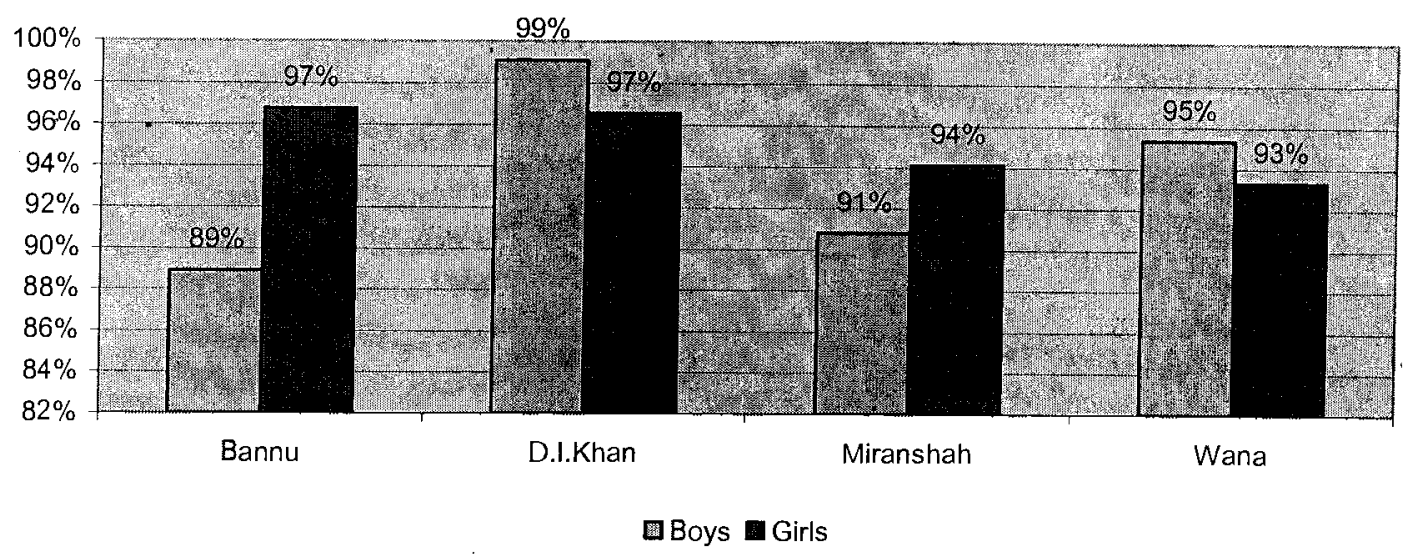

The pass percentage of students for both genders in all districts is shown in the graph above. In D.I. Khan District the pass percentage for boys and girls was calculated $99 \%$ and $97 \%$ respectively which was found to be the best in comparison to other districts, notwithstanding an impressive passing rate was also recorded in the other districts.

Detail statistics of appeared, not appeared, pass and pass percentages was computed and presented in tables separately for all districts in Resource Center Bannu as given under.

Table B7: Grade wise details of appeared and pass students in district Bannu

\begin{tabular}{|c|c|c|c|c|c|c|c|c|c|c|c|}
\hline \multirow{2}{*}{ (5) } & \multicolumn{3}{|c|}{ Appeared } & \multicolumn{3}{|c|}{ Not Apeared } & \multirow{2}{*}{$\frac{7}{\%}$} & \multicolumn{2}{|c|}{ Passed } & \multicolumn{2}{|c|}{ Passed $\%$} \\
\hline & Boys & Gils & Total & Boys & Giris & Total & & Boys & Girls & Boys: & Girls \\
\hline Grade I & 290 & 228 & 518 & 0 & 0 & 0 & 0 & 247 & 220 & $85 \%$ & $96 \%$ \\
\hline Grade II & 171 & 55 & 226 & 7 & 4 & 11 & 5 & 168 & 54 & $98 \%$ & $\overline{98}$ \\
\hline Grade III & 141 & 34 & 175 & 4 & 1 & 5 & 3 & 119 & 33 & $84 \%$ & $97^{\circ}$ \\
\hline Grade IV & 103 & 24 & 127 & 3 & 0 & 3 & 2 & 88 & 23 & $85 \%$ & 96 \\
\hline Grade V & 86 & 0 & 86 & 2 & 0 & 2 & 2 & 80 & 0 & $93 \%$ & $0 \%$ \\
\hline Grade VI & 52 & 0 & 52 & 0 & 0 & 0 & 0 & 52 & 0 & $100 \%$ & $0 \%$ \\
\hline Total & 843 & 341 & 1,184 & 16 & 5 & 21 & 2 & 754 & 330 & $89 \%$ & 97 \\
\hline
\end{tabular}


Total percentage of students who successfully passed the examination in district Bannu was recorded $89 \%$ and $97 \%$ for boys and girls respectively. The pass ratio of girls in all four grades was commendable. The boy's pass percentage was also observed above $80 \%$ which have even reached to $100 \%$ in grade 6 .

Table B8: Grade wise details of appeared and pass students in district D.I.Khan

\begin{tabular}{|c|c|c|c|c|c|c|c|c|c|c|c|}
\hline & \multicolumn{3}{|c|}{ Appeared } & \multicolumn{3}{|c|}{ Not Apeared } & \multirow{2}{*}{$\%$} & \multicolumn{2}{|c|}{ Passed } & \multicolumn{2}{|c|}{ Passed $\%$} \\
\hline & Boys & Gils & Total & Boys & Girls & Total & & Boys & Girls & Boys & Girls \\
\hline Grade I & 446 & 242 & 688 & 33 & 8 & 41 & 6 & 438 & 225 & $98 \%$ & $93 \%$ \\
\hline Grade II & 281 & 53 & 334 & 2 & 0 & 2 & 1 & 268 & 53 & $95 \%$ & $100 \%$ \\
\hline Grade III & 218 & 26 & 244 & 4 & 0 & 4 & 2 & 213 & 23 & $98 \%$ & $88 \%$ \\
\hline Grade IV & 140 & 3 & 143 & 0 & 0 & 0 & 요 & 136 & 3 & $97 \%$ & $100 \%$ \\
\hline Grade V & 106 & 0 & 106 & 3 & 0 & 3 & 3 & 93 & 0 & $88 \%$ & $0 \%$ \\
\hline Grade VI & 62 & 1 & 63 & 0 & 0 & 0 & 0 & 59 & 1 & $95 \%$ & $100 \%$ \\
\hline Total & 1,253 & 325 & 1,578 & 42 & 8. & 50 & 3 & 1,207 & 305 & $96 \%$ & $94 \%$ \\
\hline
\end{tabular}

In district D.I.Khan the total pass percentage was calculated $96 \%$ for boys and $95 \%$ for girls. A small proportion of girls have appeared in the examination and all of them were declared successful therefore, $100 \%$ successful rate was to be seen in grade 2, 4 and 6 for girls. However for boys notable and constant pass percentage above 90 was calculated in all grades (Table B8).

Table B9: Grade wise details of appeared and pass students in district Miran Shah

\begin{tabular}{|l|r|r|r|r|r|r|r|r|r|r|r|}
\hline & \multicolumn{3}{|c|}{ Appeared } & \multicolumn{3}{|c|}{ Not Apeared } & \multicolumn{2}{|c|}{ Passed } & \multicolumn{2}{|c|}{ Passed \% } \\
\cline { 2 - 12 } & Boys & Gils & Total & Boys & Girls & Total & $\%$ & Boys & Girls & Boys & Girls \\
\hline Grade I & 892 & 312 & 1204 & 17 & 2 & 19 & 2 & 800 & 289 & $90 \%$ & $93 \%$ \\
\hline Grade II & 688 & 167 & 855 & 10 & 0 & 10 & 1 & 625 & 159 & $91 \%$ & $95 \%$ \\
\hline Grade III & 528 & 24 & 552 & 10 & 0 & 10 & 2 & 484 & 20 & $92 \%$ & $83 \%$ \\
\hline Grade IV & 420 & 13 & 433 & 4 & 0 & 4 & 1 & 378 & 13 & $90 \%$ & $100 \%$ \\
\hline Grade V & 305 & 0 & 305 & 12 & 0 & 12 & 4 & 305 & 0 & $100 \%$ & $0 \%$ \\
\hline Grade VI & 210 & 0 & 210 & 4 & 0 & 4 & 2 & 209 & 0 & $100 \%$ & $0 \%$ \\
\hline Total & $\mathbf{3 , 0 4 3}$ & $\mathbf{5 1 6}$ & $\mathbf{3 , 5 5 9}$ & $\mathbf{5 7}$ & $\mathbf{2}$ & $\mathbf{5 9}$ & $\mathbf{2}$ & $\mathbf{2 , 8 0 1}$ & $\mathbf{4 8 1}$ & $\mathbf{9 2 \%}$ & $\mathbf{9 3 \%}$ \\
\hline
\end{tabular}

In districts Miran Shah there was no girls' enrollment in grade 5 and 6 as girl's school are established recently and no batch has reached to higher grades. The total pass rate calculated for boys and girls was $95 \%$ and $93 \%$ respectively. A striking pass percentage was to be seen for both boys and girls in all grades in Miran Shah and Wanna districts.

Table B10: Grade wise details of appeared and pass students in district Wanna

\begin{tabular}{|c|c|c|c|c|c|c|c|c|c|c|c|}
\hline \multirow{2}{*}{\begin{tabular}{|l|l|}
3 \\
\end{tabular}} & \multicolumn{3}{|c|}{ Appeared } & \multicolumn{3}{|c|}{ Not Apeared } & \multirow{2}{*}{$8 \%$} & \multicolumn{2}{|c|}{ Passed } & \multicolumn{2}{|c|}{ Passed \% } \\
\hline & Boys: & Gils: & Total & Boys & Girls: & Total: & & Boys & Girls & Boys: & Girls \\
\hline Grade I & 496 & 263 & & 0 & 0 & 0 & $\underline{0}$ & 483 & 242 & $97 \%$ & $92 \%$ \\
\hline Grade II & 41 & 103 & & 7 & 4 & 11 & 2 & 400 & 98 & $97 \%$ & $95 \%$ \\
\hline Grade III & 34 & 35 & & 4 & at & 5 & 1 & 329 & 34 & $96 \%$ & $97 \%$ \\
\hline Grade IV & 196 & 18 & & 3 & 0 & 3 & 1 & 183 & 18 & $93 \%$ & $100 \%$ \\
\hline Grade V & 15 & $\underline{0}$ & & 2 & 0 & $\underline{2}$ & 1 & 143 & 0 & $94 \%$ & $0 \%$ \\
\hline Grade VI & 95 & 0 & & 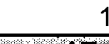 & 0 & 1 & 1 & 95 & $\underline{0}$ & $100 \%$ & $0 \%$ \\
\hline Total & 1,693 & 419 & - & 17 & 5 & 22 & 1 & 1,633 & 392 & $96 \%$ & $94 \%$ \\
\hline
\end{tabular}




\subsubsection{Graduation rate}

Graduation rate calculated in Resource Center Bannu for boys and girls was $90 \%$ and $100 \%$ respectively. It is to mention that only one girl was enrolled in grade 6 during 2002-03 in Resource Center Bannu, she has successfully passed her exam thus making the graduation rate $100 \%$ for girls'.

\section{Graduation rate}

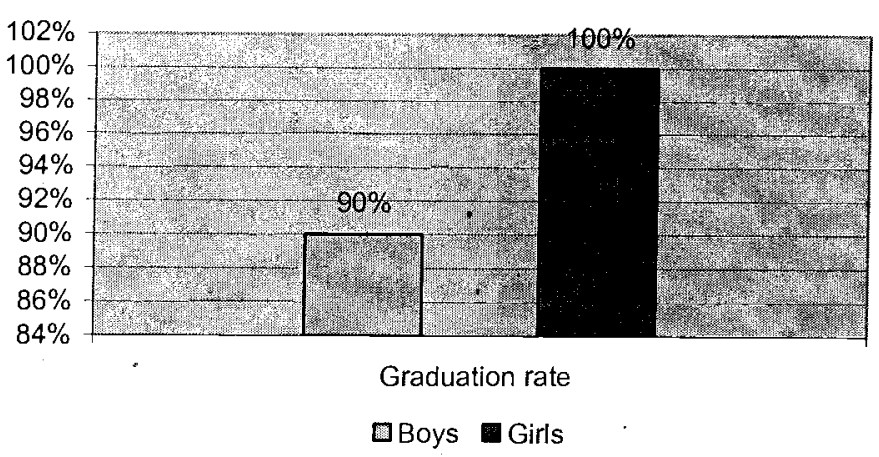

No Girl could have reached grade 6 in districts Bannu, Miran Shah and Wanna. Only one girl was enrolled in grade 6 in district D.I.Khan. An equal graduation rate $(91 \%)$ of boys was computed for districts Bannu, D.I.Khan and Miran Shah. The graduation rate has decreased in district Wanna which was calculated as 85\% (Table B11).

Table B11: Graduation rate in all districts

\begin{tabular}{|l|r|r|r|r|r|r|}
\hline \multirow{2}{*}{ District } & \multicolumn{2}{|c|}{ Enrollment in Grage 6 } & \multicolumn{2}{c|}{ Pass } & \multicolumn{2}{c|}{ Graduation Rate } \\
\cline { 2 - 7 } & Boys & Girls & Boys & Girls & Boys & Girls \\
\hline Bannu & 57 & 0 & 52 & 0 & $91 \%$ & $0 \%$ \\
\hline D. I. Khan & 65 & 1 & 59 & 1 & $91 \%$ & $100 \%$ \\
\hline Miranshah & 229 & 0 & 20 & 0 & $91 \%$ & $0 \%$ \\
\hline Wana & 112 & 0 & 95 & 0 & $85 \%$ & $0 \%$ \\
\hline
\end{tabular}

\subsubsection{Students performance in subjects and grades}

Student's average marks in each subject and grade was computed and tabulated as given under for the purpose of comparison.

\section{District Bannu}

Urdu subject was not offered in grade 1 . The maximum average marks $78 \%$ was obtained by girls' in grade 4 , while boys best performance $(75 \%)$ was to be observed in grade 6 . Performance in Urdu could fall in B and $\mathbf{C}$ category. 
In mathematic in grade 1 girls average pass marks (69\%) were better than boys $(61 \%)$. In grade 2 the marks has further reduced to $58 \%$ for boys and $59 \%$ for girls. Going along to higher grades predominantly a downward trend could be observed for both boys and girls except for girls in grade 4 where there was an increase up to $83 \%$ was to be noted. Moreover there was no girl enrolled in grade 5 and 6 . None of the student could get to "A" in math in district Bannu.

Table B12: Subject wise distribution of average marks in district Bannu

\begin{tabular}{|c|c|c|c|c|c|c|c|c|c|c|c|c|}
\hline \multirow{2}{*}{ Subject } & \multicolumn{2}{|c|}{ Grade 1} & \multicolumn{2}{|c|}{ Grade 2} & \multicolumn{2}{|c|}{ Grade 3} & \multicolumn{2}{|c|}{ Grade 4} & \multicolumn{2}{|c|}{ Grade 5} & \multicolumn{2}{|c|}{ Grade 6} \\
\hline & Boys & Gris & Boys & Gins & Boys & Gris & Boys & Ginls & Boys & Girls & Boys & Girls \\
\hline Urdu & 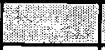 & 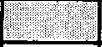 & 61 & 57 & 65 & 56 & 65 & 78 & 69 & 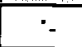 & 75 & - \\
\hline Mathematics & 61 & 69 & 58 & 59 & 62 & 59 & 60 & 83 & 66 & - & 71 & - \\
\hline Islamiat & 63 & 64 & 62 & 58 & 62 & 59 & 62 & 81 & 67 & - & 72 & - \\
\hline Drawing & 73 & 75 & 71 & 66 & 74 & 61 & 78 & 91 & 82 & - & 83 & - \\
\hline English & 3 & pir. & 62 & 56 & 59 & 56 & 61 & 81 & 66 & - & 77 & - \\
\hline Calligraphy & 75 & 77 & 73 & 80 & 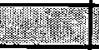 & (2) & 2942 & & 1 & 2 & & X) \\
\hline Sport & 76 & 77 & 77 & 74 & 71 & 67 & 79 & 90 & 88 & - & 86 & - \\
\hline Pashto & 62 & 67 & 62 & 58 & 64 & 56 & 62 & 73 & 64 & - & 73 & - \\
\hline Quran & 60 & 62 & 62 & 52 & 60 & 56 & 66 & 82 & 71 & - & 80 & - \\
\hline Social Study & 12 & & 24) & 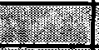 & (7) & 3 & 62 & 81 & 70 & - & 71 & - \\
\hline General Science & 2 & & 210 & 4. & $\sqrt{37}$ & 25 & 66 & 83 & 69 & - & 72 & - \\
\hline
\end{tabular}

In Islamiat girls' average marks $81 \%$ was the higher in grade 4 while for boys $72 \%$ was recorded in grade 6 . The average marks for girls' has decreased in grade 2 and 3 and increased in grade 4 . In Grade 2 and 3 girls average marks fall in category "C", while grade 4 girls could be place in "A" with $81 \%$ average marks. Boy's performance was observed to be a constant in all grades $(62 \%)$ with slight improvement in latter grade $(72 \%)$. Boys average marks in all grades come under "B".

In total Boys performance, in English was observed to be better than girls, notwithstanding the highest average marks $81 \%$ was scored by girls in grade 4 . In general Boys would come under category "B" and girls in " $C$ ".

In Pashtu girls' verage marks was found be decreasing as proceeded to higher grades. The maximum average marks $73 \%$ was calculated in $4^{\text {th }}$ grade and least figure of $56 \%$ for girls was noted in grade 3. Boys' has scored above $60 \%$ in grades and were supposed to be placed in "B".

Social Study and General Science is offered to student in grade 4 and above. The performance of girls in grade 4 in both subjects was observed to be better than boys in all grades. Boys performance was found to be improving as promoted to higher grades. Average marks for girls were above $80 \%$ in both subject and are placed in "A". Boys could be fit into "B" with average marks range between 61-80. 


\section{District D.I. Khan}

In Urdu subject boys has excelled girls in all grades with constant scoring of over $70 \%$. Girls' average marks were found to be in 60 s with maximum score of $70 \%$ was noted in grade 6.

In Mathematic the maximum and minimum average marks were to be seen in grade 6 . However, the best performance $81 \%$ was shown by boys while the girls has performed poorly and could only score $40 \%$ average marks. The average marks for both genders from grade 1 to 4 were above $60 \%$ and fall in the category "B".

Table B13: Subject wise distribution of average marks in district D.I.Khan

\begin{tabular}{|c|c|c|c|c|c|c|c|c|c|c|c|c|}
\hline \multirow{2}{*}{ Subject } & \multicolumn{2}{|c|}{ Grade 1} & \multicolumn{2}{|c|}{ - Grade 2} & \multicolumn{2}{|c|}{ Grade 3} & \multicolumn{2}{|c|}{ Grade 4} & \multicolumn{2}{|c|}{ Grade 5} & \multicolumn{2}{|c|}{ Grade 6} \\
\hline & Boys & Girls & Boys. & Gils & Boys & Girls & Boys & Girls & Boys & Girls & Boys & Girls \\
\hline Urdu & & 27 & 71 & 64 & 72 & 64 & 75 & 60 & 75 & - & 79 & 70 \\
\hline Mathematics & 71 & 66 & 68 & 60 & 71 & 62 & 72 & 67 & 71 & - & 81 & 40 \\
\hline Islamiat & 70 & 65 & 69 & 64 & 72 & 60 & 69 & 61 & 72 & - & 77 & 50 \\
\hline Drawing & 70 & 67 & 69 & 65 & 72 & 62 & 75 & 73 & 76 & - & 80 & 50 \\
\hline English & (3) & (2) & 71 & 66 & 75 & 65 & 72 & 66 & 74 & - & 80 & 74 \\
\hline Calligraphy & 71 & 68 & 73 & 61 & 6. & ry & & 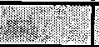 & & 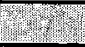 & & Whenesy \\
\hline Sport & 78 & 71 & 79 & 72 & 78 & 69 & 77 & 85 & 82 & . & 86 & 90 \\
\hline Pashto & 71 & 71 & 70 & 67 & 71 & 62 & 73 & 58 & 74 & - & 81 & 60 \\
\hline Quran & 68 & 60 & 67 & 80 & 71 & 62 & 70 & 64 & 76 & 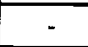 & 78 & 50 \\
\hline Social Study & 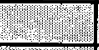 & 2 & 1 & 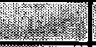 & 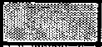 & 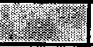 & 72 & 77 & 74 & - & 79 & 60 \\
\hline General Science & 2 & Pा? & 1 & (5) & (3) & $4=1$ & 68 & 55 & 70 & - & 79 & 50 \\
\hline
\end{tabular}

In Islamiat and the Quran boys and girls average marks could be observed in 60 s and 70 s thus come under category "B". It is amazing to note the poor display by the girls' in higher grade 6. It supposed that girls in grade 6 should have performed well in all subject in general and religious education in particular. Grade 6 girls' average marks fall in category " $C$ ", while the initial grades students could be placed in "B".

In total Boys performance in English was observed to be better than girls, as the highest average marks $80 \%$ was scored by boys in grade 6 . There was consistency observed through out the grades for boys and girls' in average marks which was to be within range of $60-70$, henceforth could be placed in category "B".

In Social Science both genders performance was nearly the same with average marks above 60\%. However the girls performance in General Studies was found to be very dismal. Girls could only score $55 \%$ and $50 \%$ marks in grade 4 and 6 . Based on the obtained marks average girls student are placed in " $C$ ". Boys have scored in 70s and are put into "B" 


\section{District Miran Shah}

In Miran Shah district the average marks could be seen in 60 s and 70 s like the other districts. In Urdu girls' average marks were computed to be better than boys. Girls' from grade 3 and 4 have scored in 70s while in other grade students score was found to be in 60 s. Therefore, they could be placed in "B".

In Mathematic an encouraging average marks $92 \%$ was scored by girls from grade 4 . Low marks in 50 s were scored by boys in grade 1, 3 and 5. Girls' average marks were found to be greater than the marks obtained by boys.

Table B14: Subject wise distribution of average marks in district Miran Shah

\begin{tabular}{|c|c|c|c|c|c|c|c|c|c|c|c|c|}
\hline \multirow{2}{*}{ Subject } & \multicolumn{2}{|c|}{ Grade 1} & \multicolumn{2}{|c|}{ Grade 2} & \multicolumn{2}{|c|}{ Grade 3} & \multicolumn{2}{|c|}{ Crade 4} & \multicolumn{2}{|c|}{ Grade 5} & \multicolumn{2}{|c|}{ Grade 6} \\
\hline & Boys & Girls & Boys & Girls & Boys & Cirls & Boys & Grrs & Boys & Girls & Boys & Cirls \\
\hline Urdu & 5 & 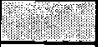 & 60 & 66 & 64 & 70 & 62 & 73 & 64 & & 69 & - \\
\hline Mathematics & 56 & 63 & 60 & 64 & 59 & 64 & 62 & 92 & 58 & & 61 & \\
\hline \begin{tabular}{|l|} 
Islamiat \\
\end{tabular} & 59 & 64 & 61 & 69 & 61 & 65 & 62 & 84 & 63 & & 72 & - \\
\hline \begin{tabular}{|l|} 
Drawing \\
\end{tabular} & 61 & 72 & 67 & 70 & 67 & 64 & 69 & 87 & 76 & & 80 & - \\
\hline English & 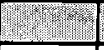 & 2 & 60 & 65 & 59 & 64 & 60 & 66 & 61 & & 66 & - \\
\hline Calligraphy & 65 & 63 & 70 & 63 & 1. & & 28 & 9 & Dis & $x_{1}$ & 2 & 1 \\
\hline Sport & 71 & 76 & 76 & 74 & 80 & 64 & 81 & 91 & 85 & & 86 & - \\
\hline Pashto & 61 & 66 & 61 & 67 & 61 & 64 & 67 & 86 & 64 & & 72 & - \\
\hline Quran & 58 & 62 & 64 & 65 & 60 & 67 & 67 & 83 & 69 & & 74 & - \\
\hline Social Study & 25 & 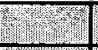 & (7) & 01 & 5 & 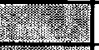 & 63 & 88 & 60 & & 68 & - \\
\hline General Science & 27 & Tin & (2) & 3 & y-2: & 2.3 & 62 & 85 & 60 & & 64 & - \\
\hline
\end{tabular}

In English, Girls' have again obtained high marks than boys. Girls' have scored $65 \%$ in grade $1,64 \%$ in grade 2 and $66 \%$ in grade 3 . Based on those average marks the girls' were to be placed in "B". Boys with less than $60 \%$ marks were to be placed in "C".

In Social Study and General Science, the girls' from this district has performed exceedingly well as compared to girls' from district D.I.Khan. Girls here have excelled boys with a good margin. $88 \%$ and $85 \%$ were the calculated average marks scored by them in grade 4. Boys' average marks in both subject in all grades was found to be in 60s. Thus a rear achievement to get "A" was realized by girls'. Boy's average marks could allow them to be placed in "B".

\section{District Wanna}

In district Wanna, Table B13 below predict a mix sort of performance by both genders. In Urdu senior students' performance could be termed satisfactory as compared to students in lower grades. Girls' in grade 4 have obtained the maximum average marks $71 \%$ and boy's $64 \%$ from grade 5 . Both Boys and Girls' have scored below $60 \%$ in initial grades. 
In Mathematics only grade 6 boys could score $61 \%$ average marks and all the students from other grades were well below $60 \%$. Category " $\mathrm{C}$ " could be accorded to those students.

In English, performance of boys and girls in initial grades was poor and has improved a little bit in upper grades. Maximum $69 \%$ average marks were found to be scored by girls' in grade 4 . Boys have scored $63 \%$ in grade 5 and $62 \%$ in grade 6 .

Table B15: Subject wise distribution of average marks in district Wanna

\begin{tabular}{|c|c|c|c|c|c|c|c|c|c|c|c|c|}
\hline \multirow{2}{*}{ Subject } & \multicolumn{2}{|c|}{ Grade 1} & \multicolumn{2}{|c|}{ Grade 2} & \multicolumn{2}{|c|}{ Grade 3} & \multicolumn{2}{|c|}{ Grade 4} & \multicolumn{2}{|c|}{ Grade 5} & \multicolumn{2}{|c|}{ Grade 6} \\
\hline & Boys & Girls & Boys & Gins & Boys & Ginls: & Boys & Girls & Boys & Girls & Boys & Girls \\
\hline Urdu & $x$ & 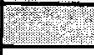 & 56 & 60 & 55 & 55 & 57 & 71 & 64 & 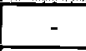 & 61 & - \\
\hline Mathematics & 57 & 56 & 60 & 55 & 57 & 48 & 59 & 66 & 62 & - & 61 & - \\
\hline Islamiat & 58 & 60 & 60 & 65 & 59 & 56 & 63 & 66 & 65 & - & 71 & - \\
\hline Drawing & 68. & 66 & 68 & 76 & 67 & 54 & 69 & 83 & 74 & - & 70 & - \\
\hline English & 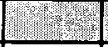 & 2 & 56 & 56 & 55 & 55 & 56 & 69 & 63 & - & 62 & - \\
\hline Calligraphy & 63 & 62 & 66 & 71 & f & 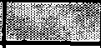 & 2 & 2. & $=0$ & 28 & 5 & $e^{3}$ \\
\hline Sport & 76 & 68 & 81 & 72 & 79 & 78 & 80 & 86 & 87 & - & 83 & - \\
\hline Pashto & 57 & 59 & 60 & 61 & 57 & 58 & 60 & 69 & 66 & - & 69 & - \\
\hline Quran & 60 & 63 & 62 & 66 & 60 & 67 & 64 & 81 & 72 & - & 68 & - \\
\hline Social Study & 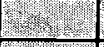 & Cevest & 2 & $=1$ & (19) & 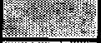 & 61 & 70 & 65. & & 64 & - \\
\hline General Science & 2 & 18 & 6 & 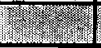 & 31 & E. & 58 & 63 & 61 & - & 63 & - \\
\hline
\end{tabular}

Average marks in 50s and 60s in Pashto were observed for both the boys and girls. In Social Study and General Science the maximum of $70 \%$ was recorded in grade 4 by girls'. However average marks in 60 s were seen to be scored by boys and girls from all grades.

In general the average marks of students in district Wanna ranges between 50 and 60 . Based on the average marks student from district Wanna could be placed in category " $\mathrm{C}$ ". 


\section{Resource Center Hangu}

\subsection{Enrollment}

In Resource Center Hangu total enrollment was 18, 902 included boys 16,043, and girls 2,859 . The proportion of boys was calculated to be four times greater than that of girls' enrollment. The contribution of Resource Center Hangu in the total enrollment $(123,660)$ was $15 \%$.

Resource Center Hangu encompassed two districts Kohat and Kurram. Among the districts greater enrollment was recorded in district Kohat which was $56 \%$ $(10,594)$ for both genders. As compare to Kohat, total enrolment of district Kurram was low and contributing $44 \%(8,308)$ to the total enrollment of Hangu Resource Center.
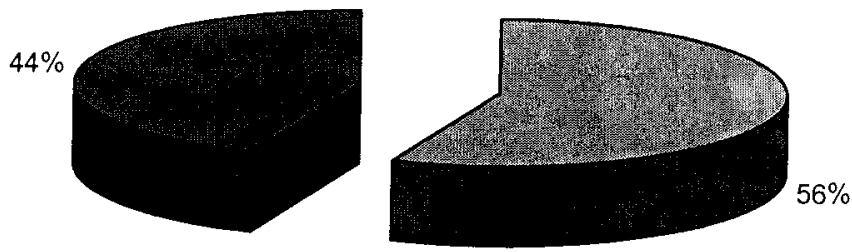

回Kohat Kurrum

High percentage of repeaters was recorded in district Kohat which was $10 \%$ (948) and $8 \%$ (109) for boys and girls respectively. In district Kurram the repeaters' percentage as a whole was low in comparison to district Kohat but among girls it was similar to that of Kohat district.

Table H1: Distribution of students by Districts

\begin{tabular}{|l|r|r|r|r|r|r|r|r|r|}
\hline \multirow{2}{*}{ District } & \multicolumn{3}{|c|}{ Enrolled } & \multicolumn{4}{c|}{ Repeater } & \multicolumn{3}{c|}{ Fresh enrollment } \\
\cline { 2 - 10 } & Boys & Girls & Total & Boys & Girls & Total & Boys & Girls & Total \\
\hline Kohat & 9286 & 1308 & 10,594 & 948 & 109 & 1,057 & 8,338 & 1,199 & 9,537 \\
\hline Kurrum & 6757 & 1551 & 8,308 & 426 & 120 & 546 & 6,331 & 1,431 & 7,762 \\
\hline Total & $\mathbf{1 6 0 4 3}$ & $\mathbf{2 8 5 9}$ & $\mathbf{1 8 , 9 0 2}$ & $\mathbf{1 3 7 4}$ & $\mathbf{2 2 9}$ & $\mathbf{1 , 6 0 3}$ & $\mathbf{1 4 , 6 6 9}$ & $\mathbf{2 , 6 3 0}$ & $\mathbf{1 7 , 2 9 9}$ \\
\hline
\end{tabular}




\subsection{Dropout}

In Resource Center Hangu high rate of dropout was recorded in girls in all grades in Kohat district. Similarly boys' dropout rate was high in grade 2, 3 and 5 in the same district. While in Kurram district the dropout rate was high among boys in comparison to girls especially in grade 4 and 5 . In Kurram district dropout rate among girls as a whole was low.

\section{District, Grade and Gender Wise Dropout}

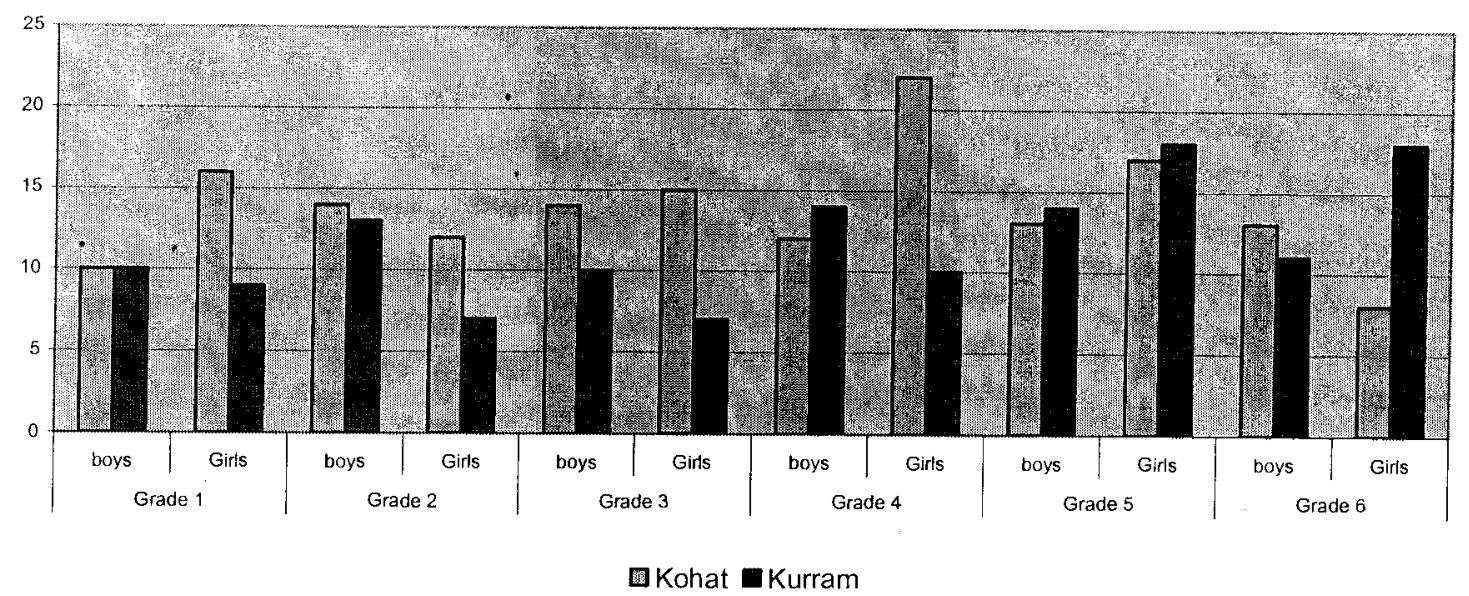

\section{Grade wise dropout statistic of all districts in Hangu Resource Center}

The overall dropout ratio in Kohat was calculated $12 \%$ and $16 \%$ for boys and girls respectively: The highest dropout in boy was recorded in grade 2 and 3 which was $14 \%$ in each case while in girls the highest dropout $(22 \%)$ rate was recorded in grade 4.

Significant number of dropout in boys was noted in grade $2,3,5$ and 6 which was $14 \%$ and $13 \%$ in each case. As boys are supposed to help their father in the work like helping in the shop, harvesting season for which they seasonally migrate as well, therefore their dropout rate has increased.

Similarly in girls high dropout was observed in grade 1, 4 and 5 which was $16 \%$, $22 \%$ and $17 \%$ respectively. Girls also assist in household chores such as collecting fire wood, bringing water and looking after the younger siblings were the major factor contributed to the dropout of younger girls. In upper grades the girls also dropped out after reaching the age of puberty and engagement. At this age their parents would prefer them to stay at home to observe Pardha to maintain chastity. 
Table H2: Grade wise details of dropout of Kohat District

\begin{tabular}{|l|r|r|r|r|r|r|r|}
\hline & \multicolumn{2}{|c|}{ Enrolled } & \multicolumn{3}{c|}{ Dropped } & \multicolumn{1}{c|}{ Dropout in \% } \\
\cline { 2 - 8 } & \multicolumn{1}{|c|}{ Boys } & \multicolumn{1}{c|}{ Girls } & \multicolumn{1}{c|}{ Boys } & Girls & Overall & \multicolumn{1}{c|}{ Boys } & \multicolumn{1}{c|}{ Girls } \\
\hline Grade I & 3088 & 544 & 295 & 89 & 384 & $10 \%$ & $16 \%$ \\
\hline Grade II & 1,862 & 357 & 267 & 44 & 311 & $14 \%$ & $12 \%$ \\
\hline Grade III & 1,509 & 148 & 218 & 22 & 240 & $14 \%$ & $15 \%$ \\
\hline Grade IV & 1,210 & 139 & 149 & 30 & 179 & $12 \%$ & $22 \%$ \\
\hline Grade V & 986 & 95 & 126 & 16 & 142 & $13 \%$ & $17 \%$ \\
\hline Grade VI & 631 & 25 & 85 & 2 & 87 & $13 \%$ & $8 \%$ \\
\hline Total & $\mathbf{9 , 2 8 6}$ & $\mathbf{1 , 3 0 8}$ & $\mathbf{1 , 1 4 0}$ & $\mathbf{2 0 3}$ & $\mathbf{1 , 3 4 3}$ & $\mathbf{1 2 \%}$ & $\mathbf{1 6 \%}$ \\
\hline
\end{tabular}

Overall dropout ratio in Kurram district was recorded as $12 \%$ and $10 \%$ for boys and girls correspondingly. The highest percentage of dropout (14\%) among boys was recorded in grade 4 and 5 while in girls it was $18 \%$ in grade 5 and 6 respectively.

With the establishment of new camp in Kurram district families started to shift to new camp for seeking freshly arrived assistance contributed to high dropout in Kurram. It has been observed that in Hangu center the dropout ratio among girls was low in Kurram except grade 5. The reason given for this dropout was no facility of middle school for girls, due to lack of opportunity for continuation of education the interest diminishes at primary level and girls dropout started from grade 4 and reaches to its peak in grade 6.

Table H3: Grade wise details of dropout of district Kurram

\begin{tabular}{|l|r|r|r|r|r|r|r|}
\hline & \multicolumn{2}{|c|}{ Enrolled } & \multicolumn{4}{|c|}{ Dropped } & \multicolumn{2}{|c|}{ Dropout in \% } \\
\cline { 2 - 8 } & Boys & Girls & Boys & Girls & Overall & Boys & Girls \\
\hline Grade I & 2035 & 666 & 210 & 61 & 271 & $10 \%$ & $9 \%$ \\
\hline Grade II & 1530 & 287 & 199 & 19 & 218 & $13 \%$ & $7 \%$ \\
\hline Grade III & 1206 & 227 & 116 & 17 & 133 & $10 \%$ & $7 \%$ \\
\hline Grade IV & 939 & 173 & 131 & 17 & 148 & $14 \%$ & $10 \%$ \\
\hline Grade V & 670 & 138 & 92 & 25 & 117 & $14 \%$ & $18 \%$ \\
\hline Grade VI & 377 & 60 & 41 & 11 & 52 & $11 \%$ & $18 \%$ \\
\hline Total & $\mathbf{6 , 7 5 7}$ & $\mathbf{1 , 5 5 1}$ & $\mathbf{7 8 9}$ & $\mathbf{1 5 0}$ & $\mathbf{9 3 9}$ & $\mathbf{1 2 \%}$ & $\mathbf{1 0 \%}$ \\
\hline
\end{tabular}

\subsection{Results analysis}

\subsubsection{Appeared and Pass ratio}

In Hangu Resource Center total of 18, 902 students were enrolled in the session 2002-2003. The figure included 16,043 boys and 2,859 girls. Among them a total of $15,682(13,215$ boys and 2,467$)$ were appeared in the final exam.

During the result analysis it was observed that the total pass percentage of Hangu Resource Center was $89 \%$ (14,034 students). Out of this figure 11,830 $(86 \%)$ boys and 2,204 (85\%) girls were declared successful. 
Total pass percentage of Hangu Resource Center was $89 \%$. District Kurram with $94 \%$ pass percentage leads the district Kohat with $85 \%$ figure. Similarly in districts the performance of both genders was found to be better than in district Kurram than that of Kohat.

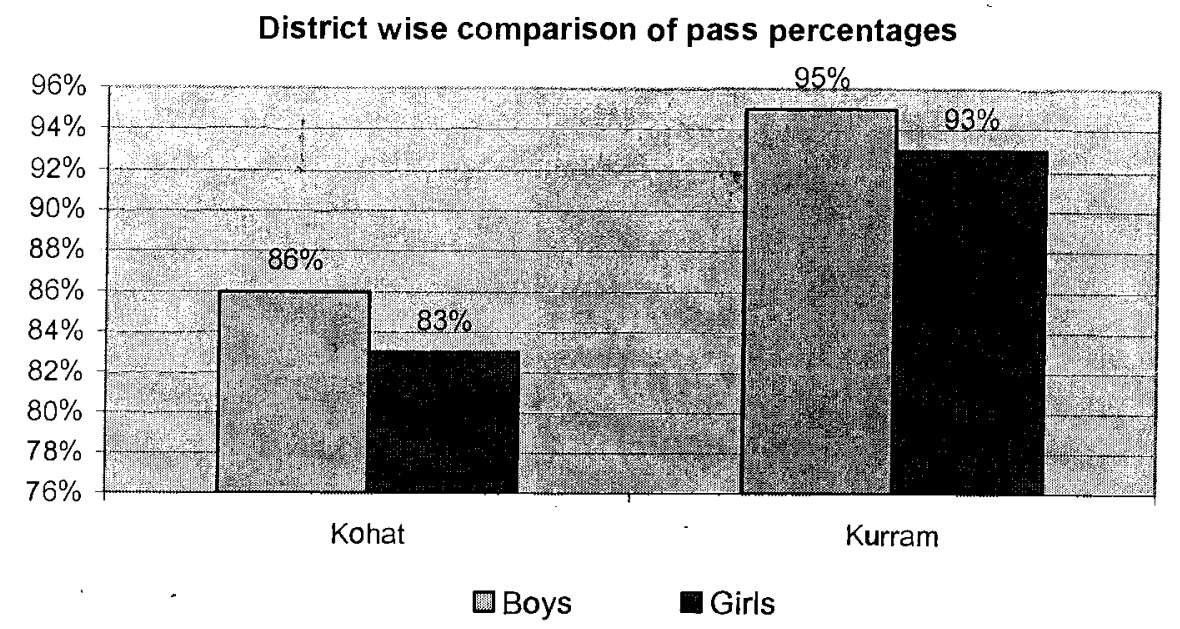

Following are the details of appeared, not appeared and pass percentage of all districts falling under the administration of Hangu Resource Center.

\section{Districts Kohat}

During academic year 2002-2003 a total of 8,929 students comprising 7,861 boys and 1,068 girls appeared in the annual exam. The overall pass percentage of boys in Kohat district was $81 \%$ while in girls it was $91 \%$. This is indicative of the fact that girls' performance was better than the boys with a difference of $10 \%$. The difference can easily be observed in the grade and gender wise analysis as well. Boys pass percentage in grade 1 was $64 \%$ whereas girls' pass ratio was calculated as $89 \%$. It is important to mention that $100 \%$ pass percentage was achieved by girls in grade 6 .

The students who did not appear in annual exam were 322 comprising $3 \%$ of the total. The higher percentage (5\%) of not appeared students was recorded in grade 2

Table H4: Grade wise details of appeared and pass students in district Kohat

\begin{tabular}{|c|c|c|c|c|c|c|c|c|c|c|c|}
\hline & \multicolumn{3}{|c|}{ Appeared } & \multicolumn{3}{|c|}{ Not Apeared } & 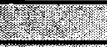 & \multicolumn{2}{|c|}{ Passed } & \multicolumn{2}{|c|}{ Passed \% } \\
\hline & Boys & Gils & Total & Boys & Girls & Total & $9 \%$ & Boys & Girls & Boys & Girls \\
\hline Grade 1 & 2725 & 438 & 3163 & 68 & 17 & 85 & 3 & 1731 & 389 & $64 \%$ & $89 \%$ \\
\hline Grade II & 1517 & 301 & 1818 & 78 & 12 & 90 & $\underline{5}$ & 1362 & 273 & $90 \%$ & $91 \%$ \\
\hline Grade III & 1240 & 123 & 1363 & 51 & & 54 & 4 & 1115 & 115 & $90 \%$ & $93 \%$ \\
\hline Grade IV & 1032 & 107 & 1139 & 29 & 2 & 31 & 3 & 932 & 103 & $90 \%$ & $96 \%$ \\
\hline Grade V & 820 & 76 & 896 & 40 & 3 & 43 & 5 & 755 & 73 & $92 \%$ & $96 \%$ \\
\hline Grade VI & 527 & 23 & 550 & 18 & 0 & 19 & 3 & 507 & 23 & $96 \%$ & $100 \%$ \\
\hline Total & 7861 & 1068 & 8929 & 285 & 37 & 322 & 3 & 6,402 & 976 & $81 \%$ & $91 \%$ \\
\hline
\end{tabular}




\section{$\underline{\text { 2. District Kurram }}$}

A total number of 7,058 students appeared in the annual exam 2002-2003. The figure included 5,738 boys and 1,320 , out of which $95 \%(5,428)$ of boys and $93 \%$ $(1,228)$ of girls were successful. In gender and grade wise analysis it was observed that pass ratio for both genders improved as they move to the higher grade. For instance, pass percentage of boys in grade 1 was $94 \%$ and girls $92 \%$ whereas in grade 6 the percentage has increased to $97 \%$ for boys and $100 \%$ for girls. Nonetheless, the girls' performance in grade 3 has decreased to $91 \%$.

The overall percentage of not appeared students in exam was noted as $4 \%$ while in grade wise analysis the highest percentage was recorded in grade 5 which is $6 \%$ in Kurram district.

Table H5: Grade wise details of appeared and pass students in district Kurram

\begin{tabular}{|c|c|c|c|c|c|c|c|c|c|c|c|}
\hline \multirow{2}{*}{ (2) } & \multicolumn{2}{|c|}{ Appeareo } & \multicolumn{4}{|c|}{ Not Appeared } & \multirow{2}{*}{$\frac{2}{2 \%}$} & \multicolumn{2}{|c|}{ Passed } & \multicolumn{2}{|c|}{ Passed $\%$} \\
\hline & Boys & Gils & Total & Roys & errs & Total & & Boys & Girls & Boys & Girls \\
\hline Grade I & 1746 & 580 & 2326 & 79 & 25 & 104 & 4 & 1636 & 533 & $94 \%$ & $92 \%$ \\
\hline Grade II & 1286 & 253 & 1539 & 45 & 15 & 60 & 4 & 1210 & 241 & $94 \%$ & $95 \%$ \\
\hline Grade III & 1057 & 198 & 1255 & 33 & 12 & 45 & 3 & 1006 & 181 & $95 \%$ & $91 \%$ \\
\hline Grade IV & 777 & 145 & 922 & 31 & 11 & 42 & 4 & 736 & 132 & $95 \%$ & $91 \%$ \\
\hline Grade V & 550 & 102 & 652 & 28 & 11 & 39 & 6 & 527 & 99 & $96 \%$ & $97 \%$ \\
\hline Grade VI & 322 & 42 & 364 & 14 & 7 & 21 & 5 & 313 & 42 & $97 \%$ & $100 \%$ \\
\hline Total & 5738 & 1320 & 7058 & 230 & 0 & 311 & 4 & 5,428 & 1.228 & $95 \%$ & $93 \%$ \\
\hline
\end{tabular}

\subsubsection{Graduation rate}

During the academic session 2002-2003 a total of 1,008 boys and 85 girls were enrolled in grade 6 out of which $81 \%$ of boys and $76 \%$ of girls were graduated. The higher graduation rate was recorded for girls in Kohat district which was $92 \%$ whereas in Kurram district the higher percentage of graduates was observed among boys.

Table H6: District wise graduation rate

\begin{tabular}{|l|r|r|r|r|r|r|}
\hline \multirow{2}{*}{ District } & \multicolumn{2}{|c|}{ Enrollment } & \multicolumn{2}{|c|}{ Pass } & \multicolumn{2}{|c|}{ Percentage } \\
\cline { 2 - 8 } & Boys & Girls & Boys & Girls & Boys & Girls \\
\hline Kohat & 631 & 25 & 507 & 23 & $80 \%$ & $92 \%$ \\
\hline Kurram & 377 & 60 & 313 & 42 & $83 \%$ & $70 \%$ \\
\hline Total & 1,008 & $\mathbf{8 5}$ & $\mathbf{8 2 0}$ & $\mathbf{6 5}$ & $\mathbf{8 1} \%$ & $\mathbf{7 6 \%}$ \\
\hline
\end{tabular}


Graduation Rate of Resource Center Hangu

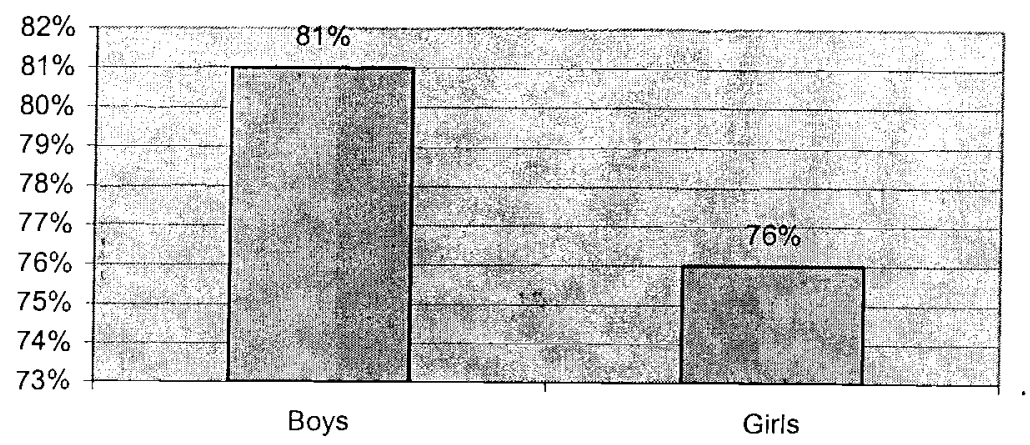

\subsubsection{Student performance in subjects and grade}

\section{District Kohat}

In the grade, gender and subject wise analysis of Kohat district it was observed that in Urdu subject all grades including both genders got grade "B" (min.60 max.71). Fluctuations were observed in the boys average marks while among girls an increasing trend in marks was noted. While in grade 6 the girls obtained $85 \%$ marks and remained in grade " $\mathrm{A}$ ".

Similarly in Mathematics the average marks ranged from 58-64 in majority of the grades except girls of grade 5 and 6 who got $71 \%$ and $85 \%$ marks and remained in " $B$ " and " $A$ " respectively.

In the comparative analysis of Islamiat and the Quran somehow fluctuation in the same grade (category) as well as from one grade to another was noted. The lowest marks in Islamiat was noted among girls in grade 2 which was $58 \%$ while in the Quran the lowest marks were noted among boys in grade 1. The highest average marks in the said subject were observed among girls in grade 6 as $92 \%$ and $76 \%$ respectively. 
Table H7: Subject wise distribution of average marks in Haripur District

\begin{tabular}{|c|c|c|c|c|c|c|c|c|c|c|c|c|}
\hline \multirow{2}{*}{ Subject } & \multicolumn{2}{|c|}{ Grade 1} & \multicolumn{2}{|c|}{ Grade 2} & \multicolumn{2}{|c|}{ Grade 3} & \multicolumn{2}{|c|}{ Grade 4} & \multicolumn{2}{|c|}{ Grade 5} & \multicolumn{2}{|c|}{ Grade 6} \\
\hline & Boys & Girls & Boys & Girls & Boys & Girls & Boys & Girls & Boys & Girls & Boys & Girls \\
\hline Urdu & & ๑ै। & 60 & 66 & 64 & 68 & 60 & 69 & 67 & 71 & 64 & 85 \\
\hline Mathematics & 60 & 60 & 60 & 60 & 58 & 61 & 57 & 64 & 58 & 70 & 61 & 80 \\
\hline Islamiat & 61 & 60 & 63 & 67 & 58 & 66 & 57 & 63 & 65 & 74 & 73 & 92 \\
\hline Drawing & 69 & 67 & 73 & 58 & 67 & 70 & 67 & 76 & 73 & 76 & 74 & 91 \\
\hline English & 18 & 4 & 61 & 67 & 62 & 60 & 57 & 65 & 61 & 63 & 63 & 85 \\
\hline Calligraphy & 62 & 66 & 71 & 80 & 2) & Prostis & (1) & & त् & 1 & 24 & (1) \\
\hline Sport & 79 & 80 & 85 & 59 & 82 & 85 & 79 & 89 & 85 & 85 & 84 & 100 \\
\hline Pashto & 60 & 61 & 61 & 60 & 59 & 64 & 61 & 66 & 64 & 74 & 70 & 92 \\
\hline Quran & 58 & 63 & 60 & 63. & 62 & 68 & 63 & 73 & 68 & 73 & 72 & 76 \\
\hline Social Study & 19. & 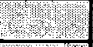 & (n) & (3) & (2) & 21 & 58 & 65 & 65 & 80 & 67 & 89 \\
\hline General Science & 2 & in? & & 20 & 2 & 1.2. & 55 & 68 & 62 & 72 & 65 & 86 \\
\hline
\end{tabular}

While analyzing Social Study and General Science, low average marks were noted among boys in grade $4(58 \%$ and $55 \%)$ in both subjects, grade wise and gender wise fluctuation was noted. In grade 6 the girls' performance in two subjects was under grade "A" by obtaining $89 \%$ and $86 \%$ average marks respectively.

\section{District Kurram}

During subject, grade and gender wise analysis of Kurram district it was noted that the average marks of the boys in Urdu subject variation in average marks were observed whereas in girls the increasing trend was noted in average marks.

In Mathematic grade "B" (min. 61, max. 70) was sustained in all grades including girls and boy except girls in grade 1 who got $57 \%$ average marks and remained under grade "C".

Table H8: Subject wise distribution of average marks in Kurram District

\begin{tabular}{|c|c|c|c|c|c|c|c|c|c|c|c|c|}
\hline \multirow{2}{*}{ Subject } & \multicolumn{2}{|c|}{ Grade 1} & \multicolumn{2}{|c|}{ Grade 2} & \multicolumn{2}{|c|}{ Grade 3} & \multicolumn{2}{|c|}{ Grade 4} & \multicolumn{2}{|c|}{ Grade 5} & \multicolumn{2}{|c|}{ Grade 6} \\
\hline & Boys & Girls & Boys & Sms & Boys & Cirls & Boys & Girls & Boys & Girls & Boys & Girls \\
\hline Urdu & 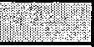 & 2 & 67 & 62 & 67 & 65 & 66 & 65 & 69 & 71 & 69 & 72 \\
\hline Mathematics & 65 & 57 & 64 & 65 & 61 & 68 & 60 & 61 & 62 & 67 & 66 & 70 \\
\hline Islamiat & 65 & 56 & 64 & 68 & 66 & 66 & 60 & 62 & 68 & 69 & 76 & 83 \\
\hline Drawing & 73 & 74 & 72 & 72 & 75 & 77 & 77 & 72 & 79 & 82 & 78 & 88 \\
\hline English & Pry & 2 & 62 & 58 & 66 & 67 & 62 & 63 & 62 & 64 & 64 & 80 \\
\hline Calligraphy & 69 & 62 & 69 & 62 & 2y & & & 3 & 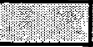 & & & 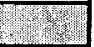 \\
\hline Sport & 85 & 81 & 83 & 83 & 88 & 83 & 87 & 84 & 87 & 93 & 88 & 89 \\
\hline Pashto & 62 & 60 & 65 & 67 & 65 & 72 & 69 & 66 & 68 & 69 & 76 & 81 \\
\hline Quran & 63 & 58 & 63 & 67 & 68 & 63 & 69 & 68 & 73 & 76 & 78 & 87 \\
\hline Social Study & 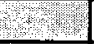 & & 1. & 28x & 28 & 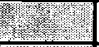 & 64 & 67 & 68 & 70 & 72 & 73 \\
\hline General Science & 2 & & ret & & 15: & 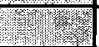 & 63 & 60 & 69 & 73 & 74 & 73 \\
\hline
\end{tabular}

In comparison of the subjects Islamiat and Quran it was observed that both genders in all grades obtained grade "B" (min. 60, max.76) (min. 63, max. 78) respectively except grade 1 where the average marks in both subjects were $56 \%$ 
and $58 \%$ and remained under grade "C" but at the same time it is very surprising that in both subjects the highest marks $(83 \%$ and $87 \%)$ were scored by the girls in grade 6 and got to " $A$ ".

Similarly in Pashto, Social Study and General Science subjects throughout the grades in both genders "B" was observed with increasing trend. Whereas the highest marks $(81 \%)$ in Pashto were again scored by the girls in grade 6. 


\section{Resource Centre Mardan}

\subsection{Enrollment}

Total enrollment in Mardan Resource Centre was recorded 17,622 included 12,874 boys and 4,748 girls. Mardan Resource Centre contributed $14 \%$ to the total enrollment 123,660 . Out of the total 12,874 boys enrolled 1,159 were the repeat cases. In 4,748 girls enrollment 277 were the repeaters.

Resource Centre Mardan has four districts namely Charsadda, Mardan, Peshawar and Swabi. District Mardan is the most populace with 10, 942 students.

Table M1: Distribution of students by districts

\begin{tabular}{|c|c|c|c|c|c|c|c|c|c|}
\hline \multirow{2}{*}{ District } & \multicolumn{3}{|c|}{ Enrolled } & \multicolumn{3}{|c|}{ Repeater } & \multicolumn{3}{|c|}{ Fresh } \\
\hline & Boys & Cirls & Total & Boys & Girls & Total & Boys & $\mathrm{Clll}$ & Total \\
\hline charsada & - & 228 & - & - & - & - & 0 & 228 & 228 \\
\hline Mardan & 8,913 & 3,128 & 12,041 & 872 & 227 & 1,099 & 8,041 & 2901 & 10942 \\
\hline Peshawar & 3,875 & 630 & 4,505 & 287 & 20 & 307 & 3,588 & 610 & 4198 \\
\hline Swabi & 86 & 762 & 848 & 0 & 30 & 30 & 86 & 732 & 818 \\
\hline Total & 12,874 & 4,748 & 17.394 & 1,159 & 2277 & 1,136 & 11,715 & 4471 & 16186 \\
\hline
\end{tabular}

In Mardan district the number of repeaters $(1,099)$ was high comparing to the other districts $(307,30)$.

In Charsadda district there was only one newly established girl's school due to which there was no repeat case documented. In Swabi district all were girl's school except one co-education school with 86 boys and there was no repeater noted as well. Comparatively girls had less \% of repeaters then boys.

Girls' constituted $27 \%(4,471)$ of the total fresh enrollment 16,186 . Mardan district has the highest numbers of girls' student $(2,901)$ and camps encompassed in Peshawar district has (610) girls enrollment. The repatriation from Peshawar district was high due to which two female schools in Akora khattak has been shifted to another side of the camp after the camp was demolished by UNHCR.

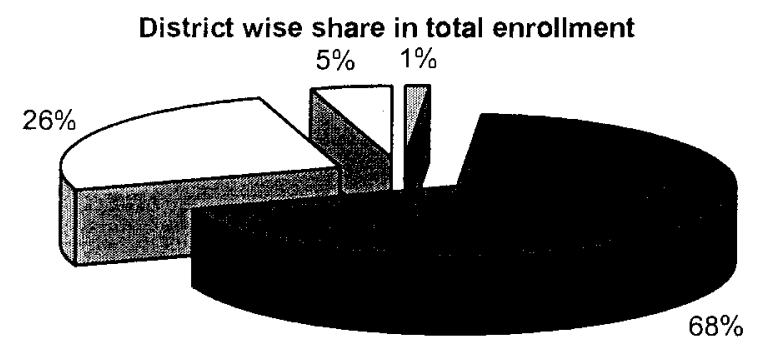

๑Charsadda Mardan $\square$ Peshawar $\square$ Swabi 


\subsection{Dropout}

The total dropout ratio calculated in Mardan was $15 \%$ (boys $15 \%$ and girls $16 \%$ ). It is observed that the girls' dropout rate (16\%) was high than boys $(15 \%)$. The highest dropout was recorded in district Peshawar (27\% girls and $25 \%$ boys) followed by Mardan (16\%). District Swabi showed a high dropout rate of boys $(17 \%)$

Table M2 indicates very high Girls' dropout in Peshawar district which was computed $25 \%$ in boys and $27 \%$ in girls.

Table M2: Districts wise dropout of students

\begin{tabular}{|l|r|r|r|r|r|r|}
\hline \multirow{2}{*}{ Districts } & \multicolumn{2}{|c|}{ Enrolled } & \multicolumn{2}{c|}{ Dropped } & \multicolumn{2}{c|}{ Dropout in \% } \\
\cline { 2 - 7 } & \multicolumn{1}{|c|}{ Boys } & \multicolumn{1}{c|}{ Girls } & \multicolumn{1}{c|}{ Boys } & Girls & \multicolumn{1}{c|}{ Boys } & Girls \\
\hline Charsada & 0 & 228 & 0 & 0 & $0 \%$ & $0 \%$ \\
\hline Mardan & 8,913 & 3,128 & 975 & 507 & $11 \%$ & $16 \%$ \\
\hline Peshawar & 3,875 & 490 & 975 & 130 & $25 \%$ & $27 \%$ \\
\hline Swabi & 86 & 762 & 15 & 112 & $17 \%$ & $15 \%$ \\
\hline Total & $\mathbf{1 2 , 8 7 4}$ & $\mathbf{4 6 0 8}$ & $\mathbf{1 9 6 5}$ & $\mathbf{7 4 9}$ & $\mathbf{1 5} \%$ & $\mathbf{1 6 \%}$ \\
\hline
\end{tabular}

The graph indicates no dropout rate in Charsadda where the school was recently established. In district Mardan the dropout rate of girls and boys was estimated $16 \%$.

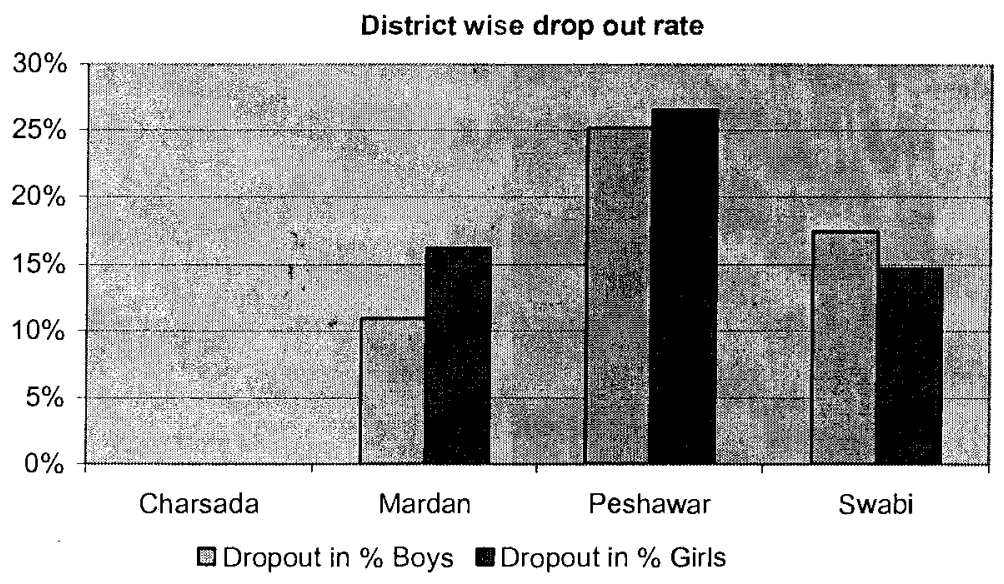




\section{Grade wise dropout statistic of all districts in Mardan Resource Center}

Table M3: Grade wise dropout details of district Mardan

\begin{tabular}{|l|r|r|r|r|r|r|}
\hline & \multicolumn{2}{|c|}{ Enrolled } & \multicolumn{2}{c|}{ Dropped } & \multicolumn{2}{c|}{ Dropout in \% } \\
\cline { 2 - 7 } & \multicolumn{1}{c|}{ Boys } & Girls & \multicolumn{1}{c|}{ Boys } & Girls & \multicolumn{1}{c|}{ Boys } & \multicolumn{1}{c|}{ Girls } \\
\hline Grade I & 2,559 & 1,387 & 270 & 229 & $11 \%$ & $17 \%$ \\
\hline Grade II & 2,016 & 602 & 222 & 90 & $11 \%$ & $15 \%$ \\
\hline Grade III & 1,545 & 478 & 168 & 75 & $11 \%$ & $16 \%$ \\
\hline Grade IV & 1,210 & 313 & 152 & 53 & $13 \%$ & $17 \%$ \\
\hline Grade V & 919 & 252 & 101 & 50 & $11 \%$ & $20 \%$ \\
\hline Grade VI & 664 & 96 & 62 & 10 & $9 \%$ & $10 \%$ \\
\hline Total & $\mathbf{8 , 9 1 3}$ & $\mathbf{3 , 1 2 8}$ & $\mathbf{9 7 5}$ & $\mathbf{5 0 7}$ & $\mathbf{1 1 \%}$ & $\mathbf{1 6 \%}$ \\
\hline
\end{tabular}

In Mardan district boys' dropout rate was $11 \%$ in all grades. While in girls the highest dropout rate was observed in grade $1(17 \%)$ and in grade $5(20 \%)$. There was a variation trend in girls dropout along grades.

Table M4: Grade wise dropout details of district Peshawar

\begin{tabular}{|l|r|r|r|r|r|r|}
\hline & \multicolumn{2}{|c|}{ Enrolled } & \multicolumn{2}{c|}{ Dropped } & \multicolumn{2}{c|}{ Dropout in \% } \\
\cline { 2 - 7 } & Boys & Girls & Bays & Girls & Boys & Girls \\
\hline Grade I & 1,236 & 54 & 270 & 17 & $22 \%$ & $31 \%$ \\
\hline Grade II & 873 & 127 & 222 & 12 & $25 \%$ & $9 \%$ \\
\hline Grade III & 658 & 100 & 168 & 17 & $26 \%$ & $17 \%$ \\
\hline Grade IV & 496 & 92 & 152 & 13 & $31 \%$ & $14 \%$ \\
\hline Grade V & 385 & 74 & 101 & 6 & $26 \%$ & $8 \%$ \\
\hline Grade VI & 227 & 43 & 62 & 11 & $27 \%$ & $26 \%$ \\
\hline Total & $\mathbf{3 , 8 7 5}$ & 490 & 975 & 76 & $\mathbf{2 5} \%$ & $16 \%$ \\
\hline
\end{tabular}

Some areas of district Peshawar was included in Resource Centre Mardan and those areas have the highest dropout rate $(17 \%)$ in girls and $(25 \%)$ in boys. The dropout rate in grade 1 was $22 \%$ in boys and $31 \%$ in girls. Usually it has been seen that girls dropout in comparison to boys was high but in case of Peshawar district boys dropout (25\%) was found to be higher than girls (16\%).

Major reason was the repatriation from Akora Khattak camp, thereby half the camp was demolished.

Table M5: Grade wise dropout details of district Swabi

\begin{tabular}{|c|c|c|c|c|c|c|}
\hline & Enro & led & Drop & ped & Dropo & it in $\%$ \\
\hline & Boys & Girls & Rovs & Ginls & Boys & Girls \\
\hline Grade I & 70 & 496 & 15 & 76 & $21 \%$ & $15 \%$ \\
\hline Grade II & 16. & 217 & 0 & 33 & $0 \%$ & $15^{\circ}$ \\
\hline Grade III & 0 & 49 & 0 & 3 & $0 \%$ & $6 \%$ \\
\hline Grade IV & 0 & 0 & 0 & 0 & $0 \%$ & $0 \%$ \\
\hline Grade V & 0 & 0 & 0 & 0 & $0 \%$ & $0 \%$ \\
\hline Grade VI & o] & $\underline{0}$ & 0 & 0 & $0 \%$ & $0 \%$ \\
\hline Total & 86 & 762 & 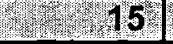 & 112 & $17 \%$ & $15 \%$ \\
\hline
\end{tabular}


In Swabi district there were three girls schools and one co-education school. Boy's enrollment in the co-education schools was low. In grade 1 the dropout rate of boys was $21 \%$ while in girls it was observed $15 \%$.

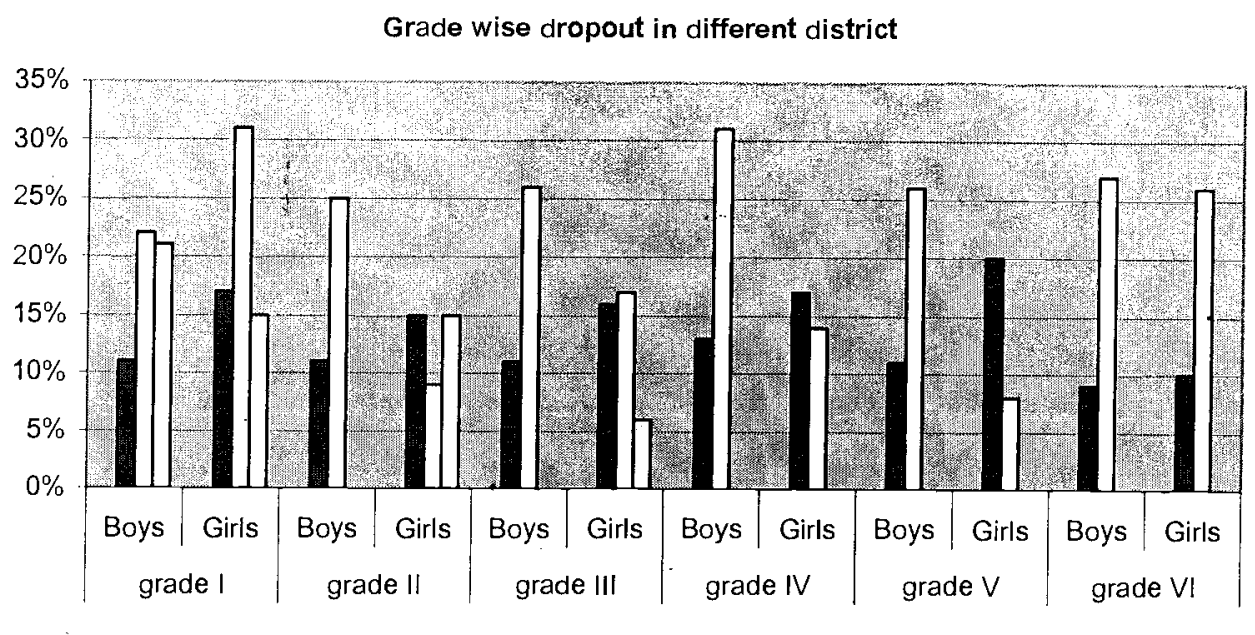

DCharsada Mardan DPeshawar $\square$ Swabi

The graph indicates high dropout rate of boys in district Peshawar almost in all grades. The greatest percentage could be seen in grade $4(31 \%)$. A significant percentage of dropout was also seen in girls in the said district. In grade 1 girl's dropout was $31 \%$. Main reason for dropout in grade 1 would be the admission policy of the schools administration. To increase enrollment under age students were admitted who put considerable constraints on teaching style and efficiency and affects adversely the rates of student's progression. In grade 1 we have normally $60+$ students in one class with one teacher. Because of the strength teacher cannot satisfy students and they start disliking school environment results in high dropout.

It is interesting to mention that in grade 4 boys' dropout were $27 \%$ and girls $26 \%$, 'although it has been seen very often that girls' dropout increases in higher grades and boys dropout decreases.

\subsection{Result analysis}

\subsubsection{Appeared and Pass ratio}

The total pass percentage of Resource Center Mardan was computed $91 \%$ (boys $91 \%$ and girls $91 \%$ ). Total 17,622 students were enrolled in Resource Center Mardan during the academic year 2002-03, out of which 14,756 students appeared in the examination. The number of student declared successful was 13,409 (9,903 boys and 3,506 girls) and 1,289 students were declared fail in the exanimation ( 945 boys and 344 girls). 
Comparison of passed percentage

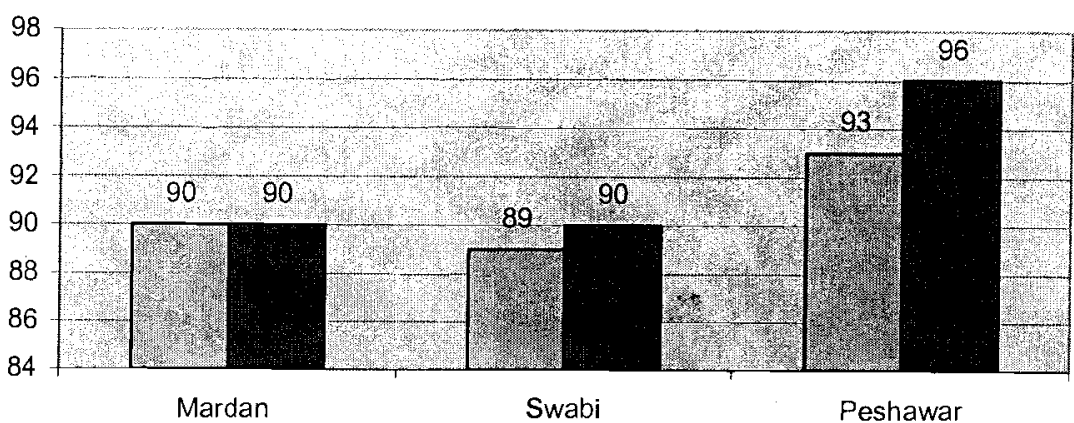

Dassed \% Boys Dassed \% Girls

The graph shows pass percentage for both genders in all districts of Resource Centre Mardan. In Peshawar district the pass percentage for boys and girls was calculated $93 \%$ and $96 \%$ respectively which was found to be the best in comparison to other districts, nonetheless an encouraging pass percentage were also recorded in the other districts. In Swabi district the pass percentage of boys was $89 \%$ in comparison to girls $90 \%$.

Detail statistics of appeared, not appeared, pass and pass percentages was computed and presented in tables separately for all districts in Resource Center Mardan and given below:

Table M6: Grade wise details of appeared and pass students in district Mardan

\begin{tabular}{|c|c|c|c|c|c|c|c|c|c|c|c|}
\hline \multirow{2}{*}{ 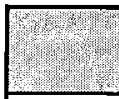 } & \multicolumn{3}{|c|}{ Appeared } & \multicolumn{3}{|c|}{ Not aporad } & \multirow{2}{*}{$\%$} & \multicolumn{2}{|c|}{ Passed } & \multicolumn{2}{|c|}{ Passed $\%$} \\
\hline & Boys & Gils & Total & Boys & girs. & Total & & Boys & Girls & Boys & Girs \\
\hline Grade I & 32 & & 3122 & 157 & 168 & 325 & $9 \%$ & 1863 & 858 & & $87 \%$ \\
\hline rade II & 1723 & 402 & 2205 & 71 & 30 & 101 & $4 \%$ & 1566 & 428 & $31 \%$ & $89 \%$ \\
\hline Grade III & 332 & 304 & 1716 & 45 & 19 & 64 & $4 \%$ & 1211 & 352 & & $92 \%$ \\
\hline Grade IV & 1028 & 246 & 1274 & 30 & 14 & 44 & $3 \%$ & 922 & 227 & & $92 \%$ \\
\hline rade $\mathrm{V}$ & 796 & 182 & 978 & 22 & 20 & 42 & $4 \%$ & 740 & 177 & $93 \%$ & $97 \%$ \\
\hline Grade VI & 586 & 78 & 664 & 16 & 8 & 24 & $3 \%$ & 550 & 78 & 9470 & $100 \%$ \\
\hline otal & 7,597 & 2,362 & 9959 & 341 & 259 & 600 & $6 \%$ & 6,852 & 2,120 & $90 \%$ & $90 \%$ \\
\hline
\end{tabular}

In district Mardan the total pass percentage for boys and girls was calculated $90 \%$ each. $87 \%$ boys and girls were declared successful in grade 1. Pass percentage in grade 1 was usually less in comparisons to other grades. Main reason for the comparatively low percentage could be the teacher students' ratio in grade 1, which is usually 1:60+ The pass percentage has increased in the higher levels specially for girls in grade 6 where it reaches to $100 \%$. 
Table M7: Grade wise details of appeared and pass students in district Peshawar

\begin{tabular}{|c|c|c|c|c|c|c|c|c|c|c|c|}
\hline & \multicolumn{3}{|c|}{ Appeared } & \multicolumn{3}{|c|}{ Not Apeared } & \multirow{2}{*}{$\begin{array}{l}\% \\
\%\end{array}$} & \multicolumn{2}{|c|}{ Passed } & \multicolumn{2}{|c|}{ Passed $\%$} \\
\hline & Boys & Gils & Total & Boys & Girls & Total & & Boys & Girls & Boys & Girls \\
\hline Grade I & 1071 & 181 & 1252 & 111 & 72 & 183 & $18 \%$ & 974 & 173 & $91 \%$ & $96 \%$ \\
\hline Grade II & 721 & 73 & 794 & 25 & 18 & 43 & $6 \%$ & 677 & 69 & $94 \%$ & $95 \%$ \\
\hline Grade III & 544 & 58 & 602 & 14 & 10 & 24 & $4 \%$ & 505 & 55 & $93 \%$ & $95 \%$ \\
\hline Grade IV & 390 & 31 & 421 & 14 & 19 & 33 & $8 \%$ & 370 & 31 & $95 \%$ & $100 \%$ \\
\hline Grade V & 304 & 23 & 327 & 7 & 4 & 11 & $3 \%$ & 293 & 23 & $96 \%$ & $100 \%$ \\
\hline Grade VI & 177 & 9 & 186 & 7 & 2 & 9 & $5 \%$ & 173 & 9 & $98 \%$ & $100 \%$ \\
\hline Total & 3,207 & 375 & 3,582 & 178 & 125 & 303 & $9 \%$ & 2,992 & 360 & $93 \%$ & $96 \%$ \\
\hline
\end{tabular}

The total pass rate calculated for boys and girls was $93 \%$ and $96 \%$ respectively. A significant pass percentage was to be seen for both boys and girls in all grades in district Peshawar. $100 \%$ girls have passed examination in grade 4, 5 and 6. The overall percentage of not appeared students was high $(9 \%)$. Not appeared percentage in girls was 33\%. Peshawar district showed high dropout rate $(25 \%$ boys and $27 \%$ girls) yielded in high percentage of not appeared students in exam.

Table M8: Grade wise details of appeared and pass students in district Swabi

\begin{tabular}{|c|c|c|c|c|c|c|c|c|c|c|c|}
\hline & \multicolumn{3}{|c|}{ Appeared } & \multicolumn{3}{|c|}{ Not apeared } & \multirow{2}{*}{$\frac{1}{2}$} & \multicolumn{2}{|c|}{ Passed } & \multicolumn{2}{|c|}{ Passed $\%$} \\
\hline & Boys & Gils & Total & Boys & Ginls & Total & & Boys & Girls & Boys & Girls \\
\hline Grade I & 52 & 370 & 422 & 3 & 50 & 53 & $11 \%$ & 47 & 339 & $90 \%$ & $92 \%$ \\
\hline Grade II & 14 & 174 & 188 & 2 & 10 & 12 & $6 \%$ & 12 & 151 & $86 \%$ & $87 \%$ \\
\hline Grade III & 0 & 46 & 46 & 0 & 0 & 0 & $0 \%$ & 0 & 43 & $0 \%$ & $93 \%$ \\
\hline Grade IV & 0 & 0 & 0 & 0 & 0 & 0 & $0 \%$ & 0 & 0 & $0 \%$ & $0 \%$ \\
\hline Grade V & 0 & 0 & 0 & 0 & 0 & 0 & $0 \%$ & 0 & 0 & $0 \%$ & $0 \%$ \\
\hline Grade VI & 0 & 0 & 0 & 0 & 0 & 0 & $0 \%$ & 0 & 0 & $0 \%$ & $0 \%$ \\
\hline Total & 66 & 590 & 656 & 5 & 60 & 65 & $9 \%$ & 59 & 533 & $89 \%$ & $90 \%$ \\
\hline
\end{tabular}

Not appeared students in district Peshawar and Swabi were calculated ( $9 \%$ ) and Mardan district $(6 \%)$. The passed percentage of girls $(90 \%)$ in comparison to boys (89\%) was promising.

\subsubsection{Graduation rate}

Graduation rate calculated in Resource Center Mardan for boys and girls was $81 \%$ and $74 \%$ respectively. (118) girls were enrolled in academic year $2002-2003$ in grade 6 , out of which $74 \%$ have successfully passed grade 6 Girls.

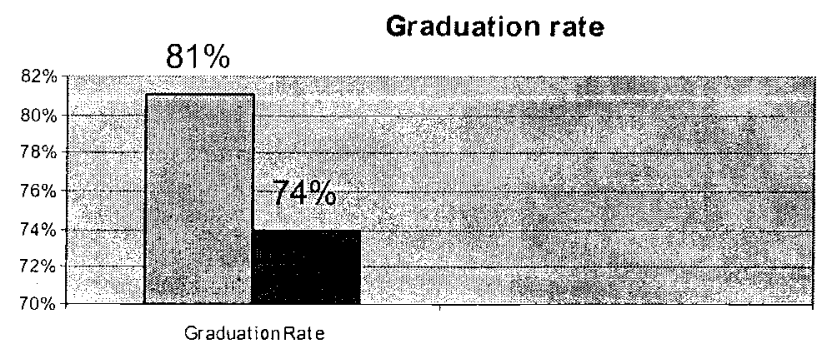

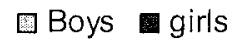


No Girl could have reached grade 6 in districts Charsadda, and swabi. As the schools were newly established and a batch has yet to reach grade 6

Table M9: Graduation rate

\begin{tabular}{|l|r|r|r|r|r|r|}
\hline \multirow{2}{*}{ District } & \multicolumn{2}{|c|}{ Enrollment in Grade 6 } & \multicolumn{2}{c|}{ Pass } & \multicolumn{2}{c|}{ Graduation Rate } \\
\cline { 2 - 7 } & \multicolumn{1}{|c|}{ Boys } & Girls & Boys & Girls & \multicolumn{1}{c|}{ Boys } & \multicolumn{1}{c|}{ Girls } \\
\hline Mardan & 664 & 96 & 550 & 78 & $83 \%$ & $81 \%$ \\
\hline Pehawar & 227 & 22 & 173 & 9 & $76 \%$ & $41 \%$ \\
\hline Total & $\mathbf{8 9 1}$ & $\mathbf{1 1 8}$ & $\mathbf{7 2 3}$ & $\mathbf{8 7}$ & $\mathbf{8 1 \%}$ & $\mathbf{7 4 \%}$ \\
\hline
\end{tabular}

\subsubsection{Students Performance in Subjects and grades}

Student's average marks in each subject and grade was computed and tabulated as given under for comparision.

\section{District Mardan}

Table M10. Subject wise distribution of average marks in district Mardan

\begin{tabular}{|c|c|c|c|c|c|c|c|c|c|c|c|c|}
\hline \multirow{2}{*}{ Subject } & \multicolumn{2}{|c|}{ Grade 1} & \multicolumn{2}{|c|}{ Grade 2} & \multicolumn{2}{|c|}{ Erade 3} & \multicolumn{2}{|c|}{ Grade 4} & \multicolumn{2}{|c|}{ Grade 5} & \multicolumn{2}{|c|}{ Grade 6} \\
\hline & Boys & Girls & Boys & Ehrs: & Boys & Girls & Bovs & Gins & Boys & Girs & Boys & Gins \\
\hline Urdu & my & 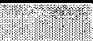 & 61 & 60 & 63 & 67 & 63 & 70 & 64 & 73 & 65 & 75 \\
\hline Mathematics & 64 & 60 & 62 & 58 & 59 & 58 & 60 & 66 & 57 & 66 & 59 & 76 \\
\hline Islamiat & 63 & 59 & 65 & 60 & 62 & 63 & 60 & 67 & 63 & 71 & 71 & 82 \\
\hline Drawing & 72 & 64 & 69 & 65 & 68 & 69 & 70 & 75 & 69 & 77 & 70 & 78 \\
\hline English & 60 & 2. & 59 & 56 & 62 & 64 & 59 & 65 & 61 & 64 & 61 & 70 \\
\hline Calligraphy & 70 & 62 & 69 & 62 & 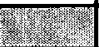 & 2037) & 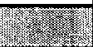 & 18 & VIf & & 217? & \\
\hline Sport & 80 & 71 & 82 & 70 & 80 & 78 & 82 & 83 & 83 & 79 & 84 & 87 \\
\hline Pashto & 62 & 60 & 60 & 59 & $\overrightarrow{60}$ & 61 & 65 & 68 & 63 & 70 & 71 & 83 \\
\hline Quran & 64 & 63 & 61 & 59 & 63 & $\overline{66}$ & 66 & 74 & 68 & 74 & 74 & 84 \\
\hline Social Study & Plen & 87 & 2017: & 18 & 64 & 210 & 61 & 70 & 62 & 73 & 64 & 81 \\
\hline General Science & 7. & & $\sqrt{212}$ & & 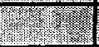 & 28 & 61 & $6 \hat{3}$ & 65 & 67 & 67 & 76 \\
\hline
\end{tabular}

Urdu subject was not offered in grade 1 . The maximum average marks $75 \%$ was obtained by girls' in grade 6 , while boys best performance (65\%) was to be observed in grade 6 as well. Performance in Urdu could fall in " $B$ " and " $C$ " category.

In Mathematic, in grade 1 boys average pass marks (64\%) was better than girls $(60 \%)$. In grade 2 the marks has further reduced to $58 \%$ for girls and $62 \%$ for boys. In grade 3 low average marks in mathematics was recorded that is $59 \%$ for boys and $58 \%$ for girls, as in higher grades the performance in mathematics has not improved and none of the student could get to " $A$ " in math in district Mardan.

In Islamiat, the average marks of students could fall in "B" was noted in grade 6 , $82 \%$ being scored by girls'. 
English is not offered in grade 1 . In grade 2 average obtained marks was $59 \%$ for boys and $56 \%$ for girls. In grade 3 students performance of both genders has improved and was documented $62 \%$ for boys and $64 \%$ for girls. In grade 4 , the average marks obtained has decreased in boys $59 \%$ and girls $65 \%$. None of the grades for both gender in English reached to $70 \%$ except girls in grade 6 . Students' performance in English was observed to be grade " $B$ " in district Mardan.

Average marks obtained in Pashto, in grade 1 were $62 \%$ for boys and $60 \%$ for girls. In grade 2 average marks got to $60 \%$ for boys and $59 \%$ for girls respectively. In upper grades the average performance has improved, in grade 6 girls obtained $83 \%$ marks and got to grade "A".

In social studies, except grade 6 girls $(81 \%)$ both the gender students in all grades got "B" Overall girls performance in grade 6 was impressive and was recorded in category "A"

\section{District Peshawar}

Table M11: Subject wise distribution of average marks in district Peshawar

\begin{tabular}{|c|c|c|c|c|c|c|c|c|c|c|c|c|}
\hline \multirow{2}{*}{ Subject } & \multicolumn{2}{|c|}{ Grade 1} & \multicolumn{2}{|c|}{ Grade 2} & \multicolumn{2}{|c|}{ Grade 3} & \multicolumn{2}{|c|}{ Grade 4} & \multicolumn{2}{|c|}{ Grade 5} & \multicolumn{2}{|c|}{ Grade 6} \\
\hline & Boys & Girls & Boys & Girls & Boys & Girls & Boys & Girls & Boys & Girls & Boys & Girls \\
\hline Urdu & & e & 68 & 72 & 69 & 80 & 67 & 78 & 70 & 90 & 74 & 91 \\
\hline Mathematics & 40 & 65 & 66 & 69 & 67 & $\overline{73}$ & 59 & 66 & 60 & 71 & 65 & 80 \\
\hline |slamiat & 67 & 68 & 65 & 69 & 68 & 83 & 67 & 67 & 71 & 89 & 85 & 88 \\
\hline Drawing & 69 & 83 & 70 & 93 & 72 & $\overline{82}$ & 78 & 82 & 70 & 97 & 74 & 89 \\
\hline English & 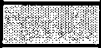 & 38 & 63 & 61 & 66 & 71 & 66 & 70 & 68 & 83 & 67 & 83 \\
\hline Calligraphy & 72 & 71 & 68 & 79 & 32 & 2 & Exy & 2 & 7 & 0 & 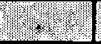 & m \\
\hline Sport & 86 & 98 & 85 & 97 & 87 & 98 & 89 & 90 & 90 & 100 & 91 & 95 \\
\hline Pashto & 64 & 60 & 61 & 67 & 63 & 73 & 66 & 83 & 62 & 91 & 78 & 88 \\
\hline Quran & 69 & 63 & 65 & 78 & 69 & 69 & 66 & 71 & 70 & 87) & 76 & 98 \\
\hline Social Study & 2. & 20 & 27 & (2): & 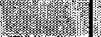 & 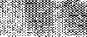 & 65 & 64 & 67 & 80 & 74 & 93 \\
\hline General Science & 랄 & Th & 28: & 201 & (2) & 20 & 66 & 63 & 64 & 85 & 70 & 91 \\
\hline
\end{tabular}

In Urdu Girls' performance in grade 6 noted to be appreciative and in comparison to boys their performance was better and acquired grade " $A$ " in all subjects. In grade 2 , boys obtained $68 \%$ average marks while girls $72 \%$, the total average marks girls were better than boys in all grades.

In Mathematics, boys in grade 1 , obtained $40 \%$ marks and were put into category "D" girls performance in mathematics was better than boys.

In Islamiat, girls' average marks (88\%) was higher in grade 6 while for boys $(85 \%)$ was recorded as the maximum in grade 6 . Student's performance in islamiat falls in category "B" except for girls in grade 3, 5 and 6 who obtained grade "A". 
The total girls' performance, in English was observed to be better than boys, notwithstanding the highest average marks $83 \%$ was scored by girls in grade 6 . In general girls in grade 5 and 6 would come under category " $A$ " and boys in "B".

Boys' performance in Pashto was very low in comparison to girls. Girls obtained $70+$ to $80 \%$ average marks in all grades while boys could only get $60+$ to 70 .

Social Study and General Science is offered to student in grade 4 and above. The performance of girls in grade 5 and 6 in both subjects was observed to be better than boys. Boys' performance was found to be improving as promoted to higher grades.

\section{District Swabi}

Table M12: Subject wise distribution of average marks in district Swabi

\begin{tabular}{|c|c|c|c|c|c|c|c|c|c|c|c|c|}
\hline \multirow{2}{*}{ Subject } & \multicolumn{2}{|c|}{ Grade 1} & \multicolumn{2}{|c|}{ Grade 2} & \multicolumn{2}{|c|}{ Grade 3} & \multicolumn{2}{|c|}{ Grade 4} & \multicolumn{2}{|c|}{ Grade 5} & \multicolumn{2}{|c|}{ Grade 6} \\
\hline & Boys & Girls & Boys & Gitls: & Boys & Girls & Boys & Girls & Boys & Girls & Boys & Girls \\
\hline Urdu & 2 & 2 & 67 & 64 & & 70 & & & & & & \\
\hline Mathematics & 64 & 59 & 62 & 62 & & 54 & & & & & & \\
\hline Islamiat & 65 & 63 & 63 & 64 & & 60 & & & & & & \\
\hline Drawing & 65 & 54 & 55 & 59 & & 61 & & & & & & \\
\hline English & & 2 & 66 & 63 & & 90 & & & & & & \\
\hline Calligraphy & 67 & 52 & 69 & 66 & 88 & 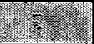 & 6is & $\sqrt{8+25}$ & 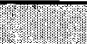 & (3) & Fipex & 2 \\
\hline Sport & 62 & 64 & 83 & 70 & & 67 & & & & & & \\
\hline Pashto & 61 & 58 & 64 & 62 & & 64 & & & & & & \\
\hline Quran & 61 & 57 & 68 & 65 & & 64 & & & & & & \\
\hline Social Study & 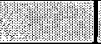 & $2 x=2$ & ? & 6- & re & a] & & & & & & \\
\hline General Science & 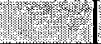 & 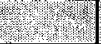 & 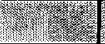 & $x=1$ & Coxt & 1.2x-2. & & & 3 & & & \\
\hline
\end{tabular}

Schools in Swabi district are for girls' and containing a nominal number of boys' students as well. Boys and girls performance was almost the same in all subjects. As the students advanced to higher grades the average performance of students was observed to be improving. 


\section{Resource Centre Peshawar}

\subsection{Enrollment}

Total enrollment in Peshawar Resource Centre was recorded 40,170 included $28,738(71 \%)$ boys and 11,432. (29\%) girls. Peshawar Resource Center contribution to the total enrollment 123,660 was $30 \%$. Peshawar Resource Centre was ahead in enrollment among all Resource Centers. Out of total 40,170 students 37,955 were fresh entrants and 2,215 were repeaters (failed students). The percentage of repeater was calculated as $6 \%$ for boys and $5 \%$ for girls. The percentage of repeating students had decreased as compared to the last year that was (9\%). Girls' enrollment had increased from $28 \%$ to $29 \%$.

Resource Center Peshawar comprised of two districts namely, Nowshera, and Peshawar including one agency that is Khyber agency (Shalman camp). In Shalman camp schools were established in emergency situation in January 2002. After the US led coalition attacked Afghanistan thousands of refugees arrived in Pakistan who were accommodated in emergency camps in NWFP. Shalman camp is one of those camps where seven schools were established.

Table P1: Distribution of students by districts

\begin{tabular}{|l|r|r|r|r|r|r|r|r|r|}
\hline \multirow{2}{*}{ District } & \multicolumn{4}{|c|}{ Enrolled } & \multicolumn{4}{|c|}{ Repeater } & \multicolumn{3}{|c|}{ Fresh enrollment } \\
\cline { 2 - 10 } & Boys & Girls & Total & Boys & Girls & Total & Boys & Girls & \multicolumn{1}{c|}{ Total } \\
\hline Nowshera & 1,996 & 854 & 2,850 & 103 & 37 & 140 & 1,893 & 817 & 2,710 \\
\hline Peshawar & 24,687 & 9,182 & 33,869 & 1,579 & 496 & 2,075 & 23,108 & 8,686 & 31,794 \\
\hline Khyber agenn & 2,055 & 1,396 & 3,451 & - & - & - & 2,055 & 1,396 & 3,451 \\
\hline Total & $\mathbf{2 8 , 7 3 8}$ & 11,432 & $\mathbf{4 0 , 1 7 0}$ & $\mathbf{1 , 6 8 2}$ & $\mathbf{5 3 3}$ & $\mathbf{2 , 2 1 5}$ & $\mathbf{2 7 , 0 5 6}$ & $\mathbf{1 0 , 8 9 9}$ & $\mathbf{3 7 , 9 5 5}$ \\
\hline
\end{tabular}

Girls' constituted $29 \%(10,899)$ to the total fresh enrollment 37,955 . Peshawar district has the highest numbers of girls' students $(9,182)$ and the lower number of girls' enrollment (854) was noted in Nowshera districts.

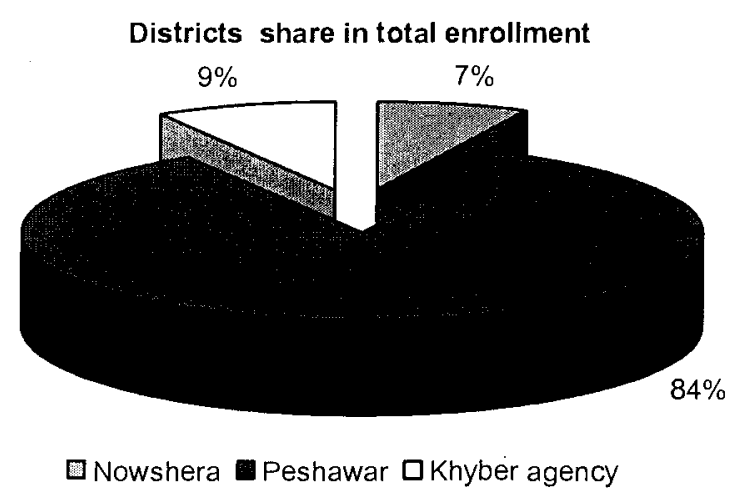


Peshawar district comprised of $84 \%$ of the total enrollment in Peshawar Resource Centre. Nowshera contributed $7 \%$ and Shalman $9 \%$.

\subsection{Dropout}

The total dropout ratio calculated in Peshawar was $26 \%$ boys and $31 \%$ girls. In academic year 2002-2003 Resource Centre Peshawar was having the highest dropout rate. Girls' dropout rate was $31 \%$ while boys were $26 \%$ comparing to last year dropout rate which was (9\%) boys and $(25 \%)$ girls. Increase in dropout rate was due to the repatriation campaign in Peshawar Resource Centre.

Table P2 indicates very high dropout in Nowshera districts which was computed $51 \%$ in boys and $52 \%$ in girls.

Table P2: Districts wise dropout of students

\begin{tabular}{|l|c|r|r|r|r|r|}
\hline \multirow{2}{*}{ Districts } & \multicolumn{2}{|c|}{ Enrolled } & \multicolumn{2}{c|}{ Dropped } & \multicolumn{2}{c|}{ Dropout in \% } \\
\cline { 2 - 7 } & Boys & Girls & Boys & Girls & Boys & Girls \\
\hline Nowshera & 1996 & 854 & 1010 & 448 & $51 \%$ & $52 \%$ \\
\hline Peshawar & 24,687 & 9,182 & 5,116 & 2,591 & $21 \%$ & $28 \%$ \\
\hline Khyber agency & 2,055 & 1,396 & 758 & 517 & $37 \%$ & $37 \%$ \\
\hline Total & $\mathbf{2 6 , 7 4 2}$ & 11432 & 6884 & $\mathbf{3 5 5 6}$ & $\mathbf{2 6 \%}$ & $\mathbf{3 1 \%}$ \\
\hline
\end{tabular}

The graph indicates $50 \%$ dropout in Nowshera district. We had 3 schools one for boys and two were co-education in Nowshera. These schools were in one camp. All the students were from one caste (Hazara). Most of them had left for their homeland after establishment of government by Persian.

\section{District wise drop out}

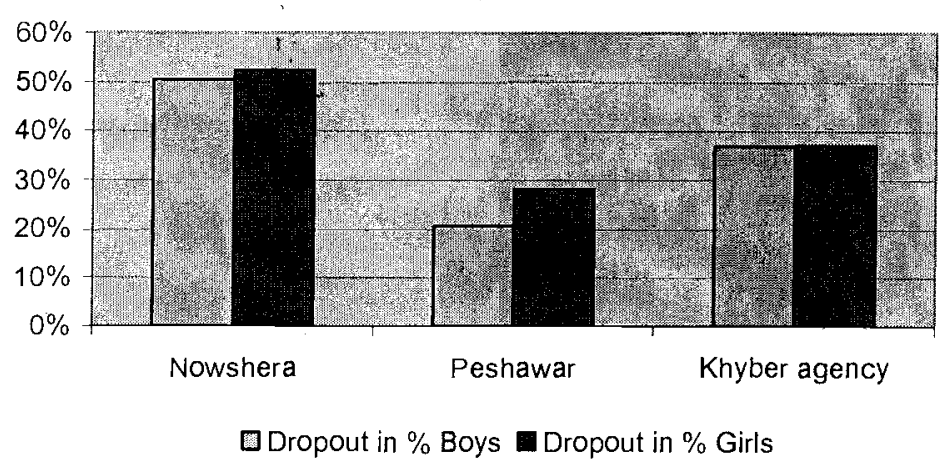

In Khyber agency (Shalman camp) the dropout rate for girls and boys was 37\% for both. Peshawar district calculated figure was $21 \%$ for boys' and $28 \%$ for girls. 


\section{Grade wise dropout statistic of all districts in Peshawar}

Table P3: Grade wise dropout details of district Peshawar

\begin{tabular}{|l|r|r|r|r|r|r|}
\hline & \multicolumn{2}{|c|}{ Enrolled } & \multicolumn{2}{c|}{ Dropped } & \multicolumn{2}{|c|}{ Dropout in \% } \\
\cline { 2 - 7 } & Boys & Girls & Boys & Girls & Boys & Girls \\
\hline Grade I & 7,305 & 4,298 & 1222 & 1248 & $17 \%$ & $29 \%$ \\
\hline Grade II & 5,784 & 1,783 & 1291 & 515 & $22 \%$ & $29 \%$ \\
\hline Grade III & 4,281 & 1,168 & 967 & 255 & $23 \%$ & $22 \%$ \\
\hline Grade IV & 3,372 & 882 & 773 & 248 & $23 \%$ & $28 \%$ \\
\hline Grade V & 2,361 & 662 & 555 & 191 & $24 \%$ & $29 \%$ \\
\hline Grade VI & 1,584 & 389 & 308 & 134 & $19 \%$ & $34 \%$ \\
\hline Total & $\mathbf{2 4 , 6 8 7}$ & $\mathbf{9 , 1 8 2}$ & $\mathbf{5 , 1 1 6}$ & $\mathbf{2 , 5 9 1}$ & $\mathbf{2 1 \%}$ & $\mathbf{2 8 \%}$ \\
\hline
\end{tabular}

The dropout in Peshawar district varies among grades. The overall dropout noticed in the district was $21 \%$ for boys and $28 \%$ for girls. In girls the dropout rate in grade 1, 2, 5 was 29\%. In grade 6 it had reached to $34 \%$. In grade 3 the dropout rate was estimated $22 \%$.

In boys the dropout rate in grade1, 6 was less $17 \%$ and $19 \%$ respectively. In grade 3, 4 and 5 the dropout rate had risen to $24 \%$. Two camps Nasir bagh and Kacha Gari were demolished. Many people repatriated to their homeland while some shifted to urban Peshawar.

Table P4: Grade wise dropout details of district Nowshera

\begin{tabular}{|l|r|r|r|r|r|r|}
\hline & \multicolumn{2}{|c|}{ Enrolled } & \multicolumn{2}{c|}{ Droped } & \multicolumn{2}{c|}{ Dropout in \% } \\
\cline { 2 - 7 } & Boys & Girls & Boys & Girls & Boys & Girls \\
\hline Grade I & 780 & 551 & 636 & 285 & $82 \%$ & $52 \%$ \\
\hline Grade II & 475 & 147 & 105 & 56 & $22 \%$ & $38 \%$ \\
\hline Grade III & 270 & 69 & 69 & 69 & $26 \%$ & $100 \%$ \\
\hline Grade IV & 232 & 47 & 98 & 27 & $42 \%$ & $57 \%$ \\
\hline Grade V & 156 & 16 & 69 & 0 & $44 \%$ & $0 \%$ \\
\hline Grade V! & 83 & 24 & 33 & 11 & $40 \%$ & $46 \%$ \\
\hline Total & 1,996 & $\mathbf{8 5 4}$ & $\mathbf{1 0 1 0}$ & $\mathbf{4 4 8}$ & $\mathbf{5 1 \%}$ & $\mathbf{5 2 \%}$ \\
\hline
\end{tabular}

The overall dropout rate in Nowshera district (50\%) was noticed the highest in all the 6 Resource Centers. This high dropout had severely affected the functionality of schools.

Table P5: Grade wise dropout details of Khyber Agency ( Shalman )

\begin{tabular}{|l|r|r|r|r|r|r|}
\hline & \multicolumn{2}{|c|}{ Enrolled } & \multicolumn{2}{c|}{ Dropped } & \multicolumn{2}{|c|}{ Dropout in \% } \\
\cline { 2 - 7 } & Boys & Girls & Boys & Girls & Boys & Girls \\
\hline Grade I & 1,115 & 1,094 & 260 & $\mathbf{3 8 1}$ & $23 \%$ & $35 \%$ \\
\hline Grade II & 461 & 253 & 237 & 122 & $51 \%$ & $48 \%$ \\
\hline Grade III & 200 & 46 & 100 & 11 & $50 \%$ & $24 \%$ \\
\hline Grade IV & 207 & 3 & 130 & 3 & $63 \%$ & $100 \%$ \\
\hline Grade V & 49 & 0 & 31 & 0 & $63 \%$ & $0 \%$ \\
\hline Grade VI & 23 & 0 & 0 & 0 & $0 \%$ & $0 \%$ \\
\hline Total & $\mathbf{2 , 0 5 5}$ & $\mathbf{1 , 3 9 6}$ & $\mathbf{7 5 8}$ & $\mathbf{5 1 7}$ & $\mathbf{3 7 \%}$ & $\mathbf{3 7 \%}$ \\
\hline
\end{tabular}


Shalman was an emergency education program; the dropout rate in grade 1 was comparatively low to the upper grades. In boys the dropout rate in grade 1 was $23 \%$, in grade 2 was $51 \%$ and $50 \%$ was in grade 3 . In grade 4 and 5 it was gone up to $63 \%$. In Shalman camp girls dropout showed high variation. In grade 1 $(35 \%)$ grade $2(48 \%)$ In grade 3 dropout was $24 \%$ and in grade $4(100 \%)$ of the female students were dropped from schools.

Grade wise drop out in different district

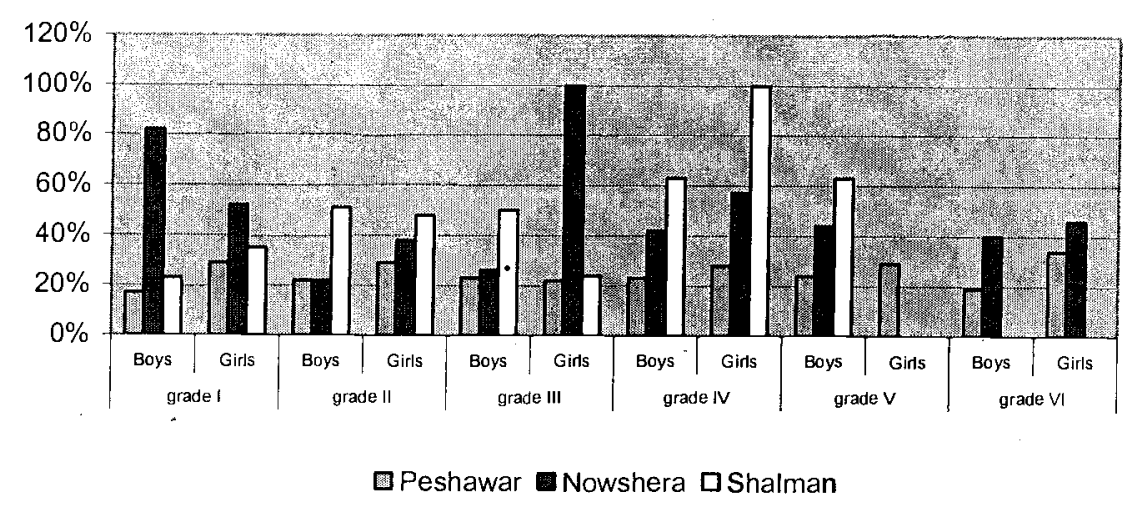

Highest dropout rates were found in all grades in district Nowshera. In Shalman camp the dropout rate has increased very much in grade 5 .

\subsection{Result analysis}

\subsubsection{Appeared and Pass ratio}

Total pass percentage of Resource Center Peshawar was computed $91 \%$. 40,170 students were enrolled in Resource Center Peshawar during the academic year 2002-03, out of which 28,244 students appeared in the examination. 26,130 students (19,328 boys and 6,802 girls) were declared successful and 2,114 students could not qualify in the examination $(1,616$ boys and 498 girls).

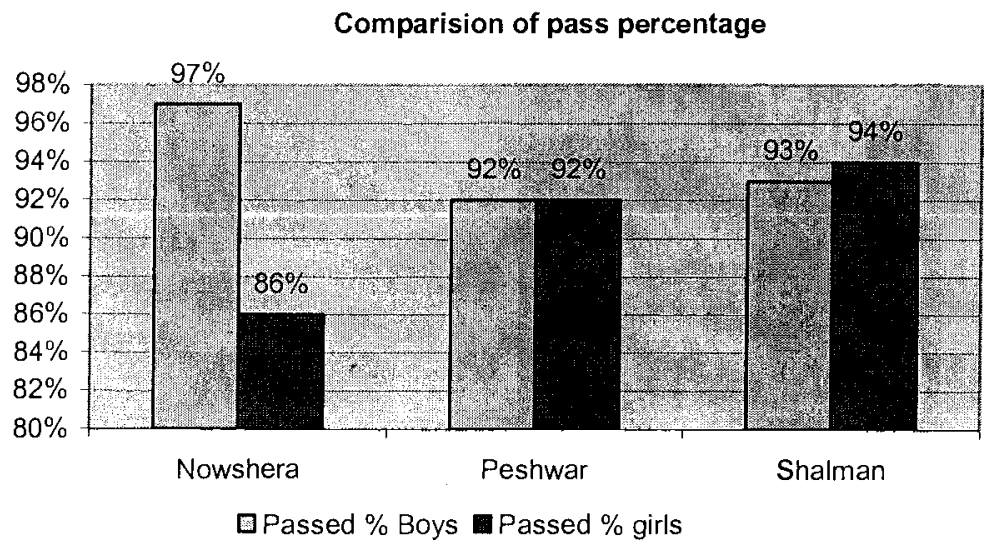


The graph shows pass percentage for both genders in all districts of Resource Centre Peshawar. In Peshawar district the pass percentage for boys and girls was calculated $93 \%$ and $96 \%$ respectively which was found to be the best in comparison to other districts; however an impressive pass percentage was also recorded in the other districts. In Nowshera district the pass percentage of girls $(86 \%)$ in comparison to boys $(97 \%)$ was found as less.

Detail statistics of appeared, not appeared, pass and pass percentages was computed and presented in tables separately for all districts in Resource Center Peshawar as under.

Table P6: Grade wise details of appeared and pass students in district Nowshera

\begin{tabular}{|c|c|c|c|c|c|c|c|c|c|c|c|}
\hline & \multicolumn{3}{|c|}{ Appeared } & \multicolumn{3}{|c|}{ Not Apeared } & \multicolumn{3}{|c|}{\begin{tabular}{|l|l|} 
& Passed \\
\end{tabular}} & \multicolumn{2}{|c|}{ Passed \% } \\
\hline & Boys & Gils & Total & Boys & Girls & Total & $9 \%$ & Boys & Girls & Boys & Girls \\
\hline Grade I & 442 & 251 & 693 & 48 & 15 & 63 & $15 \%$ & 440 & 212 & $100 \%$ & $84 \%$ \\
\hline Grade II & 354 & 84 & 438 & 16 & 7 & 23 & $5 \%$ & 336 & 77 & $95 \%$ & $92 \%$ \\
\hline Grade III & 197 & 26 & 223 & 4 & 4 & 8 & $4 \%$ & 186 & 21 & $94 \%$ & $81 \%$ \\
\hline Grade IV & 129 & 20 & 149 & 5 & 0 & 5 & $3 \%$ & 120 & $\overline{14}$ & $93 \%$ & $70 \%$ \\
\hline Grade V & 81 & 16 & 97 & 6 & 0 & 6 & $6 \%$ & 80 & 15 & $99 \%$ & $94 \%$ \\
\hline Grade VI & 46 & 13 & 59 & 4 & 0 & 4 & $6 \%$ & 46 & $\overline{12}$ & $100 \%$ & $92 \%$ \\
\hline Total & 1,249 & 410 & 1,659 & $8+83$ & 26 & 109 & $8 \%$ & 1,208 & 351 & $97 \%$ & $86 \%$ \\
\hline
\end{tabular}

Total pass percentage noted for boys $(97 \%)$ and for girls $(86 \%)$ in Nowshera district. It is very encouraging to mention that boys pass percentage in grade 1 was $100 \%$ usually a low pass percentage has been experienced in grade 1 . $(84 \%)$ girls were passed in grade 1 , while in grade 4 the pass percentage in girls' was $70 \%$.

Table P7: Grade wise details of appeared and pass students in district Peshawar

\begin{tabular}{|c|c|c|c|c|c|c|c|c|c|c|c|}
\hline & \multicolumn{3}{|c|}{ Appeared } & \multicolumn{3}{|c|}{ Not Apeared } & 398. & \multicolumn{2}{|c|}{ Passed } & \multicolumn{2}{|c|}{ Passed $\%$} \\
\hline & Boys & Girls & Total & Bovs & Girls & Total & $7 \%$ & Boys & Girls & Boys & Gris \\
\hline Grade I & 5707 & 2809 & 8516 & 376 & 241 & 617 & 7 & 5044 & 2436 & $88 \%$ & $87 \%$ \\
\hline Grade II & 4204 & 1197 & 5401 & 289 & 71 & 360 & 6 & 3895 & 1201 & $93 \%$ & $100 \%$ \\
\hline Grade III & 3162 & 889 & 4051 & 152 & 24 & 176 & 4 & 2941 & 803 & $93 \%$ & $90 \%$ \\
\hline Grade IV & 2497 & 608 & 3105 & 102 & 26 & 128 & 4 & 2299 & 576 & $92 \%$ & $95 \%$ \\
\hline Grade V & 1737 & 455 & 2192 & 69 & 16 & 85 & 4 & 1649 & 423 & $95 \%$ & $93 \%$ \\
\hline Grade VI & 1216 & 254 & 1470 & 60 & 1 & 61 & 4 & 1198 & 253 & $99 \%$ & $100 \%$ \\
\hline Total & 18,523 & 6,212 & 24,735 & 1,048 & 379 & 1.427 & 5 & 17,026 & 5,692 & $92 \%$ & $92 \%$ \\
\hline
\end{tabular}

In district Peshawar overall pass percentage of boys and girls was $92 \%$. In grade 2 and $6100 \%$ girls had passed the examination, while in grade $3(90 \%)$ was the notable figure. 
Table P8: Grade wise details of appeared and pass students in Khyber agency (Shalman Camp)

\begin{tabular}{|c|c|c|c|c|c|c|c|c|c|c|c|}
\hline & \multicolumn{3}{|c|}{ Appeared } & \multicolumn{3}{|c|}{ Not Apeared } & & \multicolumn{2}{|c|}{ Passed } & \multicolumn{2}{|c|}{ Passed \% } \\
\hline & Boys & Gils & Total & Boys & Girls & Total & $\%$ & Boys & Girls & Boys & Gîls \\
\hline rade I & 784 & 527 & 1311 & 71 & 186 & 257 & $16 \%$ & 738 & 506 & $94 \%$ & 96 \\
\hline \begin{tabular}{|l} 
Grade II \\
\end{tabular} & 196 & 116 & 312 & 28 & 15 & 43 & $12 \%$ & 191 & 100 & $97 \%$ & 86 \\
\hline Grade III & 89 & 35 & 124 & 11 & 0 & 11 & $8 \%$ & 86 & 32 & $97 \%$ & 91 \\
\hline Grade IV & 66 & 0 & 66 & 11 & 0 & 11 & $14 \%$ & 65 & 0 & $98 \%$ & $0^{\circ}$ \\
\hline Grade V & 15 & 0 & 15 & 3 & 0 & 3 & $17 \%$ & 14 & 0 & $93 \%$ & 0 \\
\hline Grade VI & 22 & 0 & 22 & 1 & 0 & 1 & $4 \%$ & 21 & 0 & $95 \%$ & $0 \%$ \\
\hline Total & 1,172 & 678 & 1,850 & 125 & 201 & 326 & $15 \%$ & 1,115 & 638 & $95 \%$ & $94 \%$ \\
\hline
\end{tabular}

Shalman camp was an emergency camp. BEFARe established schools in that camp in January 2002. Pass percentage in all grades for boys was observed to be above $90 \%$ whereas $94 \%$ in grade $1,97 \%$ in grade 2 and 3 . Pass percentage for boys in grade 6 was $95 \%$. 96\% girls passed grade $1,86 \%$ grade 2 and $91 \%$ had passed grade 3 .

Not appeared students in exam was (15\%) high in Shalman camp. Repatriation in shalman was high because of the extreme weather and withdrawal of organizations providing relief and humanitarian assistance for the camp.

\subsubsection{Graduation rate}

Graduation rate calculated in Resource Center Peshawar for boys and girls was $75 \%$ and $64 \%$ respectively. 1,690 boys were enrolled in academic year $2002-$ 2003 in grade 6 , out of which $75 \%$ have successfully passed grade 6 . While (413) girls were enrolled out of which $64 \%$ had successfully been graduated.

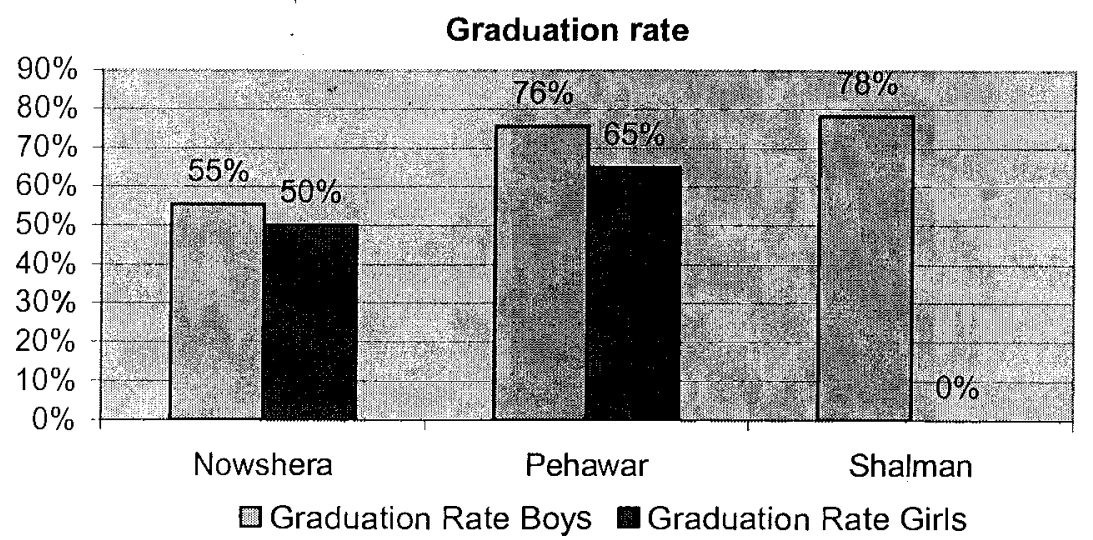

No Girl was enrolled in Shalman camp in grade 6. The graduation rate in Nowshera district was $55 \%$ for boys and $50 \%$ for girls. Overall performance of Nowshera district was not satisfactory. Peshawar district also showed low 
graduation rate. Major reason could be the demolishment of kacha gari camp in examination period.

\subsubsection{Students Performance in subjects and grades}

Student's average marks in each subject and grade was computed and tabulated as given under for comparison.

\section{District Nowshera}

Table P9. Subject wise distribution of average marks in district Nowshera

\begin{tabular}{|c|c|c|c|c|c|c|c|c|c|c|c|c|}
\hline \multirow{2}{*}{ Subject } & \multicolumn{2}{|c|}{ Grade 1} & \multicolumn{2}{|c|}{ Grade? } & \multicolumn{2}{|c|}{ Grades } & \multicolumn{2}{|c|}{ Grade 4} & \multicolumn{2}{|c|}{ Grade 5} & \multicolumn{2}{|c|}{ Grade 6} \\
\hline & Boys & Girls & Boys & Girs & Boys & Girs & Boys & Girls & Boys & Girls & Boys & Girls \\
\hline Urdu & 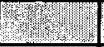 & 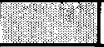 & 59 & 84 & 70 & 56 & 72 & 72 & 69 & 69 & 69 & 77 \\
\hline Mathematics & 63 & 68 & 64 & 76 & 59 & 69 & 52 & 55 & 50 & 47 & 61 & 54 \\
\hline Islamiat & 68 & 70 & 63 & 76 & 70 & 76 & 65 & 68 & 71 & 68 & 81 & 88 \\
\hline Drawing & 71 & 80 & 78 & 79 & 69 & 66 & 82 & 73 & 82 & 85 & 75 & 81 \\
\hline English & 19.20 & 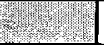 & 53 & 78 & 71 & 77 & 62 & 44 & 68 & 57 & 65 & 53 \\
\hline Calligraphy & 68 & 78 & 69 & 85 & 21 & & & 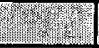 & 20 & Xive & 2 & \\
\hline Sport & 88 & 93 & 89 & 97 & 90 & 92 & 90 & 100 & 87 & 100 & 93 & 100 \\
\hline Pashto & 62 & 68 & 52 & 79 & 63 & 82 & 64 & 61 & 54 & 76 & 71 & 81 \\
\hline Quran & 62 & 69 & 57 & 81 & 69 & 73 & 73 & 69 & 68 & 82 & 84 & 81 \\
\hline Social Study & 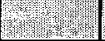 & & II & & & & 60 & 46 & 71 & 48 & 74 & 75 \\
\hline General Science & (1) & 4 & (2) & 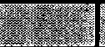 & 207 & 2 & 73 & 66 & 65 & 59 & 77 & 69 \\
\hline
\end{tabular}

Boys $59 \%$ performance in Urdu was very low in comparison to girls $84 \%$ and are accounted in category "A" whereas boys were put into " $C$ ". In higher grades a decreasing trend in average marks were noticed in girls' performance.

In Mathematic, the maximum average marks were to be seen in grade 2 obtained by girls $(76 \%)$ and minimum marks were recorded in grade 5 girls $(47 \%)$. However, girls performed poorly in higher grades. Overall students of both genders in mathematics could not perform well and were placed in category " $\mathrm{C}$ ".

In Islamiat and the Quran boys and girls average marks were in 60 s and 70 s thus came under category " $B$ ", except in grade 6 where both the gender performed well and fall in category " $A$ "

Girls' performance in English in grade 4 was recorded 44\%. In higher grades both genders performance in English was noticed to be decreasing.

Average marks in Pashto was recorded to be increasing in upper grades and falls in category "B", while in grade 1 and 2 it was noted to be put in "C" Although Pashto is the first language still students performance did not show any significant change from second language subjects. 
Girls' average marks in social studies in grade 4 and 5 were $48 \%$ and falls in category " $C$ " while in grade 6 their performance had improved (75\%). Boys with "B" grade performance was better in general science than girls, who fall in category "C".

\section{District Peshawar}

Table P10: Subject wise distribution of average marks in district Peshawar

\begin{tabular}{|c|c|c|c|c|c|c|c|c|c|c|c|c|}
\hline \multirow{2}{*}{ Subject } & \multicolumn{2}{|c|}{ Grade 1} & \multicolumn{2}{|c|}{ Grade 2} & \multicolumn{2}{|c|}{ Grade 3} & \multicolumn{2}{|c|}{ Crade 4} & \multicolumn{2}{|c|}{ Grade 5} & \multicolumn{2}{|c|}{ Grade 6} \\
\hline & Boys & Girls & Boys & Gins & Boys & Girls & Boys & Girls & Boys & Girls & Boys & Girls \\
\hline Urdu & 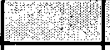 & 2.7? & 64 & 68 & 67 & 73 & 66 & 70 & 68 & 74 & 68 & 75 \\
\hline Mathematics & 61 & 60 & 62 & 67 & 59 & 63 & 62 & 66 & 59 & 62 & 61 & 70 \\
\hline Islamiat & 63 & 62 & 62 & 66 & 63 & 66 & 61 & 66 & 69 & 72 & 76 & 80 \\
\hline Drawing & 71 & 72 & 75 & 75 & 74 & 80 & 77 & 80 & 80 & 84 & 82 & 91 \\
\hline English & 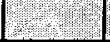 & 2 & 62 & 62 & 65 & 66 & 63 & 66 & 62 & 63 & 65 & 67 \\
\hline Calligraphy & 68 & 70 & 71 & 70 & & 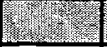 & ren & 17y: & (2) & & 20 & $\sqrt{12}$ \\
\hline Sport & 83 & 87 & 88 & 86 & 88 & 89 & 92 & 92 & 93 & 92 & 93 & 93 \\
\hline Pashto & 62 & 61 & 61 & 65 & 63 & 63 & 66 & 70 & 66 & 72 & 71 & 80 \\
\hline Quran & 60 & 62 & 60 & 66 & 63 & 68 & 68 & 70 & 71 & 76 & 75 & 82 \\
\hline Social Study & 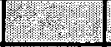 & 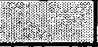 & & 12 & 3 & -1) & 61 & 67 & 65 & 70 & 68 & 71 \\
\hline General Science & Prepry & 25: & & 8 & 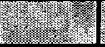 & T-2 & 63 & 66 & 63 & 69 & 67 & 79 \\
\hline
\end{tabular}

Table P10 shows average marks obtained in different subjects in district Peshawar. Maximum marks obtained in Urdu were $75 \%$ in grade 6 scored by girls, while minimum marks (64\%) were recorded in grade 2 by boys.

In Mathematic, the highest marks (70\%) were recorded in grade 6 by girls. In general students' performance in all grades fall in category "B".

In Islamiayat and the Quran, students' performance was accounted in category "B" except the girls student of grade 6 whose marks fall in "A" category. It was always assumed that refugees communities are interested in religious education and attach due importance to it. Students were attending madrassas and mosque as well; still in all grades students' average marks in religious education was observed to be less in comparison to other subjects.

The average marks in English were reflected to be $70 \%$ by both genders in all grades from district Peshawar.

In Social Studies and General Science, students performance in all grades were observed to be placed in category "B", nonetheless science subjects are practical oriented and interesting subjects and students were supposed to have performed better. 


\section{Khyber agency (Shalman camp)}

In Shalman camp the average marks could be seen in 60 s and 70 s. In Urdu girls' average marks were computed to be better than boys. Girls' from grade 2 and 3 have scored in 70s while boys score was found to be in 60s. Boys performed poor in grade 5 and 6 and were placed in category " $C$ ".

Table P11: Subject wise distribution of average marks in Shalman camp

\begin{tabular}{|c|c|c|c|c|c|c|c|c|c|c|c|c|}
\hline \multirow{2}{*}{ Subject } & \multicolumn{2}{|c|}{ Grade 1} & \multicolumn{2}{|c|}{ Grade 2} & \multicolumn{2}{|c|}{ Grade 3} & \multicolumn{2}{|c|}{ Grade 4} & \multicolumn{2}{|c|}{ Grade 5} & \multicolumn{2}{|c|}{ Grade 6} \\
\hline & Boys & Girls & Boys & Girs & Boys & Girls & Boys & Girls & Boys & Girls & Boys & Girls \\
\hline Urdu & 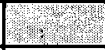 & 2.8 & 61 & 70 & 64 & 74 & 70 & - & 54 & - & 52 & - \\
\hline Mathematics & 58 & 56 & 63 & 57 & 66 & 63 & 65 & - & 69 & - & 57 & - \\
\hline Islamiat & 56 & 57 & 68 & 61 & 66 & 74 & 71 & - & 68 & - & 66 & - \\
\hline Drawing & 63 & 68 & 71 & 63 & 74 & 79 & 77 & - & 65 & - & 73 & - \\
\hline English & 47 & (2) & 62 & 63 & 67 & 76 & 65 & - & 43 & - & 46 & - \\
\hline Calligraphy & 65 & 65 & 72 & 67 & 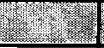 & 3. & & III: & 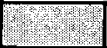 & promenty & 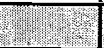 & 28 \\
\hline Sport & 79 & 77 & 76 & 88 & 84 & 93 & 90 & - & 85 & - & 93 & - \\
\hline Pashto & 63 & 56 & 65 & 57 & 71 & 74 & 73 & - & 73 & - & 66 & - \\
\hline Quran & 55 & 55 & 63 & 62 & 66 & 73 & 73 & - & 80 & - & 85 & - \\
\hline Social Study & 2 & P. & 32. & 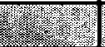 & 89 & & 75 & - & 82 & - & 73 & - \\
\hline General Science & & (2) & rem & 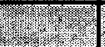 & 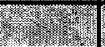 & 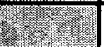 & 69 & - & 67 & - & 71 & - \\
\hline
\end{tabular}

Girls' performance trend in mathematics was found to be increasing in the higher grades. Both boys and girls performance in mathematics come under category "B".

In Islamiat and the Quran, students' performance in grade1 falls in category " $\mathrm{C}$ ". Going along the higher grades predominantly an upward trend could be observed for both boys and girls.

Boys performance in English in grade 5 and 6 falls in category " $C$ " while girls obtained $76 \%$ average marks in grade 3 ,

The performance of students in grade 1 and 2 could be termed unsatisfactory in Pashto and were set to come under category " $\mathrm{C}$ ", while performance in grade 3 has improved and promoted to category "B".

Students performed well in Social Studies and obtained above $70 \%$ marks, while in General Science students performance was poor as compared to Social Science and fall in category "B". 


\section{Resource Center Timergara}

\subsection{Enrollment}

Total enrolment in Resource Center Timergara was 16, 983.The proportion of boys and girls' enrollment was almost equal which were 8,591 and 8,392 respectively. District wise enrolment was recorded greater in district Dir which was $47 \%(7,883)$ followed by district Bajaur 45\% (7,658). Enrollment of District Chitral was recorded as $8 \%(1,442)$ of the total enrollment in Resource Center Timergara which was the least in comparison to other districts.

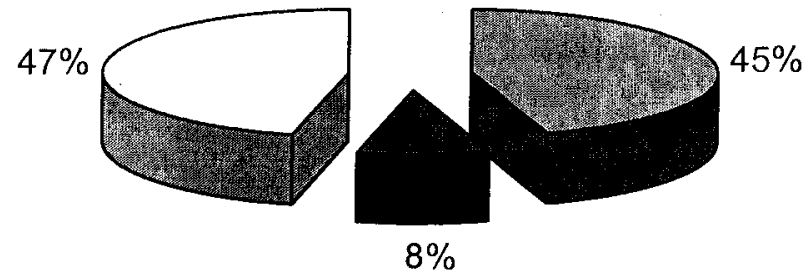

Bajaur Chitral DDir

Gender wise greater enrollment was found in district Dir which was 4,045 in boys and low girls' enrollment was found in district Chitral.

High number of repeaters was recorded in district Bajaur 709 (boys 379 and girls 330) followed by district Dir (641). District Chitral has the least number of repeat cases with total of 182 .

Table T1: Distribution of students by districts

\begin{tabular}{|l|r|r|r|r|r|r|r|r|r|}
\hline \multirow{2}{*}{ District } & \multicolumn{4}{|c|}{ Enrolled } & \multicolumn{4}{c|}{ Repeater } & \multicolumn{3}{c|}{ Fresh enrollment } \\
\cline { 2 - 11 } & Boys & Girls & Total & Boys & Girls & Total & Boys & Girls & Total \\
\hline Bajaur & 3792 & 3866 & 7,658 & 379 & 330 & 709 & 3,413 & 3,536 & 6,949 \\
\hline Chitral & 754 & 688 & 1,442 & 88 & 94 & 182 & 666 & 594 & 1,260 \\
\hline Dir & 4045 & 3838 & 7,883 & 359 & 282 & 641 & 3,686 & 3,556 & 7,242 \\
\hline Total & $\mathbf{8 , 5 9 1}$ & $\mathbf{8 , 3 9 2}$ & $\mathbf{1 6 , 9 8 3}$ & $\mathbf{8 2 6}$ & $\mathbf{7 0 6}$ & $\mathbf{1 , 5 3 2}$ & $\mathbf{7 , 7 6 5}$ & $\mathbf{7 , 6 8 6}$ & $\mathbf{1 5 , 4 5 1}$ \\
\hline
\end{tabular}




\subsection{Dropout}

In district, grade and gender wise analysis the highest rate of dropout was observed in grade 1 and 4 in boys in Dir district, Whereas Chitral district was remained prominent for the high rate among girls from grade 1 and 6 . The least rate of dropout was observed in Bajaur district in all grades. The highest rate of dropout in Resource Center Timergara was recorded for boys in grade 5 in Chitral district followed by Dir district in grade 4 for boys.

\section{District, Grade and Gender Wise Dropout}

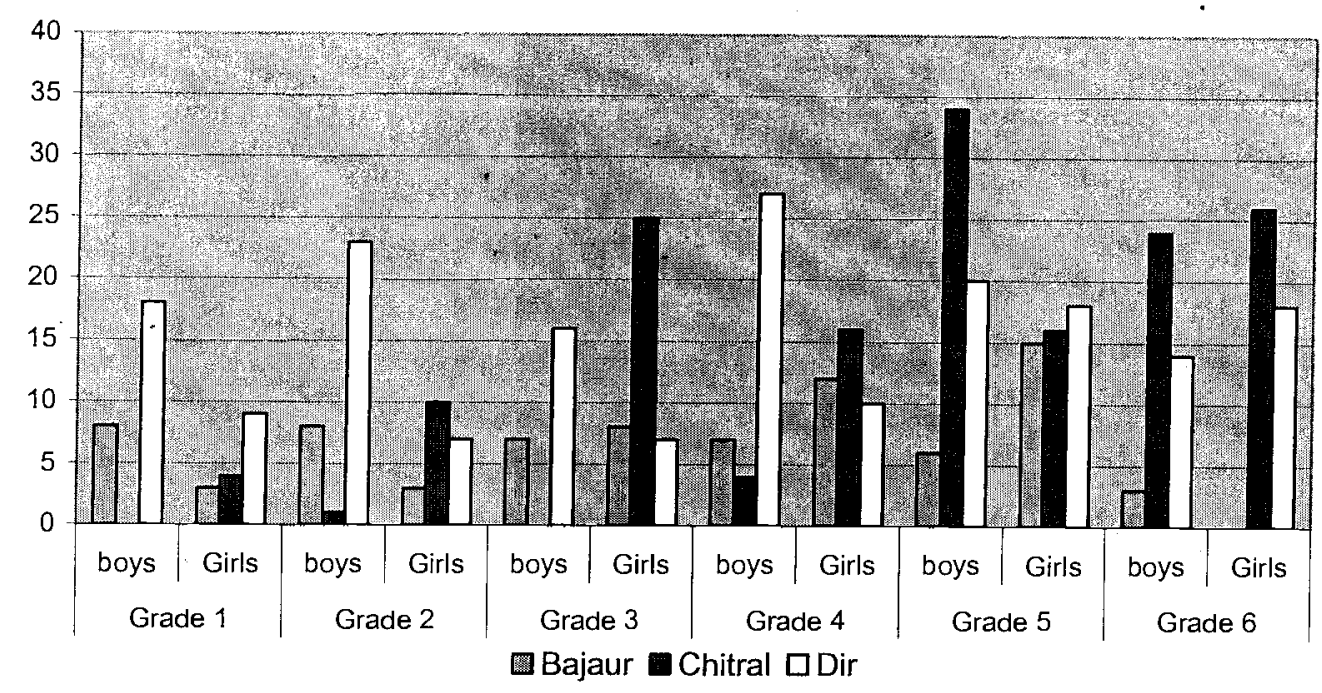

\section{Grade wise dropout of all districts in Timergara Resource Center}

Bajaur district has been observed as low among all the districts. It is interesting to quote that an equal ratio of $7 \%$ for both genders was estimated. The highest dropout rate among boys was noted in grade 1 and 2 which was $8 \%$ in both cases. The main reason for dropout in early grades in Bajaur was the establishment of Islamic Madrassas where parents prefer to send their children over school education. Furthermore they get assistance in terms of food, clothes and finance from the madrassa as well.

The dropout among girls was $15 \%$ in grade 5 . Attaining age of puberty, engagement or early marriage could be the major reason for girls' dropout.

Most interesting and surprising was that the lowest percentage in dropout was recorded in girls which were $3 \%$ in grade 1 and 2 while no dropout has been recorded in girls in grade 5. 
Table T2: Grade wise details of dropout of Bajaur District

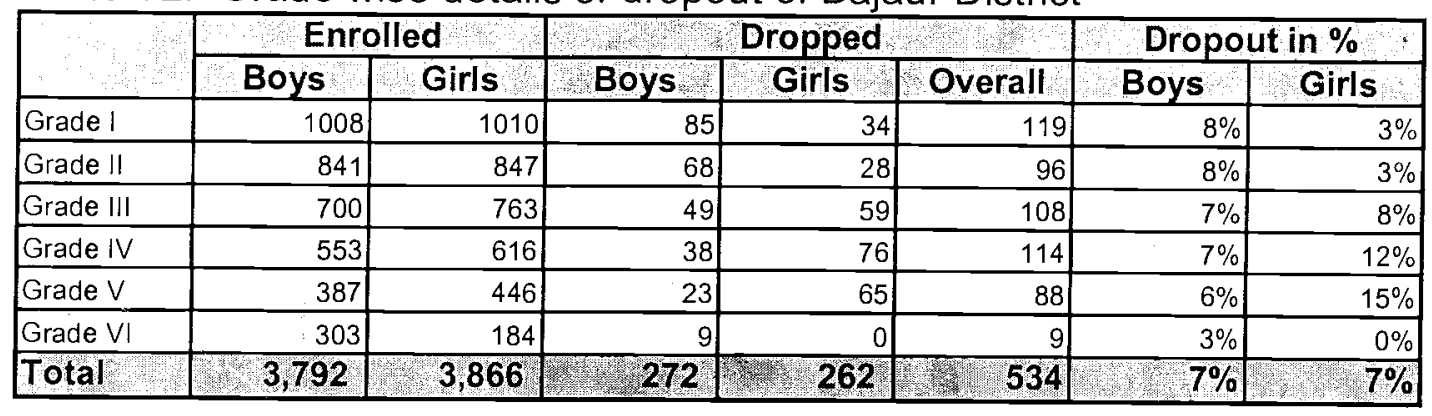

Overall dropout rate in Chitral district was recorded as $7 \%$ and $15 \%$ in boys and girls respectively. Here the girls' dropout was doubled than that of boys. The highest $(34 \%)$ dropout was observed for boys in grade 5 whereas for girls the highest dropout $(26 \%)$ was recorded in grade 6 . It is interesting that no dropout rate was observed in boys in grade 1 . The main reason of dropout for both boys and girls in Chitral district was repatriation where more than 250 families were reported to be repatriated to Afghanistan.

Table T3: Grade wise details of dropout of district Chitral

\begin{tabular}{|l|r|r|r|r|r|r|r|}
\hline & \multicolumn{2}{|c|}{ Enrolled } & \multicolumn{3}{c|}{ Dropped } & \multicolumn{2}{c|}{ Dropout in \% } \\
\cline { 2 - 8 } & Boys & Girls & Boys & Gris & Overall & Boys & Girls \\
\hline Grade I & 169 & 154 & 0 & 6 & 6 & $0 \%$ & $4 \%$ \\
\hline Grade II & 165 & 145 & 1 & 15 & 16 & $1 \%$ & $10 \%$ \\
\hline Grade III & 150 & 139 & 0 & 35 & 35 & $0 \%$ & $25 \%$ \\
\hline Grade IV & 108 & 129 & 4 & 21 & 25 & $4 \%$ & $16 \%$ \\
\hline Grade V & 92 & 68 & 31 & 11 & 42 & $34 \%$ & $16 \%$ \\
\hline Grade VI & 70 & 53 & 17 & 14 & 31 & $24 \%$ & $26 \%$ \\
\hline Total & $\mathbf{7 5 4}$ & $\mathbf{6 8 8}$ & $\mathbf{5 3}$ & $\mathbf{1 0 2}$ & $\mathbf{1 5 5}$ & $\mathbf{7} \%$ & $\mathbf{1 5 \%}$ \\
\hline
\end{tabular}

Overall dropout rate in Dir district was recorded as $20 \%$ and $10 \%$ for boys and girls' respectively. The situation in this district was contrary to that of Chitral district. Here the boys' dropout rate was doubled than that of girls. Highest rate of dropout (20\%) among boys was noted in grade 4 while in girls it was grade 4 and 5 which had dropout $18 \%$ in each case. A significant rate dropout $(23 \%, 20 \%)$ among boys was noted in grade 2 and 5 similarly in girls in grade 1 and 3 the calculated dropout was $9 \%$ and $10 \%$ respectively.

Table T4: Grade wise details of dropout of district Dir

\begin{tabular}{|l|r|r|r|r|r|r|r|}
\hline & \multicolumn{2}{|c|}{ En rolled } & \multicolumn{3}{c|}{ Droped } & \multicolumn{2}{c|}{ Dropout In \% } \\
\cline { 2 - 8 } & Boys & Girls & Boys & Girls & Overall & Boys & \multicolumn{1}{c|}{ Girls } \\
\hline Grade I & 1182 & 666 & 210 & $\mathbf{6 1}$ & 271 & $\mathbf{1 8 \%}$ & $9 \%$ \\
\hline Grade II & 876 & 287 & 199 & 19 & 218 & $23 \%$ & $7 \%$ \\
\hline Grade III & 725 & 227 & 116 & 17 & 133 & $16 \%$ & $7 \%$ \\
\hline Grade IV & 493 & 173 & 131 & 17 & 148 & $27 \%$ & $10 \%$ \\
\hline Grade V & 468 & 138 & 92 & 25 & 117 & $20 \%$ & $18 \%$ \\
\hline Grade VI & 301 & 60 & 41 & 11 & 52 & $14 \%$ & $18 \%$ \\
\hline Total & $\mathbf{4 , 0 4 5}$ & $\mathbf{1 , 5 5 1}$ & $\mathbf{7 8 9}$ & $\mathbf{1 5 0}$ & $\mathbf{9 3 9}$ & $\mathbf{2 0 \%}$ & $\mathbf{1 0 \%}$ \\
\hline
\end{tabular}




\subsection{Result Analysis}

\subsubsection{Appeared and Pass ratio}

In the year 2002-2003 a total of 16, 983 (8,591 boys and 8, 392 girls) students were enrolled in Timergara Resource Center. Among them 15, 063 ( 7,745 boys and 7,318 ) were appeared in the annual exam out of which $91 \%(7,022)$ of boys and $91 \%(6,682)$ of girls were successful. It was to be noted that Timergara was the only Resource Center among all which is equal in gender wise enrollment as well in pass percentage.

As a whole the result of Timergara Center was good as $91 \%$ where each district contributed to its fullest in achieving the target.

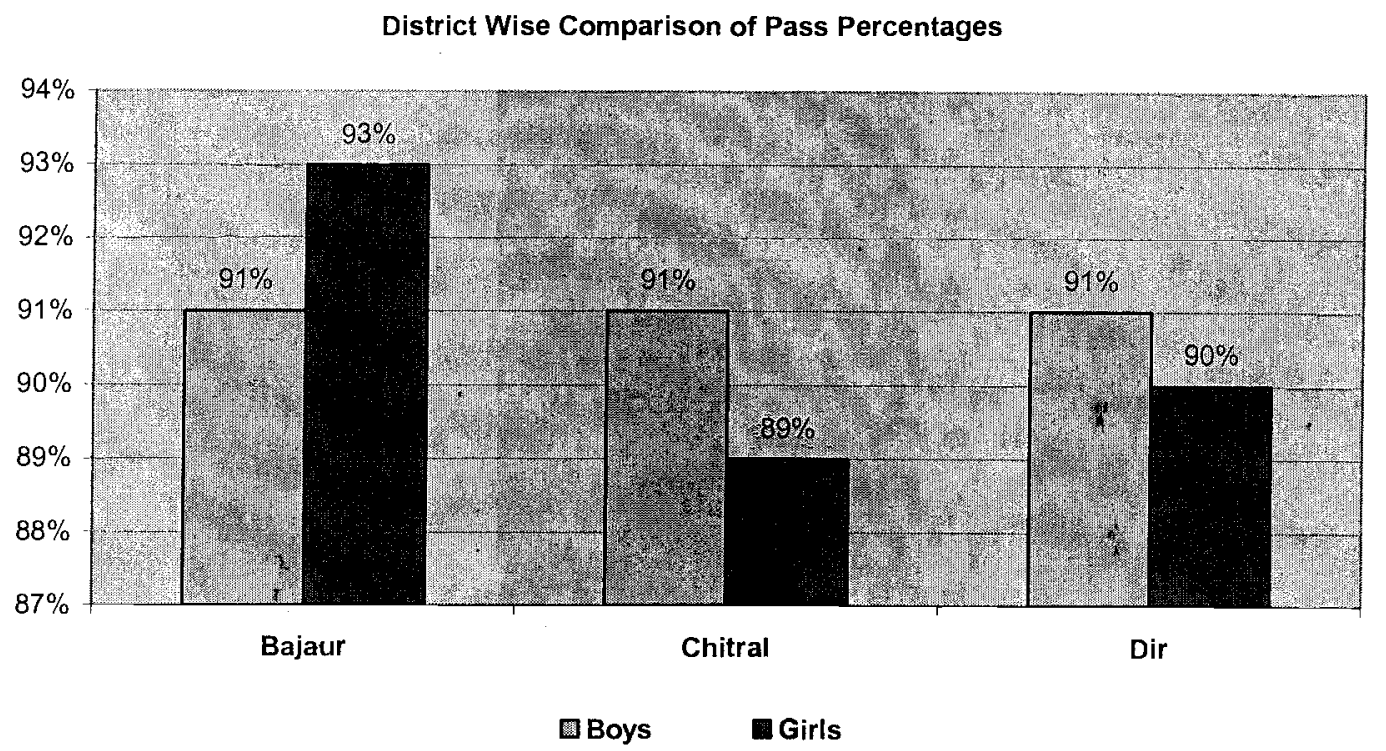

In district wise result analysis it was observed that Bajaur district stood on top with $91 \%$ and $93 \%$ pass percentage for boys and girls followed by Dir district as $91 \%$ and $90 \%$ for boys and girls successively. The lowest (91\% and $89 \%)$ pass percentage among districts was noted in Chitral district because of weak performance of girls.

District wise details of appeared, not appeared and pass percentage are given as under.

In district Bajaur during 2002-2003 total 6,849 students comprising 3,437 boys and 3,412 girls were appeared in the annual exam. Total pass percentage among boys was observed $91 \%$ while in girls $93 \%$. In both genders increase in 
pass ratio was observed as the students moved to the higher grade, for instance the pass percentage of boys in grade 1 was $88 \%$ and girls' $92 \%$, this percentage has thereby increased successively to $96 \%$ and $98 \%$ in higher grade for boys and girls.

Table T5: Grade wise details of appeared and pass students in district Bajaur

\begin{tabular}{|l|r|r|r|r|r|r|r|r|r|r|r|}
\hline & \multicolumn{3}{|c|}{ Appeared } & \multicolumn{3}{c|}{ Not Apeared } & \multicolumn{2}{c|}{ Passed } & \multicolumn{2}{|c|}{ Passed \% } \\
\hline & Boys & Gils & Total & Boys & Girls & Total & $\%$ & Boys & Girls & Boys & Girls \\
\hline Grade I & 900 & 944 & 1844 & 23 & 32 & 55 & 3 & 793 & 866 & $88 \%$ & $92 \%$ \\
\hline Grade II & 761 & 773 & 1534 & 12 & 46 & 58 & 4 & 689 & 721 & $91 \%$ & $93 \%$ \\
\hline Grade III & 627 & 650 & 1277 & 24 & 54 & 78 & 6 & 570 & .604 & $91 \%$ & $93 \%$ \\
\hline Grade IV & 503 & 503 & 1006 & 12 & 73 & 85 & 8 & 458 & 475 & $91 \%$ & $94 \%$ \\
\hline Grade V & 357 & 358 & 715 & 7 & 23 & 30 & 4 & 328 & 332 & $92 \%$ & $93 \%$ \\
\hline Grade VI & 289 & 184 & 473 & 5 & 0 & 5 & 1 & 276 & 181 & $96 \%$ & $98 \%$ \\
\hline Total & $\mathbf{3 4 3 7}$ & $\mathbf{3 4 1 2}$ & $\mathbf{6 8 4 9}$ & $\mathbf{8 3}$ & $\mathbf{2 2 8}$ & $\mathbf{3 7 1}$ & $\mathbf{4}$ & $\mathbf{3 1 1 4}$ & $\mathbf{3 , 1 7 9}$ & $\mathbf{9 1 \%}$ & $\mathbf{9 3 \%} \%$ \\
\hline
\end{tabular}

Total percentage of the students who were not appeared in annual exam was $4 \%$. In grade wise analysis clearly reflect that the higher repeat rate was recorded in 4 and 6 as $8 \%$ and $6 \%$ successively while the least percentage was noted in grade 6 as $1 \%$.

Table T6: Grade wise details of appeared and pass students in district Chitral

\begin{tabular}{|c|c|c|c|c|c|c|c|c|c|c|c|}
\hline & \multicolumn{3}{|c|}{ Appeared } & \multicolumn{4}{|c|}{ ESO Not Apeared } & \multicolumn{2}{|c|}{ Passed } & \multicolumn{2}{|c|}{ Passed \% } \\
\hline & Boys & Gils & Total & Boys & Girls & Total & $\%$ & Boys & Girls & Boys & Girls \\
\hline Grade I & 163 & 148 & 311 & 6 & 0 & 6 & 2 & 146 & 136 & $90 \%$ & $92 \%$ \\
\hline Grade II & 162 & 130 & 292 & 2 & 0 & 2 & 4 & 145 & 116 & $90 \%$ & $89 \%$ \\
\hline Grade III & 142 & 103 & 245 & 8 & 0 & 8 & 3 & 129 & 87 & $91 \%$ & $84 \%$ \\
\hline Grade IV & 101 & 108 & 209 & 3 & 0 & 3 & 1 & 92 & 93 & $91 \%$ & $86 \%$ \\
\hline Grade V & 60 & 57 & 117 & 1 & 0 & 1 & 1 & 55 & 49 & $92 \%$ & $86 \%$ \\
\hline Grade VI & 53 & 39 & 92 & 0 & 0 & 0 & 이 & 51 & 37 & $96 \%$ & $95 \%$ \\
\hline otal & 681 & 585 & 1266 & 20 & & 20 & 2 & 618 & 518 & $91 \%$ & $89 \%$ \\
\hline
\end{tabular}

In district Chitral total of 1,266 students comprising 681 boys and 585 girls were appeared in the annual exam in the session 2002-2003. Among them $91 \%$ of boys (618) and $89 \%$ of girls (518) successfully qualify the exam. In both genders grade wise progress in term of pass percentage has improved and was recorded $90 \%$ for boys $92 \%$ for girls in grade 1 which has increased to $96 \%$ and $95 \%$ for boys and girls respectively in grade 6 .

The minimum percentage of not appeared students was observed in Chitral district which was $2 \%$ as whole.

In district Dir during academic session 2002-2003, total 6,948 students comprising 3,627 boys and 3,321 girls were appeared in the annual exam, out of which $91 \%(3,290)$ boys and $90 \%(2,985)$ girls were declared successful. In gender and grade wise analysis it was observed that the pass percentage in each grade has been improving as move to higher grade except for grade girls $(88 \%)$. 
Table T8: Grade wise details of appeared and pass students in district Dir

\begin{tabular}{|l|r|r|r|r|r|r|r|r|r|r|r|}
\hline & \multicolumn{3}{|c|}{ Appeared } & \multicolumn{3}{|c|}{ Not Apeared } & & \multicolumn{2}{|c|}{ Passed } & \multicolumn{2}{|c|}{ Passed \% } \\
\cline { 2 - 12 } & Boys & Gils & Total & \multicolumn{1}{|c|}{ Boys } & Girls & Total & $\%$ & Boys & Girls & Boys & Girls \\
\hline Grade I & 1068 & 880 & 1948 & 103 & 64 & 167 & 11 & 935 & 788 & $88 \%$ & $90 \%$ \\
\hline Grade II & 776 & 670 & 1446 & 61 & 70 & 131 & 14 & 704 & 603 & $91 \%$ & $90 \%$ \\
\hline Grade III & 640 & 630 & 1270 & 67 & 83 & 150 & 18 & 595 & 556 & $93 \%$ & $88 \%$ \\
\hline Grade IV & 440 & 571 & 1011 & 40 & 56 & 96 & 19 & 406 & 513 & $92 \%$ & $90 \%$ \\
\hline Grade V & 429 & 407 & 836 & 23 & 42 & 65 & 13 & 388 & 373 & $90 \%$ & $92 \%$ \\
\hline Grade VI & 274 & 163 & 437 & 15 & 31 & 46 & 15 & 262 & 152 & $96 \%$ & $93 \%$ \\
\hline Total & $\mathbf{3 6 2 7}$ & $\mathbf{3 3 2 1}$ & $\mathbf{6 9 4 8}$ & $\mathbf{3 0 9}$ & $\mathbf{3 4 6}$ & $\mathbf{6 5 5}$ & $\mathbf{1 4}$ & $\mathbf{3 , 2 9 0}$ & $\mathbf{2 , 9 8 5}$ & $\mathbf{9 1 \%}$ & $\mathbf{9 0 \%}$ \\
\hline
\end{tabular}

The highest rate of the students who were not appeared in exam due to short attendance was recorded in Chitral district which was $14 \%$. The number of not appeared students was observed to be from grade 3 and 4 with calculated figure of $18 \%$ and $19 \%$ for boys and girls respectively.

\subsubsection{Graduation rate}

In Timergara Resource Center total of 674 boys and 443 girls were enrolled in grade 6 during 2002-2003. Out of this figure $87 \%$ of boys and $84 \%$ of girls could successfully pass the examination and become primary graduate. The least $(73 \%)$ percent of graduation among districts was observed for boys in Chitral district, and for girls it was $74 \%$ documented in Dir district.

Table T9: District wise graduation rate

\begin{tabular}{|l|r|r|r|r|r|r|}
\hline \multirow{2}{*}{ District } & \multicolumn{2}{|c|}{ Enrollment } & \multicolumn{3}{c|}{ Pass } & \multicolumn{2}{c|}{ Percentage } \\
\cline { 2 - 8 } & Boys & Girls & Boys & Girls & Boys & Girls \\
\hline Bajaur & 303 & 184 & 276 & 181 & 91 & 98 \\
\hline Chitral & 70 & 53 & 51 & 37 & 73 & 70 \\
\hline Dir & 301 & 206 & 262 & 152 & 87 & 74 \\
\hline Total & 674 & 443 & 589 & 370 & 87 & 84 \\
\hline
\end{tabular}

Graduation Rate of Resource Center Timergara

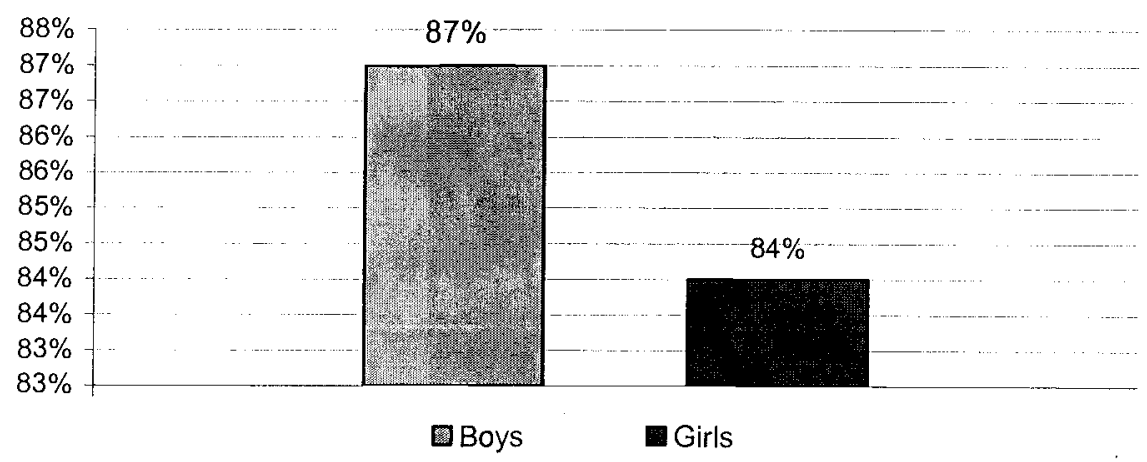




\subsubsection{Students Performance in Subjects and grades}

\section{District Bajaur}

In district Bajaur, in Urdu boys' average marks has been improving from initial grade to higher grades. In grade 2 boys with $59 \%$ marks were to be placed in "C" and in other grades with average marks above $60 \%$ they (boys) could fall in "B". Girls' performance has also improved form grade " $C$ " to " $B$ " in higher grades as compared to initial grades.

In Mathematic, an overall poor result was shown by both genders (max $64 \%$ and min 58\%). There was downward trend observed in marks for both boys and girls from grade 1 to grade 4 , which again moved up in grade 5 and 6 . However majority students' fall in grade "C" and few come under grade "B".

Table T10: Subject wise distribution of average marks in district Bajaur

\begin{tabular}{|c|c|c|c|c|c|c|c|c|c|c|c|c|}
\hline \multirow{2}{*}{ Subject } & \multicolumn{2}{|c|}{ Grade 1} & \multicolumn{2}{|c|}{ Grade 2} & \multicolumn{2}{|c|}{ Grade 3} & \multicolumn{2}{|c|}{ Grade 4} & \multicolumn{2}{|c|}{ Grade 5} & \multicolumn{2}{|c|}{ Grade 6} \\
\hline & Boys & Girls & Boys? & Gins: & Boys: & Girls: & Boys & Girls & Boys: & Girls & Boys & Girls \\
\hline Urdu & & 2 & 59 & 59 & 61 & 59 & 62 & $\overline{60}$ & 66 & 68 & 65 & 68 \\
\hline Mathematics & 61 & 61 & 59 & 58 & 60 & 59 & 57 & 59 & 62 & 63 & 59 & $\overline{64}$ \\
\hline Islamiat & 62 & 63 & 60 & 61 & 59 & 59 & 61 & 62 & $\overline{64}$ & $\overline{64}$ & 67 & 72 \\
\hline Drawing & 68 & 67 & 66 & 69 & 72 & 68 & 75 & 71 & 75 & 78 & 78 & 80 \\
\hline English & 10 & (2) & 60 & 58 & 60 & 57 & 61 & 57 & 64 & 62 & 65 & 67 \\
\hline Calligraphy & 64 & 66 & 66 & 63 & 6) & 2 & 28 & & (2). & 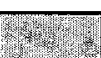 & 2 & 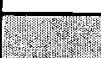 \\
\hline Sport & 80 & 83 & 79 & 77 & 81 & 75 & 86 & 80 & 88 & 93 & 86 & 92 \\
\hline Pashto & 62 & 62 & 60 & 62 & 62 & 60 & 61 & 60 & 67 & 65 & 67 & 67 \\
\hline Quran & 82 & 64 & 61 & 60 & 62 & 61 & 62 & 64 & 69 & 73 & 73 & 74 \\
\hline Social Study & Ex & & me & 2 & 2. & 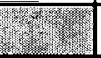 & 62 & 58 & 62 & 66 & 66 & 68 \\
\hline General Science & 2. & 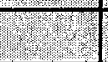 & a & 2 & (5811 & (2) & 60 & 57 & 64 & 65 & 66 & 67 \\
\hline
\end{tabular}

In English, boys marks was found be better than girls, nonetheless the best marks were scored by girls in grade 6 . There was an increasing trend observed in average marks from lower grade to higher. Boys' marks in grade 2, 3 and girls including 4 come under category " $\mathrm{C}$ ". Students' marks from the other remaining grades could well fit into grade "B".

In Social Studies and General Science, improvement was noted in girls average marks while boys' performance was constant throughout. Min $57 \%$ and max $68 \%$ average marks were scored by girls. $60 \%$ were the least average marks and highest marks $66 \%$ were being scored by boys. 


\section{District Chitral}

In Urdu, boys average marks were found to be better than girls. Boys obtained average marks were above $60 \%$ and thus fall in grade "B". Girls' average marks in all grades varied in 50 s and were placed in grade "C".

In Mathematics, the result of students in Chitral was also disappointing. None of the student could get marks above $60 \%$. The maximum marks $60 \%$ were noted in grade 6 which was scored by boys. All students in this district based on their marks were placed in grade " $\mathrm{C}$ ".

Table T11: Subject wise distribution of average marks in district Chitral

\begin{tabular}{|c|c|c|c|c|c|c|c|c|c|c|c|c|}
\hline \multirow{2}{*}{ Subject } & \multicolumn{2}{|c|}{ Grade 1} & \multicolumn{2}{|c|}{ Grade 2} & \multicolumn{2}{|c|}{ Grade 3} & \multicolumn{2}{|c|}{ Grade 4} & \multicolumn{2}{|c|}{ Grade 5} & \multicolumn{2}{|c|}{ Grade 6} \\
\hline & Boys & Girls & Boys & Girls & Boys & Girls: & Boys & Girls & Boys & Girls & Boys & Girls \\
\hline Urdu & & & 63 & 56 & 60 & 58 & 63 & 56 & 66 & 53 & 64 & 58 \\
\hline Mathema & 59 & 55 & 58 & 57 & 56 & 52 & 55 & 59 & 58 & 50 & 60 & 55 \\
\hline Islamiat & 58 & 57 & 57 & 58 & 55 & 56 & $\overline{53}$ & 57 & 58 & $\overline{49}$ & 60 & 66 \\
\hline Drawing & 62 & 60 & 61 & 62 & 67 & 60 & 63 & 64 & 67 & 63 & $\overline{65}$ & 69 \\
\hline English & & 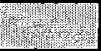 & 55 & 52 & 55 & 56 & 61 & 61 & 62 & 52 & 66 & 61 \\
\hline Calligraphy & 55 & 53 & 52 & 57 & (20) & Penter & 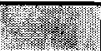 & axt & Eive & & Th & 88 \\
\hline Sport & 66 & 66 & 70 & 70 & 71 & 70 & 74 & 71 & 76 & 65 & 78 & 76 \\
\hline Pashto & 59 & 55 & 58 & 57 & 58 & 56 & 59 & 58 & 61 & 55 & 70 & 69 \\
\hline Quran & 57 & 56 & 58 & 59 & 61 & 57 & 65 & 68 & 66 & 66 & 71 & 76 \\
\hline Social Study & 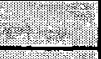 & +2 & $\sqrt{4.28}$ & 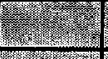 & 2 & 2 & 58 & 58 & 59 & 58 & 69 & 66 \\
\hline General Science & 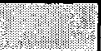 & 40 & & & $\sqrt{25}$ & 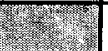 & 55 & 58 & 56 & 54 & $\overline{56}$ & 64 \\
\hline
\end{tabular}

In English, max (66\% and 61\%) were the average marks scored by boys and girls in grade 6 respectively. Only in grade 4 and 6 the average marks were noted to be above $60 \%$ and students in other grades have got below $60 \%$ marks "C".

In social studies max average marks (69\%,66\%) were being scored in grades 6 by boys and girls respectively. Marks of students from other grades varied in 50s and were to be placed in "C". In General Science poor performance was shown by both boys and girls in all grades except girls from grade $6(64 \%)$. Grade "C" could be accorded to students from all grades.

\section{District Dir}

In Urdu boys average marks were observed to be greater as compared to girls. Maximum of $65 \%$ average marks were noted in grade 6 which was scored by boys. Girls' average marks were found to be in 50 s and were placed in grade "C". 
In Mathematics, average marks were again found to be in 50 s and 60 s. Girls have performed better in this subject than boys. $66 \%$ was the maximum figure computed for girls in grade 5. Overall average marks could fall into grade " $C$ ".

Table T12: Subject wise distribution of average marks in district Chitral

\begin{tabular}{|c|c|c|c|c|c|c|c|c|c|c|c|c|}
\hline \multirow{2}{*}{ Subject } & \multicolumn{2}{|c|}{ Grade 1} & \multicolumn{2}{|c|}{ Grade 2} & \multicolumn{2}{|c|}{ Grade 3} & \multicolumn{2}{|c|}{ Grade 4} & \multicolumn{2}{|c|}{ Grade 5} & \multicolumn{2}{|c|}{ Grade 6} \\
\hline & Boys & Girls & Boys & Girls & Boys & Girls & Boys & Girls & Boys & Girls & Boys & Girls \\
\hline Urdu & & & 60 & 58 & 64 & 55 & $\frac{6}{60}$ & 60 & 59 & 60 & 65 & 57 \\
\hline Mathematics & 55 & 60 & 57 & 59 & 60 & 54 & 60 & 61 & 59 & 66 & 61 & 57 \\
\hline Islamiat & 55 & 59 & 57 & 61 & 62 & 54 & 59 & 58 & 65 & 65 & 67 & 65 \\
\hline Drawing & 61 & 58 & 66 & 62 & 66 & 57 & 67 & 64 & 69 & 69 & 75 & 71 \\
\hline English & 2 & 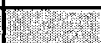 & 57 & 60 & 63 & 55 & 60 & 55 & 58 & 56 & 64 & 51 \\
\hline Calligraphy & 56 & 56 & 63 & 61 & & & 27 & & & 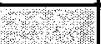 & & \\
\hline Sport & 78 & 75 & 81 & 74 & 84 & 72 & 82 & $74 \mid$ & 85 & 74 & 86 & 76 \\
\hline Pashto & 55 & 60 & .57 & 60 & 63 & 57 & 63 & 64 & 63 & 67 & 65 & 65 \\
\hline Quran & 54 & 56 & 57 & 58 & 64 & 60 & 64 & 66 & 67 & 69 & 72 & 71 \\
\hline Social Study & 2 & se & 8 & (5) & 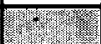 & 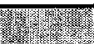 & 62 & 57 & 62 & 63 & 65 & 66 \\
\hline General Science & - & 2 & me & 2. & 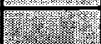 & 25 & 57 & 57 & 58 & 03 & 64 & 59 \\
\hline
\end{tabular}

In English, average marks were found below $60 \%$. Only figure above $60 \%$ was scored by boys in grade 6 . Based on the average marks the student could be given grade " $C$ ".

A better result was seen in Social Studies to General Science in terms of average marks. The result gradually has improved form lower grade to higher grades. Best average marks (66\%) were found to be scored by girls in grade 6 in Social Study. While in General Science $64 \%$ was again seen to be scored in grade 6 but by boys. Generally average marks in those subjects fall in grade "B". 


\section{Annexures}

